\title{
Implementação e comparação de métodos de estimativa da dimensão fractal e sua aplicação à análise e processamento de imagens
}

\author{
André Ricardo Backes
}

Orientador: Prof. Dr. Odemir Martinez Bruno

Dissertação apresentada ao Instituto de Ciências Matemáticas e de Computação - ICMC-USP, como parte dos requisitos para obtenção do título de Ciências de Computação e Matemática Computacional.

"VERSÃO REVISADA APÓS A DEFESA"

Data da Defesa:

27/03/2006

Visto do Orientador:

USP - São Carlos

Abril / 2006 
Implementação e comparação de métodos de estimativa da dimensão fractal e sua aplicação à análise $e$ processamento de imagens 
Aos meus pais, que sempre me apoiaram em todas as etapas da minha vida. 


\section{Agradecimentos}

Ao Instituto de Ciências Matemáticas e de Computação da Universidade de São Paulo (ICMCUSP), pela oportunidade da realização do curso de Mestrado.

Ao prof. Odemir Martinez Bruno, pela orientação, disposição e entusiasmo. Pelo bom humor e paciência.

A Fundação de Amparo à Pesquisa do Estado de São Paulo (FAPESP), pela concessão da bolsa de Mestrado.

Aos professores e funcionários do ICMC-USP.

Aos colegas de pós-graduação e a todos aqueles que fizeram deste, um período de crescimento, discussões, trocas de conhecimentos e lazer. 


\section{Resumo}

A Dimensão Fractal pode ser utilizada para medir algumas características ligadas a complexidade da imagem, permitindo seu uso em análise de formas e texturas e reconhecimento de padrões. Neste trabalho é apresentado um estudo comparativo entre alguns dos principais métodos de estimativa da Dimensão Fractal. Foi realizada uma análise experimental e um estudo de casos para cada uma das técnicas, levando em consideração aspectos de implementação, precisão, variação de resultados segundo ajuste de parâmetros e tolerância a ruídos.

Neste trabalho também foi desenvolvido um estudo sobre a Dimensão Fractal Multiescala, visando seu emprego como metodologia de assinatura de complexidade. Na literatura a técnica de multiescala é limitada ao método de Bouligand-Minkowski, sendo aqui ela estendida para outras metodologias de estimativa de Dimensão Fractal. Por meio de análise experimental as metodologias propostas foram comparadas e os resultados discutidos, enfatizando as vantagens e desvantagens destas técnicas. 


\begin{abstract}
Fractal Dimension can be used to measure some characteristics related to the image complexity, allowing its use on shape and texture analysis and pattern recognition. In this work is presented a comparative study among some of the most important methods to estimate Fractal Dimension. It was performed a experimental analysis and a case study for each one of the techniques, considering implementation aspects, precision, variation of results under parameters adjustments and noise tolerance.

In this work is also performed a study about MultiScale Fractal Dimension, aiming at its use as a methodology of complexity signature. In the literature the multiscale technique is limited to Bouligand-Minkowski method, being here it extended to other methodologies of estimative of Fractal Dimension. By experimental analysis the proposed methodologies were compared and the results argued, emphasizing the advantages and disadvantages of those techniques.
\end{abstract}




\section{Sumário:}

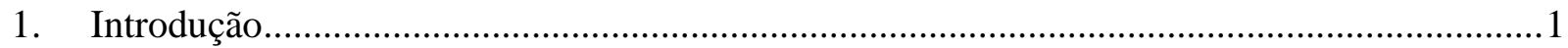

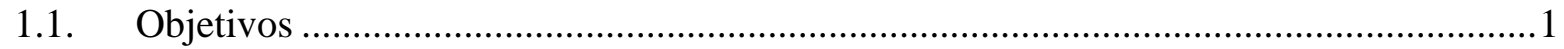

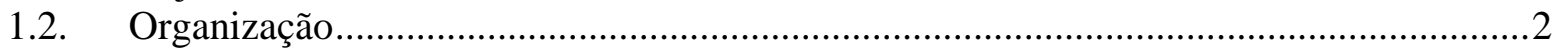

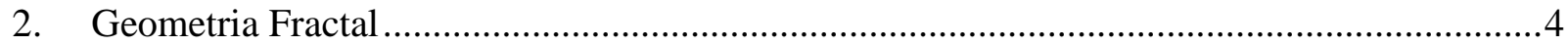

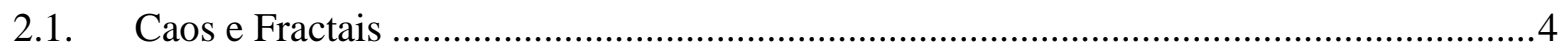

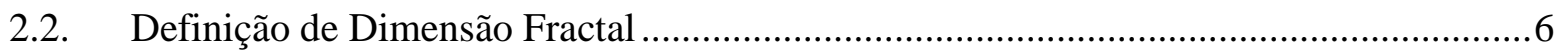

2.3. Dimensão Fractal e Processamento de Imagens ......................................................... 7

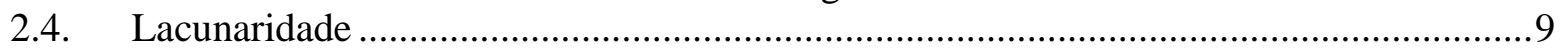

2.5. Relação entre complexidade, análise de formas e texturas. .......................................... 10

3. Principais Métodos Para Estimativa da Dimensão Fractal...................................................12

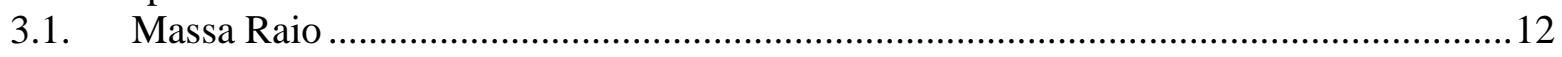

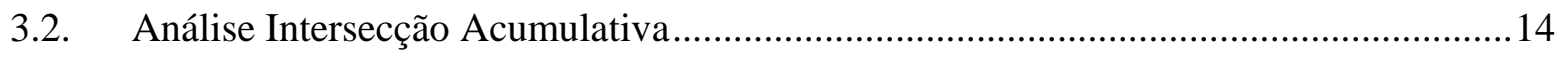

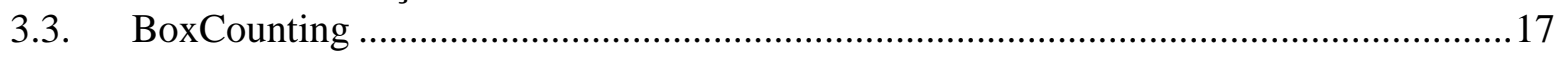

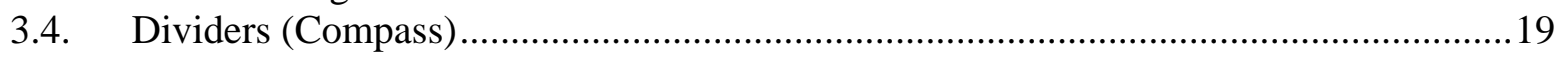

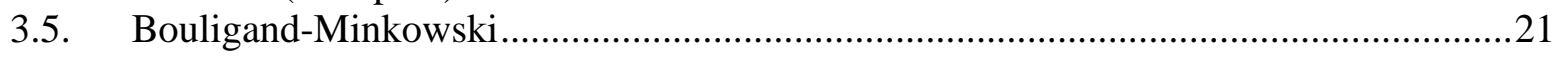

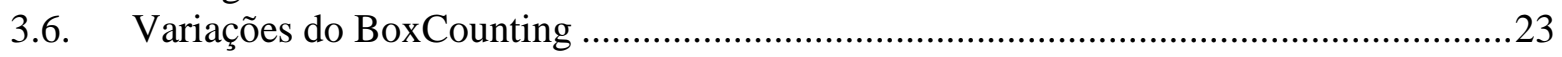

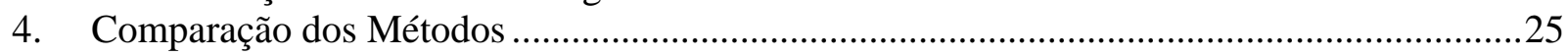

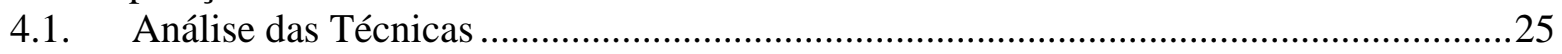

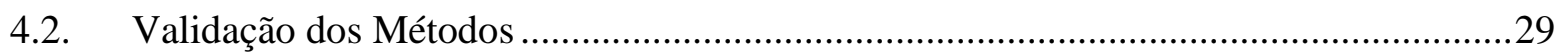

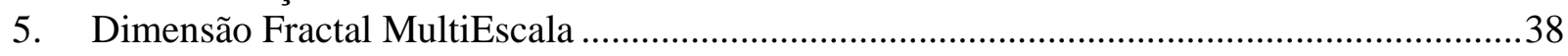

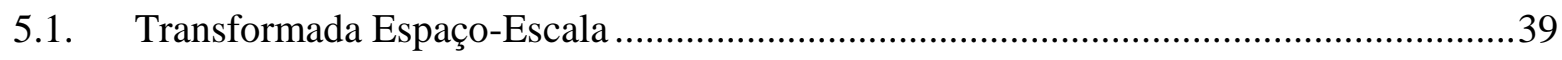

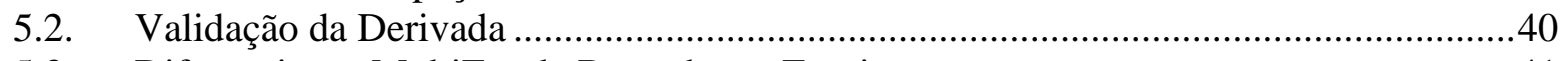

5.3. Diferenciação MultiEscala Baseada em Fourier ......................................................... 41

5.4. Diferenciação MultiEscala por Diferenças Finitas.....................................................4

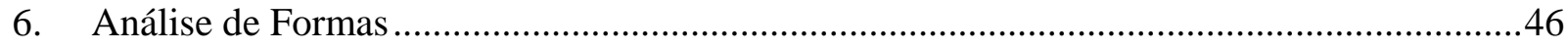

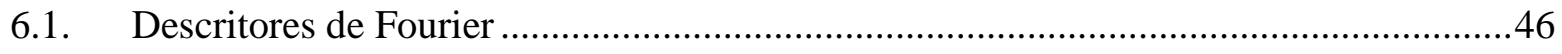

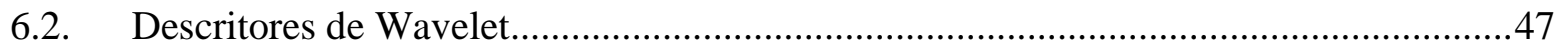

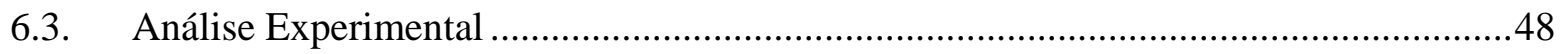

6.4. Análise da Propriedade MultiEscala em outros Métodos .........................................57

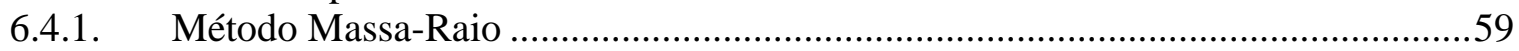

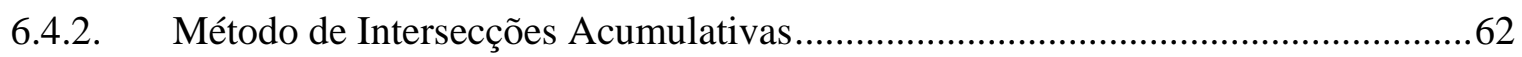

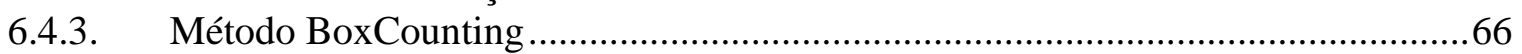

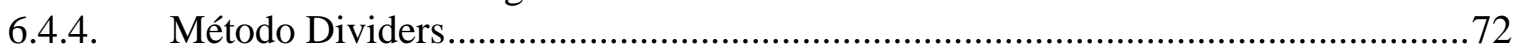

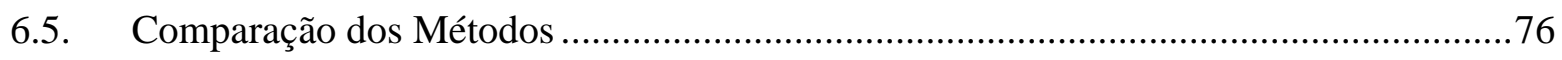

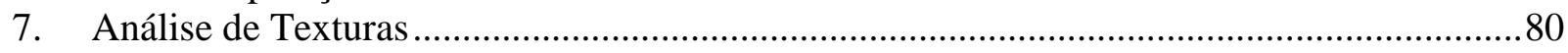

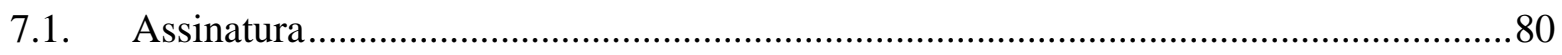

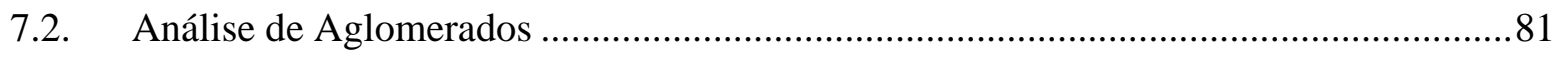

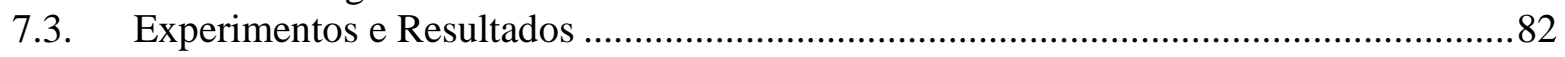

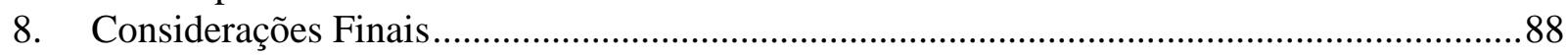

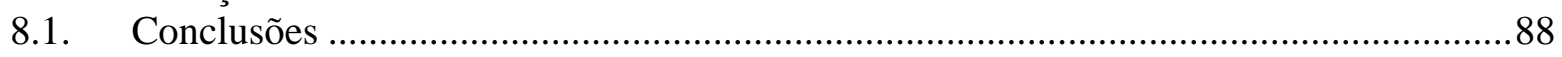

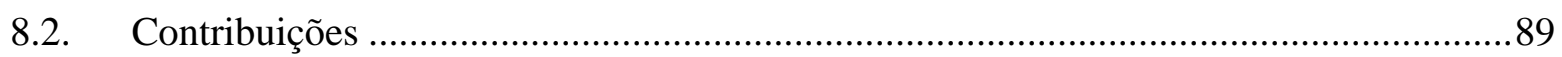

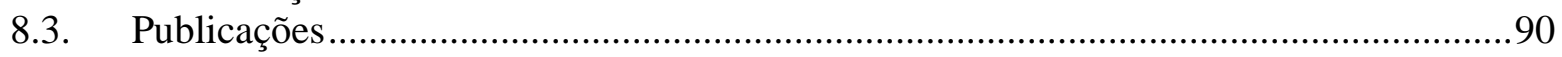

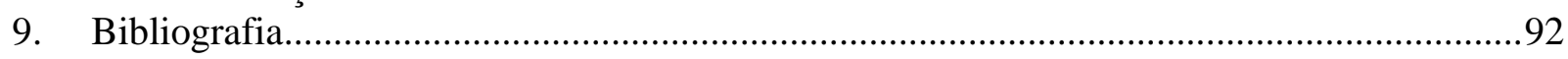




\section{Índice de Figuras:}

Figura 1 - Exemplo de um Fractal.....................................................................................

Figura 2 - Conjunto de Mandelbrot para diferentes valores do expoente k: (a) k=1; (b) k=2; (c) $\mathrm{k}=3 ;(\mathrm{d}) \mathrm{k}=4$;

Figura 3 - Sobreposição dos círculos pelo método Massa-Raio ...............................................12

Figura 4 - Gráfico Log - Log da variação da massa acumulada em relação ao raio. Para fractais matemáticos estritamente auto-semelhantes a dimensão da Massa é a mesma da dimensão de Hausdorff (SCHROEDER, 1996) (HONDA et. al, 1991) (LANDINI; RIPPIN, 1993)........14

Figura 5 - Uma pequena seção de uma imagem é mostrada, com um simples círculo correspondendo ao raio selecionado em um algum ponto durante a análise. Pontos consecutivos que também são adjacentes são mostrados por $\mathrm{A}$, enquanto que pontos que não são adjacentes são mostrados por B

Figura 6 - Exemplo da verificação das intersecções no vetor. .....................................................16

Figura 7 - Gráfico log-log da variação do número de intersecções em relação ao raio.................17

Figura 8 - Divisão de uma imagem pelo Método do BoxCounting ............................................17

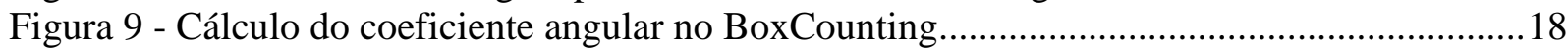

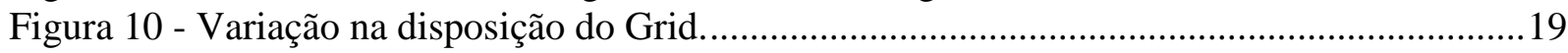

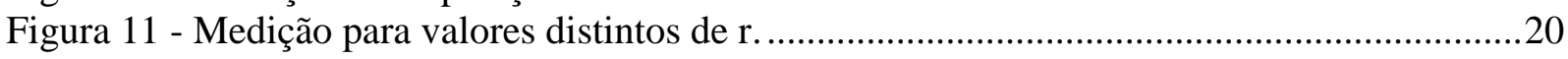

Figura 12 - Cálculo do coeficiente angular no Dividers. .........................................................21

Figura 13 - Dilatação de uma curva com um disco....................................................................22

Figura 14 - Cálculo do coeficiente angular no método de Bouligand-Minkowski.......................23

Figura 15 - variações na implementação do BoxCounting .........................................................24

Figura 16 - Método Dividers não leva em consideração a informação interna do objeto. A

Dimensão Fractal calculada é a mesma para os dois objetos.

Figura 17 - (a) Imagem Original; (b) Esqueleto da Imagem Obtido por Afinamentos Sucessivos.

Figura 18 - O Método de Massa-Raio necessita da informação interna do objeto para o cálculo.

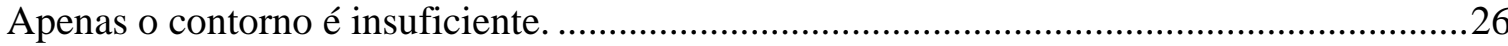

Figura 19 - (a) e (b) são execuções do Dividers para um mesmo tamanho de régua, mas pontos iniciais distintos.

Figura 20 - (a) Grid alinhado ao início da imagem minimiza a contagem. (b) Grid sem alinhamento

Figura 21 - Conjuntos diferentes de caixas geram valores diferentes para a Dimensão Fractal ....29

Figura 22 - (a) gráfico da curva log-log gerada pelo método de Minkowski. (b) gráfico da curva de Dimensão Fractal MultiEscala obtida a partir de (a).

Figura 23 - Validação das derivadas: (a) curva da função $f(x)=x^{2}$; (b) Derivada Numérica; (c)

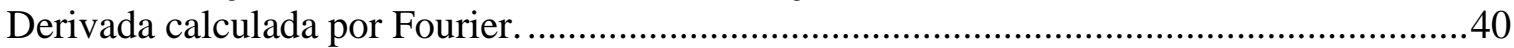

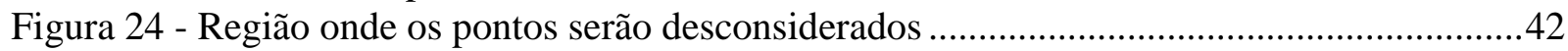

Figura 25 - Fenômeno de Gibbs apresentado nas descontinuidades............................................42

Figura 26 - Esquema de Replicação e Reflexão para tornar o sinal contínuo..................................43

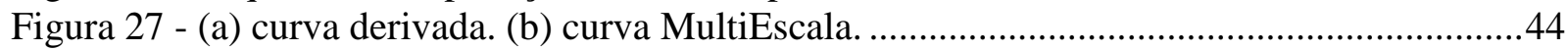

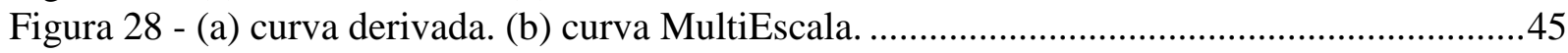

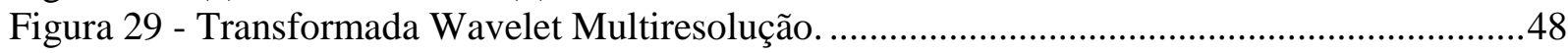

Figura 30 - Exemplo de curvas MultiEscalas para diferentes letras do alfabeto. ..........................49 
Figura 31 - Imagens com diferentes intensidades de ruído: (a)Imagem Original; (b)Imagem com o

$1^{\circ}$ Nível de Ruído; (c)Imagem com o $2^{\circ}$ Nível de Ruído; (d)Imagem com o $3^{\circ}$ Nível de

Ruído; (e)Imagem com o $4^{\circ}$ Nível de Ruído.

Figura 32 - Processo de adição de ruído a uma imagem.

Figura 33 - Curvas MultiEscala: (a)Sigma = 10; (b)Sigma = 15; (c)Sigma = 20; (d)Sigma = 25.51

Figura 34 - Demonstração da criação de uma curva Multiescala média.......................................52

Figura 35 - Comparação dos resultados para os descritores de Wavelet ......................................54

Figura 36 - Comparação dos resultados para os descritores de Fourier.........................................55

Figura 37 - Comparação entre o número de descritores Wavelet utilizados e a taxa de acertos alcançada.

Figura 38 - Letra com abertura interna. Seu centro de massa é um ponto pertencente ao fundo da imagem.

Figura 39 - Comparação dos resultados obtidos para o método Massa-Raio. ................................60

Figura 40 - Curvas MultiEscala obtidas pelo método Massa-Raio: (a)Sigma = 1,5; (b)Sigma = 2,$0 ;(\mathrm{c})$ Sigma $=2,5 ;(\mathrm{d})$ Sigma $=3,0$.

Figura 41 - Comparação dos resultados obtidos para o método Intersecções Acumulativas. .......65

Figura 42 - Curvas MultiEscala obtidas pelo método Intersecções Acumulativas: (a)Sigma = 1,5;

(b)Sigma $=2,0$; (c)Sigma $=2,5$; (d)Sigma $=3,0$.

Figura 43 - Curva log-log com poucos pontos. Insuficiente para gerar uma curva de Dimensão

Fractal MultiEscala sa tisfatória.

Figura 44 - Sobreposição das caixas sobre a imagem: (a) grid; (b) caixas ajustadas. ...................68

Figura 45 - Comparação dos resultados obtidos para o método BoxCounting..............................68

Figura 46 - Curva log-log com trechos constantes, onde a derivada é igual a zero.......................70

Figura 47 - Curvas MultiEscala obtidas pelo método BoxCounting: (a)Sigma =1,5; (b)Sigma =

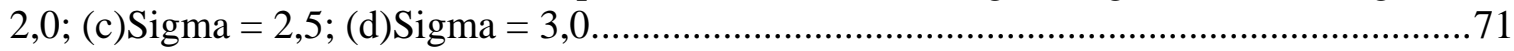

Figura 48 - Execuções do Dividers para um mesmo tamanho de ruler, mas pontos iniciais distintos.

Figura 49 - Comparação dos resultados obtidos para o método Dividers......................................74

Figura 50 - Simplificação do contorno provocada pelo uso de um ruler muito grande no método Dividers.

Figura 51 - Descontinuidade provocada pelo fenômeno de Gibbs na curva MultiEscala obtida pelo método Dividers.

Figura 52 - Curvas MultiEscala obtidas pelo método Dividers: (a)Sigma = 1,5; (b)Sigma = 2,0;

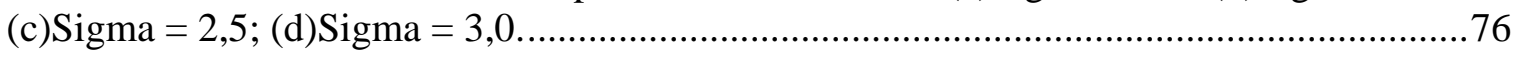

Figura 53 - Comparação da tolerância a ruídos de cada método. ...............................................77

Figura 54 - Comparação do tempo necessário para o cálculo da curva MultiEscala em cada método.

Figura 55 - Gráfico log-log da lacunaridade e da Dimensão Fractal pelo tamanho da caixa. .......81 


\section{Índice de Tabelas:}

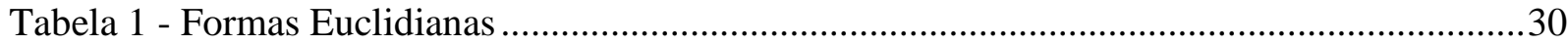

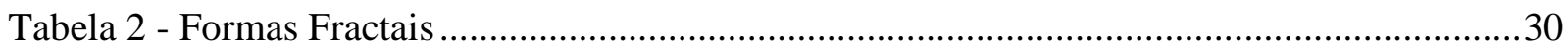

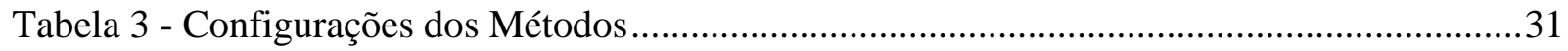

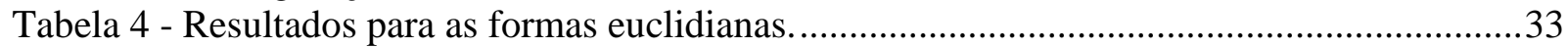

Tabela 5 - Resultados para as formas fractais Box e Triângulo de Sierpinski................................33

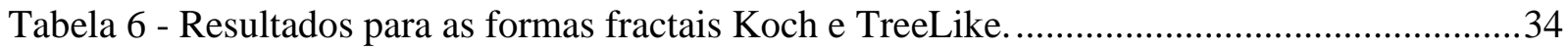

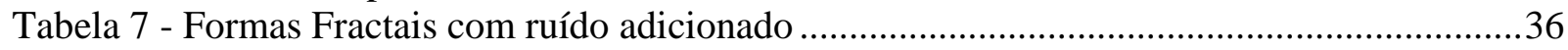

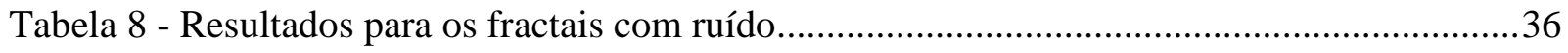

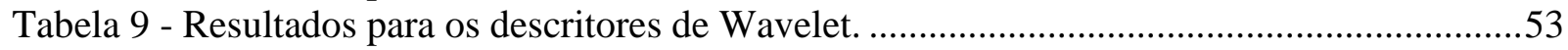

Tabela 10 - Resultados para os descritores de Fourier...............................................................54

Tabela 11 - Quantidade de pontos presentes nas diversas configurações dos descritores de

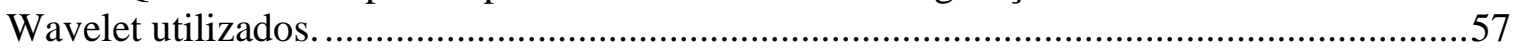

Tabela 12 - Configurações e resultados obtidos para o método Massa-Raio.................................61

Tabela 13 - Configurações e resultados obtidos para o método Intersecções Acumulativas.........64

Tabela 14 - Configurações e resultados obtidos para o método BoxCounting. ............................69

Tabela 15 - Configuraçõos e resultados obtidos para o método Dividers.......................................73

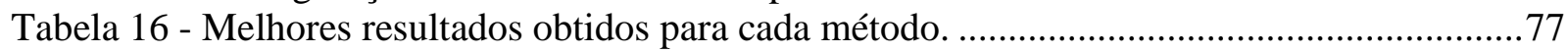

Tabela 17 - Tempo necessário para o cálculo da curva MultiEscala em cada método.................78

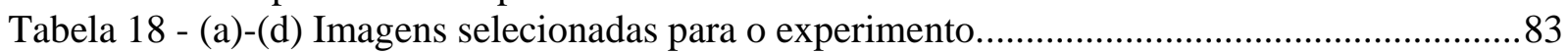

Tabela 19 - Resultados dos experimentos para a imagem (a) da Tabela 18 ..............................85

Tabela 20 - Resultados dos experimentos para a imagem (b) da Tabela 18................................86

Tabela 21 - Resultados dos experimentos para a imagem (c) da Tabela 18 ................................86

Tabela 22 - Resultados dos experimentos para a imagem (d) da Tabela 18 ...............................87 


\section{Introdução}

A Dimensão Fractal (DF) é uma propriedade dos objetos fractais. Ela representa o nível de ocupação do espaço euclidiano por um objeto fractal. Trata-se de uma característica importante dos fractais, uma vez que um nível maior de ocupação do espaço implica em uma estrutura fractal mais complexa.

Essa ligação entre nível de ocupação de espaço e complexidade faz com que a Dimensão Fractal possa ser utilizada também como uma ferramenta para análise de formas. Isto pode ser observado acompanhando a literatura dos últimos anos, aonde a Dimensão Fractal vem ganhando muita atenção, passando a ser utilizada nas mais diversas áreas do conhecimento, em especial, na área de processamento e análise de imagens (PLOTZE et. al, 2004) (CARLIN, 2000) (KENKEL; WALKER, 1993).

No entanto, Fractais são objetos exclusivamente matemáticos, ou seja, que inexistem no mundo físico. Isso faz com que a técnica utilizada para o cálculo da Dimensão Fractal necessite ser adaptada para trabalhar com as limitações que o mundo físico impõe. Várias são as técnicas desenvolvidas de modo a adaptar a estimativa da Dimensão Fractal para objetos não-fractais, em especial imagens, como pode ser visto em aplicações.

Os métodos existentes utilizam medições de diferentes características da imagem, o que torna alguns deles limitados a certo grupo de imagens. Além dessas limitações, percebe-se que determinados métodos são mais adequados para certas aplicações e grupos de imagens. Na maioria dos casos, os diferentes métodos foram comparados e testados pelo próprio autor, sendo esses testes e comparações realizados de forma empírica ou então concentrados em uma única aplicação ou método.

\subsection{Objetivos}

Este projeto teve como principal objetivo estudar, comparar e validar experimentalmente alguns dos mais importantes algoritmos de estimativa da Dimensão Fractal em imagens digitais, observando-se as diferenças de aplicação, desempenho e exatidão de cada um. Tais considerações são essenciais para viabilizar a aplicação dos algoritmos de estimativa de Dimensão Fractal no processamento e reconhecimento de padrões em imagens digitais. 
Além disso, teve-se também por objetivo estudar e validar a Dimensão Fractal MultiEscala, atualmente o estado da arte na Geometria Fractal, verificando também a existência da propriedade MultiEscala em outras técnicas de estimativa da Dimensão Fractal.

Os objetivos deste trabalho foram:

- Verificar as restrições para a utilização de cada método;

- Verificar quais os métodos mais tolerantes a variações de rotação;

- Medir o nível de tolerância a ruídos de cada método;

- Verificar que métodos apresentam os melhores resultados em experimentos de classificação de formas;

- Verificar a possibilidade de extrair a propriedade MultiEscala de outros métodos, desde que observadas as restrições de aplicabilidade de cada método;

- Medir o nível de tolerância a ruído das diferentes curvas MultiEscala calculadas;

- Verificar como o nível de suavização da curva MultiEscala afeta os resultados de classificação.

O trabalho foi realizado com base na análise dos cinco algoritmos (Massa-Raio, Análise de Intersecções Acumulativas, BoxCounting, Dividers e Bouligand-Minkowski) para estimativa da Dimensão Fractal (Capítulo 3) passiveis de comparação, tendo sido confirmada a propriedade MultiEscala para todos eles. Além disso, experimentos de classificação de imagens foram realizados, validando o seu uso na maior classe de problemas de análise e classificação de imagens digitais.

\subsection{Organização}

Esta dissertação está dividida da seguinte forma: No Capítulo 2 são formalmente apresentadas as definições necessárias à compreensão do restante do texto, bem como um levantamento de diversas aplicações da Dimensão Fractal, de forma a ilustrar sua importância na análise de imagens. O Capítulo 3 apresenta as principais técnicas de estimativa da Dimensão Fractal de imagens digitais, incluindo uma breve descrição de suas limitações. O Capítulo 4 apresenta uma comparação dos algoritmos anteriormente citados e os resultados obtidos dessa comparação. No Capítulo 5 são apresentados todos os conceitos necessários para a compreensão da Dimensão Fractal MultiEscala. O Capítulo 6 apresenta um estudo validando a curva MultiEscala obtida pelo método de Minkowski, juntamente com um estudo abordando a 
possibilidade de se extrair a propriedade MultiEscala a partir de outros métodos de estimativa da Dimensão Fractal. Além disso, experimentos de classificação de imagens foram realizados, validando o uso da Dimensão Fractal na análise de textura (Capítulo 7).

O Capítulo 8 apresenta as conclusões obtidas com base nos trabalhos desenvolvidos ao longo do mestrado, bem como as contribuições e publicações decorrentes do mesmo. 


\section{Geometria Fractal}

\subsection{Caos e Fractais}

Desde os primórdios, a curiosidade e a inteligência humana procuraram padrões naquilo que era aparentemente aleatório. Assim foi construindo o conhecimento científico, desvendando a ordem que se escondia por detrás dos fenômenos naturais.

A Teoria do Caos, ao contrário do que o seu nome possa sugerir, dá continuidade a essa busca por um padrão no comportamento irregular. Ao que indicam as últimas descobertas, o caos não é um conceito absoluto, que designaria o estado de desordem ou entropia de um sistema. Ao contrário, a suposta desordem do caos resulta de nossa incapacidade em compreender a fundo os sistemas aperiódicos, típicos da natureza e da sociedade, exemplificados pela turbulência dos fluidos, variações da economia, transformações meteorológicas, crescimento de populações e muitos outros fenômenos que escapam das famosas CNTP (Condições Normais de Temperatura de Pressão, inexistentes em qualquer lugar do planeta). O caos é, na verdade, um sistema aperiódico, ou não-linear, e por esse mesmo motivo apresenta uma elevada sensibilidade às condições iniciais.

Uma parte importante da Teoria do Caos é a chamada Geometria Fractal. Enquanto a geometria euclidiana se preocupava com as formas perfeitas (círculos, quadrados, retas e cones), a Geometria Fractal se preocupa com as imperfeições das formas que encontramos na natureza. Enquanto a geometria clássica, ao estudar uma montanha, a transforma em um cone, para a geometria fractal o que interessa são justamente as irregularidades da montanha.

A Geometria Fractal, criada pelo matemático Benoit Mandelbrot, ficou famosa pelos gráficos criados para representar fenômenos caóticos: os fractais. Esses gráficos apresentam uma característica curiosa: quando ampliamos uma parte do desenho, ele se revela muito parecido com a imagem maior, apresentando auto-semelhança em nível de escala (Figura 1). 


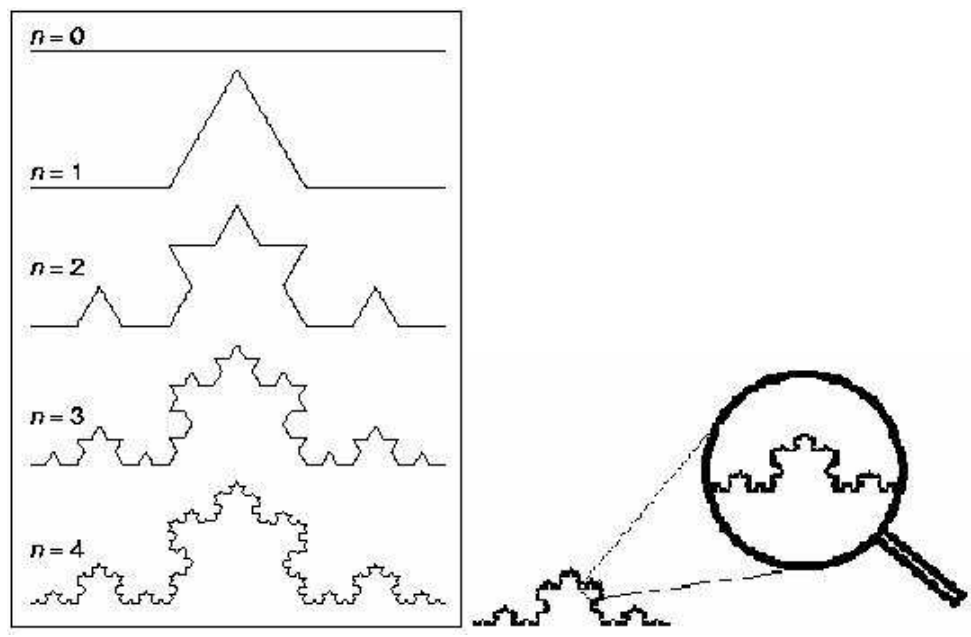

Figura 1 - Exemplo de um Fractal.

Do mesmo modo que os sistemas caóticos, os fractais também apresentam uma elevada sensibilidade às condições iniciais, de modo que a mais simples mudança dos dados iniciais altera toda a estrutura do fractal. Isso pode ser comprovado com o estudo do conjunto de Mandelbrot, onde a simples alteração do expoente $k$ da equação $Z_{n+1}=Z_{n}^{k}+c$ altera significativamente o aspecto da forma fractal (Figura 2).

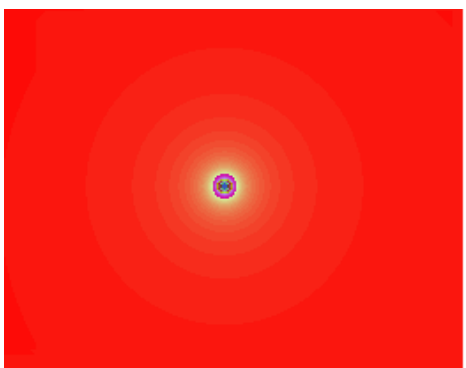

(a)

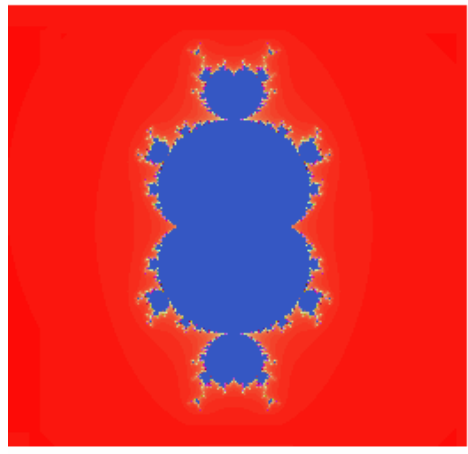

(c)

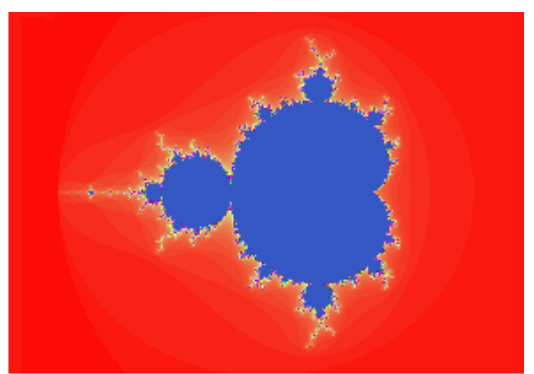

(b)

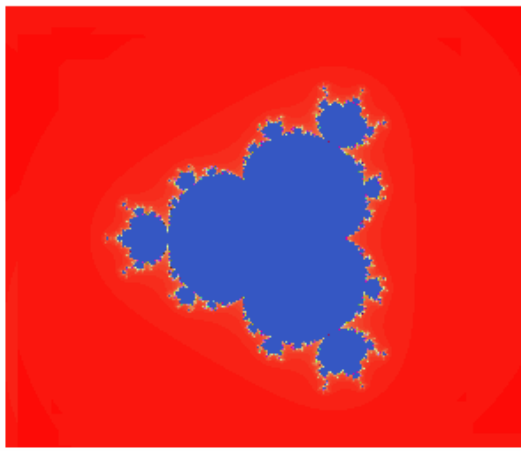

(d)

Figura 2 - Conjunto de Mandelbrot para diferentes valores do expoente k: (a) k=1; (b) k = 2; (c) k= 3; (d) k $=4$; 


\subsection{Definição de Dimensão Fractal}

Num primeiro momento, a noção de uma dimensão não-inteira como, por exemplo, 1,6 e 2,1 , pode parecer absurda. Isso porque, nosso senso comum está acostumado a considerar os objetos como tendo uma, duas ou três dimensões, podendo ainda considerar o tempo como uma quarta dimensão.

Durante séculos as formas observadas na natureza tem sido tratadas por meio de elementos e conceitos de formas extraídas da Geometria Euclidiana. A Natureza nada mais era que uma extensão dessa geometria perfeita, baseada em retas, planos, círculos e outras formas. Desde cedo somos acostumados a classificar formas irregulares, como montanhas, por meio de objetos mais simples, como cones, e a procurar todas as respostas para os mais diversos eventos ocorridos na natureza dentro da Geometria Euclidiana.

No entanto, isso começou a mudar quando matemáticos como Cantor, Von Koch, Peano, Hausdorff e Besicovitch criaram formas incapazes de serem classificadas nos moldes da Geometria Euclidiana. Surgia então uma nova classe de figuras que tinham como base regras simples de construção, mas que ao serem repetidas inúmeras vezes, geravam figuras de uma complexidade espantosa. Além disso, essas novas formas apresentavam auto-semelhança em nível de escala, ou seja, o conjunto total era constituído por pequenas réplicas dele mesmo independente da escala utilizada para visualizá-lo (GULICK, 1992).

Essas novas formas foram chamadas de fractais, nome este cunhado por Mandelbrot e originário da palavra fractus, do latim "fração", "fragmento", "irregular ou fragmentado" (MANDELBROT, 2000), sendo que para uma classificação e estudo mais preciso delas surgiu uma nova geometria, a Geometria Fractal.

Outra característica importante dessa nova classe de figuras era relativa a sua dimensão. Enquanto objetos como retas e planos possuíam dimensões com valores inteiros, esses novos objetos possuíam um valor fracionário para a dimensão. Isso acontece por que o valor da dimensão indica o grau de complexidade / irregularidade que a figura possui, ou seja, o quanto do espaço físico ela ocupa. Dito de outra forma, a dimensão de uma curva fractal é um número que caracteriza a maneira na qual a medida do comprimento entre dois pontos aumenta à medida que a escala diminui (FALCONER, 1990) (TRICOT, 1995). 
Para calcular o valor da Dimensão Fractal, considere uma linha de comprimento $L$ e outra de comprimento $u$, de modo que $L>u$. Sobrepondo a linha $u$ sobre a linha $L$ até cobri-la completamente, encontra-se um valor $N=L / u$, que nada mais é do que uma medida da linha.

Do mesmo modo que foi feito para a linha, pode-se medir um quadrado de lado $L$ sobrepondo-o com pequenos quadrados de lado $u$, obtendo-se a mesma relação $N=(L / u)^{2}$.

De uma maneira mais geral, esse processo leva a uma relação do tipo

$$
N=(L / u)^{D}
$$

ou, se extraindo o logaritmo de ambos os lados,

$$
D=\frac{\ln (N)}{\ln (L / u)}
$$

onde $D$ é a Dimensão Fractal ou dimensão de Hausdorff do objeto analisado. Para um objeto uniforme e compacto, $D$ é um inteiro igual à dimensão topológica. Mas, para um fractal, tem-se que $D$ é um número fracionário (FALCONER, 1990) (TRICOT, 1995) (SHROEDER, 1996).

\subsection{Dimensão Fractal e Processamento de Imagens}

A Dimensão Fractal juntamente com a auto-semelhança em escala e a complexidade infinita são as características básicas que um objeto necessita para ser considerado um fractal. Ela representa o nível de complexidade e ocupação espacial que um certo fractal apresenta.

No entanto, fractais verdadeiros são objetos teóricos que ocorrem exclusivamente no mundo matemático. Algumas formas encontradas na natureza apresentam algumas características fractais e se aproximam do conceito em alguns aspectos (apresentam auto-semelhança em vários níveis de escala e são altamente complexas, mas essas características não tendem ao infinito). Entretanto, os objetos manufaturados, bem como as imagens, não possuem auto-semelhança em escala nem complexidade infinita, tornando questionável relacionar a eles o termo fractal ou estimar sua Dimensão Fractal (CARLIN, 2000). Entretanto, em análise de imagens a estimativa de Dimensão Fractal tem sido utilizada como uma metodologia para aferir a complexidade de uma imagem (PLOTZE et. al, 2004). 
O que é feito então é adaptar a técnica de estimativa da Dimensão Fractal para trabalhar com as limitações físicas de escala e auto-similaridade dos objetos, tornando a técnica útil para objetos não-fractais, tais como as imagens.

Como visto anteriormente, o valor da Dimensão Fractal de uma linha de comprimento $L$ pode ser obtido a partir da relação

$$
D=\frac{\ln (N)}{\ln (L / u)},
$$

onde $u$ é o comprimento de outra linha, sendo que $L>u$, e $N=(L / u)^{D}$.

Para objetos não fractais, essa relação varia em função de $u$. Faz-se então necessário obter um valor para o qual a equação acima convirja. Esse valor pode ser estimando como sendo:

$$
D=\lim _{u \rightarrow 0} \frac{\ln (N)}{\ln (L / u)} .
$$

O cálculo da equação acima resolve o problema de se estimar a Dimensão Fractal em objetos não-fractais, mas adiciona o problema do cálculo de um limite. O que se faz então é adaptar o cálculo do limite para um espaço discreto, como é o caso das imagens. Ao invés de se estimar o limite acima citado, o que se faz é desenhar o gráfico

$$
\ln (N) \times \ln (L / u)
$$

e calcular a inclinação, $\alpha$, da curva gerada. A Dimensão Fractal, $D$, é então estimada como sendo:

$$
D=\alpha \text {. }
$$

Essa adaptação permite estimar com precisão a Dimensão Fractal de objetos não-fractais. O resultado obtido passa a ser uma estimativa do nível de complexidade que um dado objeto apresenta (CARLIN, 2000).

A Dimensão Fractal vem sendo aplicada de diversas maneiras no processamento de imagens digitais. Entre suas aplicações destacam-se:

- Segmentação de imagens: tem-se a Dimensão Fractal como uma representação do nível de ocupação do espaço, servindo assim de veículo para separar e rotular as partes constituintes de uma imagem (CESAR; COSTA, 2000); 
- Comprimento de Curvas: são utilizadas algumas das técnicas de estimativa da Dimensão Fractal e não o valor em si obtido por meio da aplicação da técnica. Desse modo é possível estimar o comprimento de curvas irregulares e linhas costeiras (FALCONER, 1990);

- Extração de características, Análise e Comparação de Imagens: a Dimensão Fractal é uma característica importante em objetos, servindo de parâmetro para analisar e comparar diferentes objetos em uma imagem. Além disso, a outras técnicas se apresentam como ferramentas adicionais à Dimensão Fractal, representando um conjunto muito maior de características de uma imagem (PLOTZE et. al, 2004);

- Análise de texturas: Técnicas de estimativa da Dimensão Fractal podem ser adaptadas de forma a analisarem a variação dos diferentes níveis de cinza presentes numa imagem, de modo a fazer uma estimativa da textura presente nela (EBERT, 1994).

\subsection{Lacunaridade}

A lacunaridade constitui uma medida baseada no grau de invariância a translação que um fractal apresenta. Ela caracteriza a maneira como os pixels estão distribuídos e organizados em uma determinada região da imagem, ou seja, ela quantifica como o espaço euclidiano está preenchido, diferente da Dimensão Fractal, que mede o quão preenchido está o espaço euclidiano. De fato, a lacunaridade pode ser compreendida como um complemento da Dimensão Fractal, uma vez que formas com a mesma Dimensão Fractal podem apresentar diferentes lacunaridade (PLOTNICK, 1996).

A lacunaridade é obtida medindo a distribuição espacial dos buracos ou "gaps" existentes na imagem. Por meio dela é possível quantificar a homogeneidade de uma imagem ou de parte dela, de modo a torná-la comparável com outras imagens (ALLAIN; CLOITRE, 1991) (PLOTNICK, 1996).

Um dos algoritmos mais populares para se estimar a lacunaridade é o Gliding-box (PLOTNICK, 1996). Esse algoritmo utiliza os momentos de probabilidade de primeira e segunda ordem da imagem a fim de estimar a sua lacunaridade.

O algoritmo do Gliding-box é similar ao algoritmo do BoxCounting utilizado para estimar a Dimensão Fractal. Nele, uma caixa de lado $r$ é colocada sobre o canto superior esquerdo da imagem e o número de pontos da imagem é contado. Esse processo é repetido para todas as linhas e colunas da imagem, produzindo uma distribuição de frequiência da massa da imagem. $\mathrm{O}$ 
número de caixas de lado $r$ contendo uma massa $S$ da imagem é designado por $n(S, r)$ e o total de caixas contadas por $N(r)$. Essa distribuição de freqüência é então convertida para uma distribuição de probabilidade $Q(S, r)$, onde

$$
\begin{gathered}
N(r)=\sum_{S} n(S, r), \\
Q(S, r)=n(S, r) / N(r) .
\end{gathered}
$$

O primeiro e o segundo momentos dessa distribuição são determinados como:

$$
\begin{aligned}
Z^{(1)} & =\sum S Q(S, r), \\
Z^{(2)} & =\sum S^{2} Q(S, r) .
\end{aligned}
$$

A lacunaridade para uma caixa de tamanho r é então definida como:

$$
\Lambda(r)=Z^{(2)} /\left(Z^{(1)}\right)^{2}
$$

Outras características relativas a lacunaridade podem ser obtidas alterando o tamanho da caixa utilizada no gliding-box (PLOTNICK, 1996).

\subsection{Relação entre complexidade, análise de formas e texturas.}

A análise de formas e a análise de texturas constituem dois problemas clássicos na área da visão computacional. A literatura atual fornece uma grande quantidade de técnicas e diferentes abordagens para realizar a análise e a segmentação de formas e texturas. Esses dois tipos de análise apresentam diferentes focos de atuação numa imagem: a análise de formas visa extrair informações relacionadas ao aspecto geométrico do objeto sob análise servindo de veículo para separar e rotular as partes constituintes de uma imagem, enquanto que a análise de texturas atua de forma a analisar a variação dos diferentes níveis de cinza presentes na imagem, de maneira a distinguir regiões que apresentem as mesmas características de refletância (e, portanto, mesmas cores em determinada combinação de bandas) (EBERT, 1994).

Entre as diversas técnicas existentes na literatura voltadas à análise de formas e texturas encontramos a Dimensão Fractal. Essa técnica aborda a análise de complexidade como ferramenta para analisar formas e texturas. A Dimensão Fractal atua na análise de formas como 
uma medida do nível de complexidade existente no objeto, sendo o nível de complexidade de um objeto diretamente relacionado com o seu formato, bem como com o nível de ocupação do espaço por ele. Já na análise de texturas, a Dimensão Fractal atua como uma medida da complexidade da organização dos pixels que constituem a textura, sendo o nível de complexidade da textura diretamente relacionado com seu aspecto visual, bem como com a homogeneidade. 


\section{Principais Métodos Para Estimativa da Dimensão Fractal}

Diversos métodos para calcular a Dimensão Fractal podem ser encontrados na literatura. Neste capítulo, serão discutidos e analisados alguns dos métodos mais relevantes relacionados à análise de imagens digitais.

\subsection{Massa Raio}

O método de cálculo de Massa-Raio consiste de sobrepor círculos sobre uma forma presente numa imagem binária e contar a quantidade de pontos dessa forma presentes no interior do círculo (Figura 3).

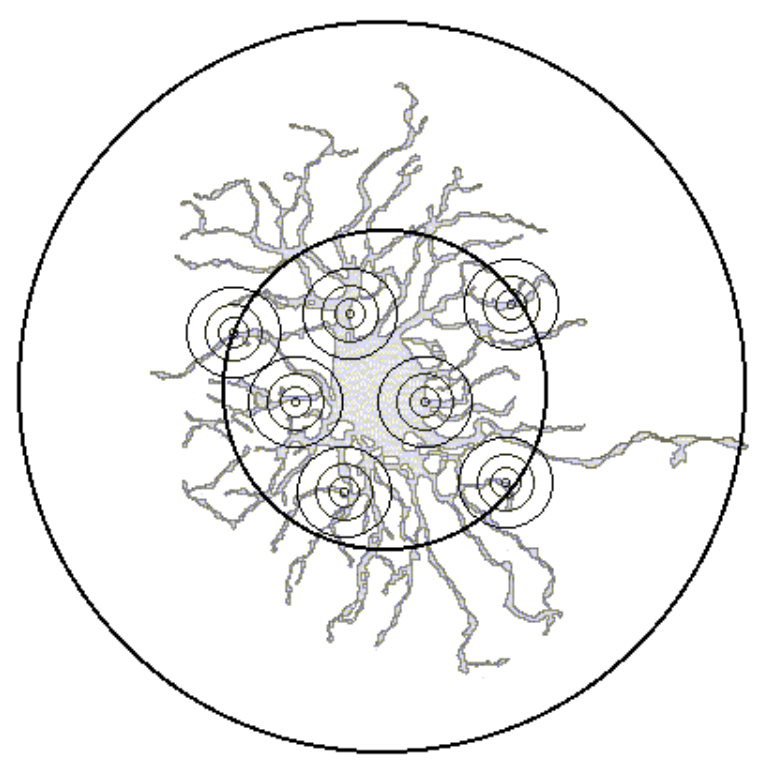

Figura 3 - Sobreposição dos círculos pelo método Massa-Raio

Sendo $A, C_{r} \in R^{2}$ a forma analisada e o círculo de raio $r, M_{r}(A)$ é o número de pontos de $A$ presentes em $C_{r}$, obedecendo a relação 


$$
\begin{gathered}
C_{r} \subset A, \\
M_{r}(A)=\mu r_{\text {para }}^{D}>0 .
\end{gathered}
$$

Obtém-se então a Dimensão Fractal a partir da relação acima como sendo:

$$
D=\lim _{r \rightarrow 0} \frac{\ln \left(M_{r}(A)\right)}{\ln (r)},
$$

onde $D$ é a Dimensão Fractal pelo método Massa-Raio.

Para calcular esse método, um ou mais círculos podem ser utilizados. No caso de se utilizar apenas um círculo, é interessante escolher o centro do círculo como sendo o centro de massa da forma analisada. O centro de massa $c_{x y}$ para uma imagem $A=\{0,1\}$, onde o valor um representa a forma analisada, pode ser calculado como sendo:

$$
\begin{gathered}
\text { Area }=\sum_{x=0}^{m} \sum_{y=0}^{n} A(x, y), \\
c_{x}=\frac{1}{\text { Area }} \sum_{x=0}^{m} \sum_{y=0}^{n} x \quad \text { e } c_{y}=\frac{1}{\text { Area }} \sum_{x=0}^{m} \sum_{y=0}^{n} y .
\end{gathered}
$$

Já no caso de se utilizar vários círculos, um mecanismo de sorteio pode ser utilizado para se escolher os diferentes centros dos círculos. Deve-se também considerar a massa média calculada nesse caso.

Outro detalhe desse método se refere ao raio máximo que será utilizado na expansão dos círculos. Apesar de esse valor poder ser definido por usuário, é comum utilizar o raio de giro da imagem. Este raio de giro é definido como

$$
\begin{gathered}
r_{\max }=\max \left(\sqrt{\left(\left(c_{x}-p_{x}\right)^{2}+\left(c_{y}-p_{y}\right)^{2}\right)}\right) \text {, onde } p_{x y} \in A_{\mathrm{e}} \\
A\left(p_{x}, p_{y}\right)=1 .
\end{gathered}
$$

Os raios $\mathrm{r}$ utilizados no método variam então entre $1 \leq r \leq r_{\max }$, sendo a cada nova iteração o raio incrementado em 1 e o cálculo da massa realizado novamente. (CORNFORTH et. al, 2002). 
Traçando o gráfico de log-log entre $M_{r}(A)$, massa acumulada para um raio $r$, e $r$, raio do círculo usado, obtém-se a aproximação de uma reta com coeficiente angular $\alpha$, onde é $D=\alpha$ é Dimensão Fractal de $A$ (Figura 4) (FALCONER, 1990) (MANDELBROT, 2000).

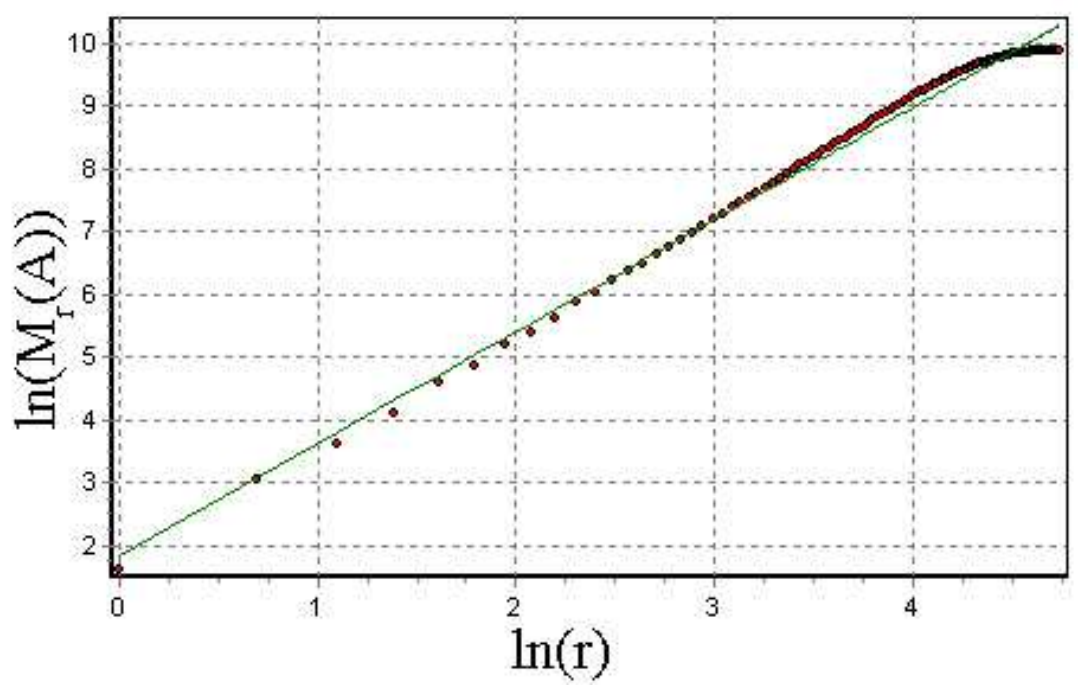

Figura 4 - Gráfico Log - Log da variação da massa acumulada em relação ao raio. Para fractais matemáticos estritamente auto-semelhantes a dimensão da Massa é a mesma da dimensão de Hausdorff (SCHROEDER, 1996) (HONDA et. al, 1991) (LANDINI; RIPPIN, 1993).

\subsection{Análise Intersecção Acumulativa}

O método da intersecção acumulativa foi desenvolvido por Schierwagen (SCHIERWAGEN, 1990), baseado no trabalho de Sholl (SHOLL, 1953). Trata-se de um método similar ao método Massa-Raio, no entanto, ao invés de calcular a massa de uma região esse método calcula o número de intersecções ou subdivisões existentes nessa região (Figura 5) (CORNFORTH et. al, 2002). 


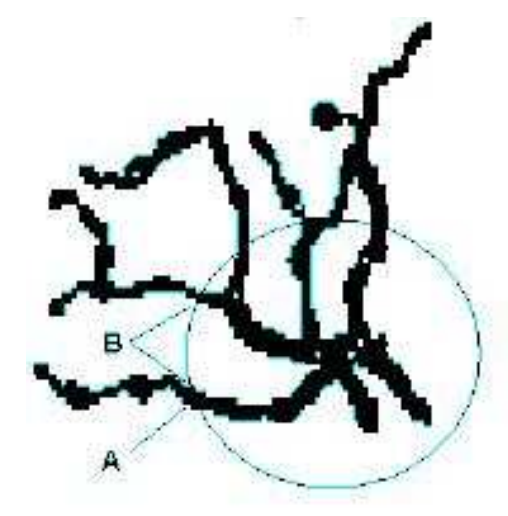

Figura 5 - Uma pequena seção de uma imagem é mostrada, com um simples círculo correspondendo ao raio selecionado em um algum ponto durante a análise. Pontos consecutivos que também são adjacentes são mostrados por A, enquanto que pontos que não são adjacentes são mostrados por $B$.

Sendo $A, C_{r} \in R^{2}$ a forma analisada e o perímetro de um círculo de raio $r, M_{r}(A)$ é o número de pontos de $A$ presentes em $C_{r}$, obedecendo a relação:

$$
\begin{gathered}
C_{r} \subset A, \\
M_{r}(A)=\mu r^{D} \text { para } r>0 .
\end{gathered}
$$

Obtém-se a Dimensão Fractal a partir da relação acima como sendo

$$
D=\lim _{r \rightarrow 0} \frac{\ln \left(M_{r}(A)\right)}{\ln (r)}
$$

onde $D$ é a Dimensão Fractal pelo método de Intersecções Acumulativas.

Para calcular esse método, um ou mais círculos podem ser utilizados. No caso de se utilizar apenas um círculo, é interessante escolher o centro do círculo como sendo o centro de massa da forma analisada. O centro de massa $c_{x y}$ para uma imagem $A=\{0,1\}$, onde o valor um representa a forma analisada, pode ser calculado como sendo:

$$
\begin{gathered}
\text { Area }=\sum_{x=0}^{m} \sum_{y=0}^{n} A(x, y), \\
c_{x}=\frac{1}{\text { Area }} \sum_{x=0}^{m} \sum_{y=0}^{n} x \quad \text { e } c_{y}=\frac{1}{\text { Area }} \sum_{x=0}^{m} \sum_{y=0}^{n} y .
\end{gathered}
$$


Já no caso de se utilizar vários círculos, um mecanismo de sorteio pode ser utilizado para se escolher os diferentes centros dos círculos. Deve-se também considerar o número de intersecções médias calculada nesse caso.

Depois de sobreposto este círculo de raio $r$ sobre a forma, são colocados em um vetor todos os pontos de sua borda que também pertençam a forma, ordenados pelo ângulo que fazem a partir do centro do círculo (Figura 6). Feito isso, basta atravessar o vetor verificando a adjacência de pontos consecutivos, contando onde essa adjacência não é satisfeita devido à intersecção (CORNFORTH et. al, 2002).
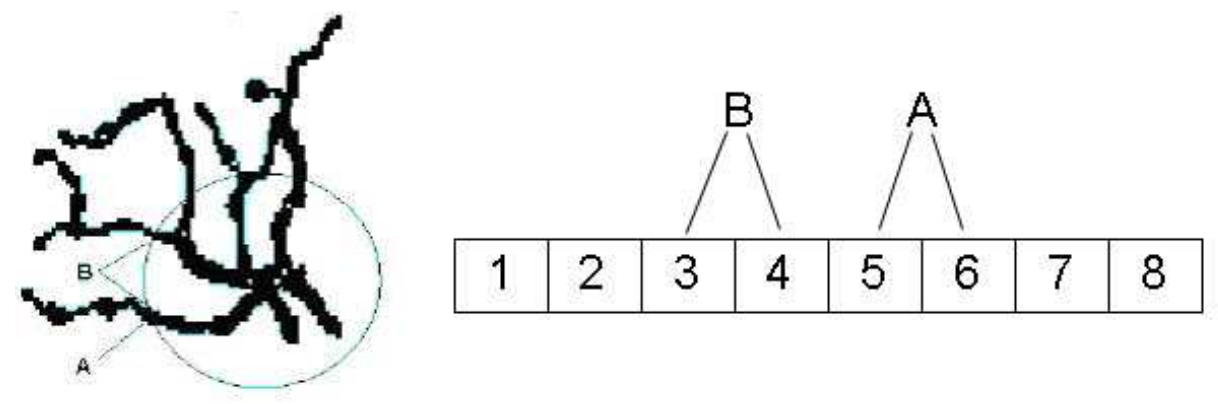

Figura 6 - Exemplo da verificação das intersecções no vetor.

Outro detalhe desse método se refere ao raio máximo que será utilizado na expansão dos círculos. Apesar de esse valor poder ser definido por usuário, é comum utilizar o raio de giro da imagem. Este raio de giro é definido como:

$$
\begin{gathered}
r_{\max }=\max \left(\sqrt{\left(\left(c_{x}-p_{x}\right)^{2}+\left(c_{y}-p_{y}\right)^{2}\right)}\right), \text { onde } p_{x y} \in A_{\mathrm{e}} \\
A\left(p_{x}, p_{y}\right)=1 .
\end{gathered}
$$

Os raios $r$ utilizados no método variam então entre $1 \leq r \leq r_{\max }$, sendo a cada nova iteração o raio incrementado em 1 e o cálculo do total de intersecções realizado novamente. (CORNFORTH et. al, 2002).

Traçando o gráfico de log-log entre $M_{r}(A)$, número de intersecções para um raio $r$, e $r$, raio do círculo usado, obtém-se a aproximação de uma reta com coeficiente angular $\alpha$, onde $D=\alpha$ é Dimensão Fractal de $A$ (Figura 7) (FALCONER, 1990) (MANDELBROT, 2000). 


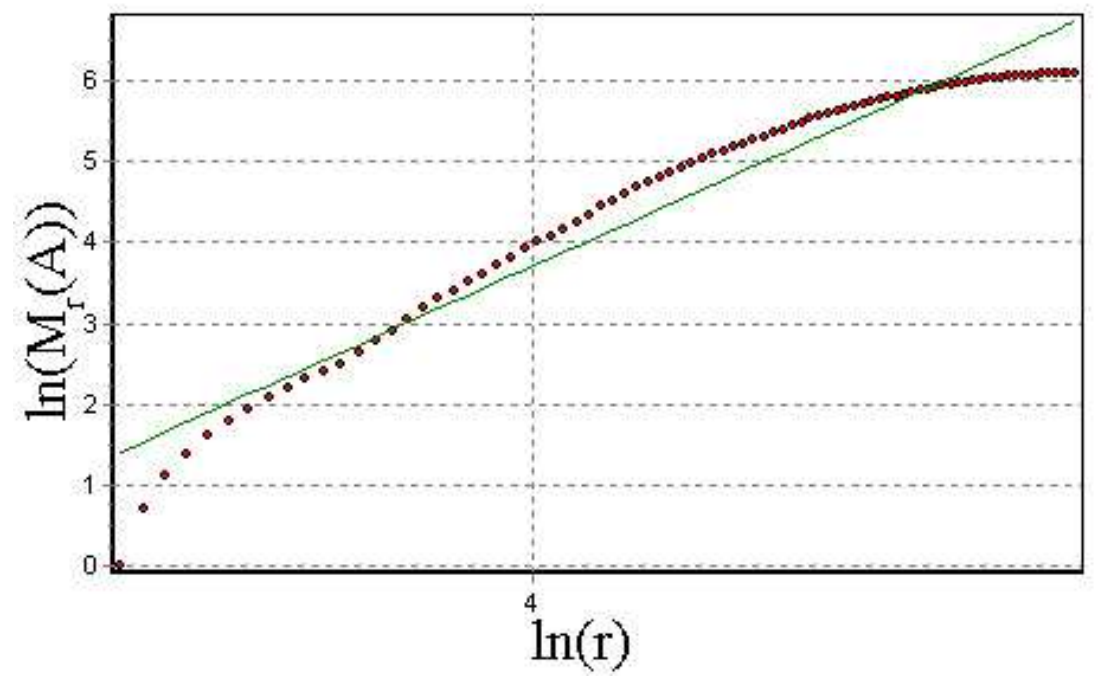

Figura 7 - Gráfico log-log da variação do número de intersecções em relação ao raio.

\subsection{BoxCounting}

O BoxCounting é um dos métodos mais conhecidos e utilizados para estimar a Dimensão Fractal de uma forma ou imagem. Isso se deve a sua simplicidade e facilidade de implementação. Este método consiste em sobrepor à imagem uma malha de quadrados e contar o número de quadrados necessários para cobrir toda a forma (Figura 8) (COELHO; COSTA, 1995).
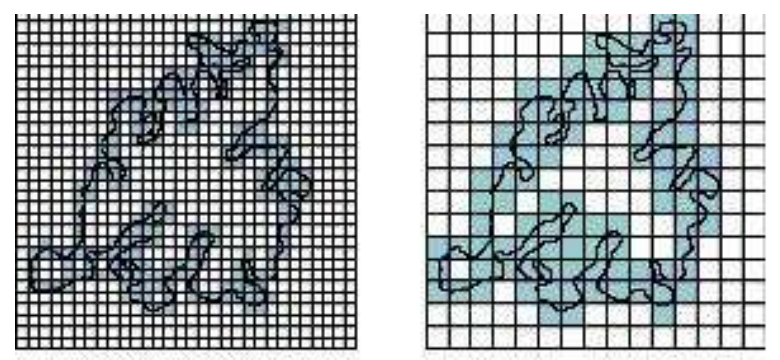

Figura 8 - Divisão de uma imagem pelo Método do BoxCounting

Sendo $A \in R^{2}$ a forma analisada, $N_{r}(A)$ é o número de caixas de lado $r$ necessárias para cobrir $A$, obedecendo a relação

$$
N_{r}(A)=\mu r^{-D} \text {. }
$$

A Dimensão Fractal pode então ser obtida a partir da relação acima, de modo que 


$$
D=-\lim _{r \rightarrow 0} \frac{\ln \left(N_{r}(A)\right)}{\ln (r)},
$$

onde $D$ é a Dimensão Fractal calculada pelo método do BoxCounting.

Para a execução desse método é necessário definir um conjunto $B$ de tamanhos de lados $r$ a ser utilizado nas diversas iterações do método. Apesar de $B$ poder ser definido inicialmente por um usuário, é padrão calculá-lo com base nas dimensões da imagem, de modo que:

$$
\forall r_{i} \in B \quad\left\{\begin{array}{l}
r_{0}=\max (\text { altura, largura) } \\
r_{i+1}=r_{i} / 2
\end{array}\right.
$$

Traçando-se um gráfico log-log de $N_{r}(A)$ (número de caixas ocupadas) por $r$ (tamanho do lado dessa caixa) obtém-se a aproximação de uma reta com coeficiente angular $\alpha$. Deste modo, é possível definir $D=-\alpha$ como Dimensão Fractal de $A$ (Figura 9) (TRICOT, 1995) (FALCONER, 1990).

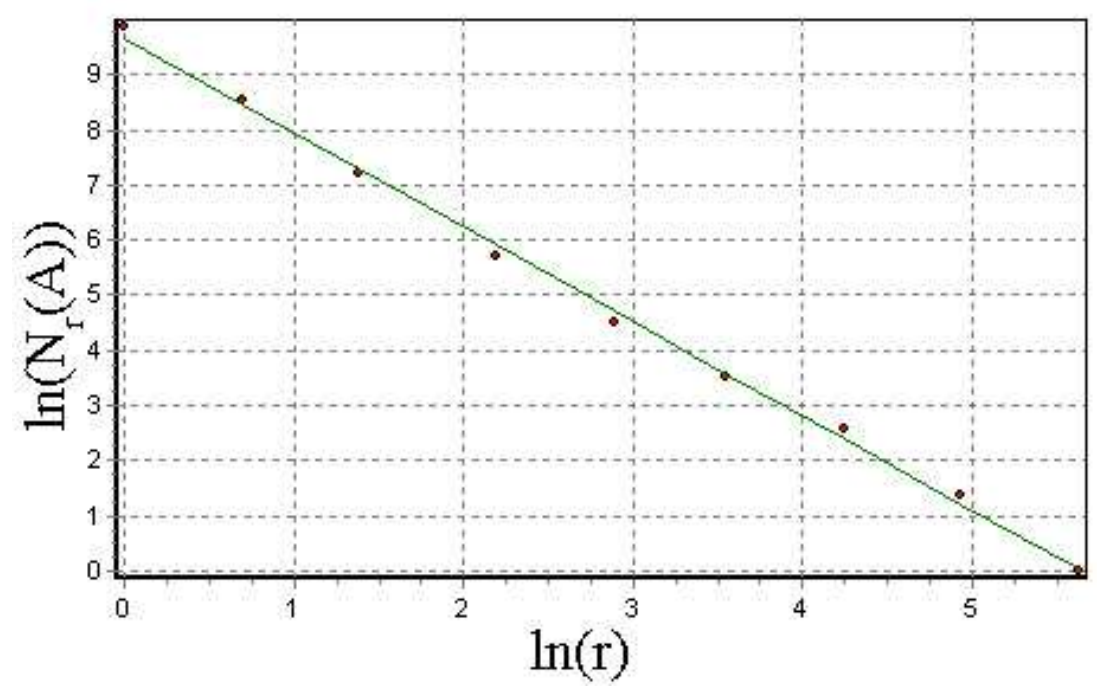

Figura 9 - Cálculo do coeficiente angular no BoxCounting

Por se tratar de um método bastante simples, o BoxCounting permite a inserção de refinamentos em sua técnica. Um deles seria introduzir uma distinção entre células parcialmente ocupadas e completamente ocupadas. Isto permite calcular várias dimensões fractais, calculando 
o logaritmo da combinação de células: completamente ocupadas, completamente não-ocupadas, parcialmente ocupadas (MORENCY; CHAPLEAU, 2003).

Pelo mesmo motivo, sua simplicidade, o BoxCounting é muito sensível a variações. Variações como qualidade da imagem influenciam no seu cálculo. Outro problema que esse método apresenta se refere à disposição e orientação da malha sobre a imagem (Figura 10) e ao tamanho das caixas escolhidas. Todas essas pequenas variações podem levar o método a calcular valores errôneos, diferentes de resultados esperados (MORENCY; CHAPLEAU, 2003).
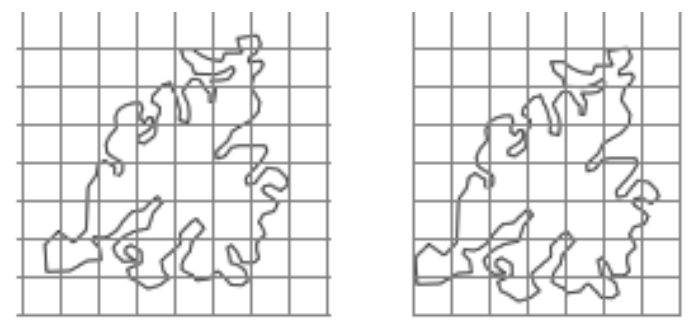

Figura 10 - Variação na disposição do Grid.

\subsection{Dividers (Compass)}

O método dividers (STOYAN; STOYAN, 1994), também conhecido como Compass (MANDELBROT, 2000), é um dos métodos mais simples para estimar a Dimensão Fractal de objetos e curvas que possuam um contorno definido (membrana de célula, linha costeira...). Trata-se de um método exato apenas para curvas auto-semelhantes (TAKAYASU, 1990) (NORMANT; TRICOT, 1991) (TRICOT, 1995).

Ele é baseado no fato do perímetro de um fractal ser proporcional ao tamanho de uma régua $r$ usada para medir o seu contorno (Figura 11). 


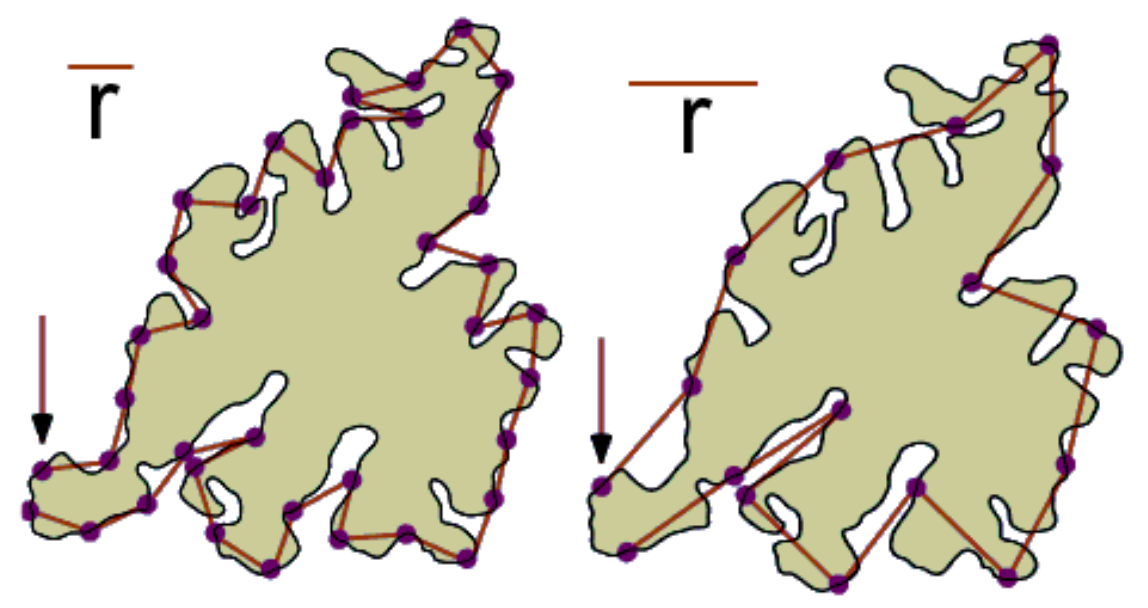

Figura 11 - Medição para valores distintos de $r$.

Sendo $A \in R^{2}$ a forma analisada, temos que $P$ é o perímetro de $A$, dado por:

$$
P \subset A \text {. }
$$

Movendo-se uma régua de tamanho $r$ ao longo do perímetro $P$, obtém-se o comprimento $l(r)$ do perímetro, obedecendo a relação

$$
l(r)=c \cdot r^{1-D}
$$

A Dimensão Fractal do perímetro pode ser calculada então com sendo:

$$
D=1-\lim _{r \rightarrow 0} \frac{\ln (l(r))}{\ln (r)} .
$$

Traçando o gráfico log-log de $l(r)$ (comprimento do perímetro para uma régua $r$ ) por $r$ (tamanho da régua) obtém-se a aproximação de uma reta com coeficiente angular $\alpha$, onde $D=1-\alpha$ é Dimensão Fractal de $P$ (Figura 12) (MANDELBROT, 2000) 


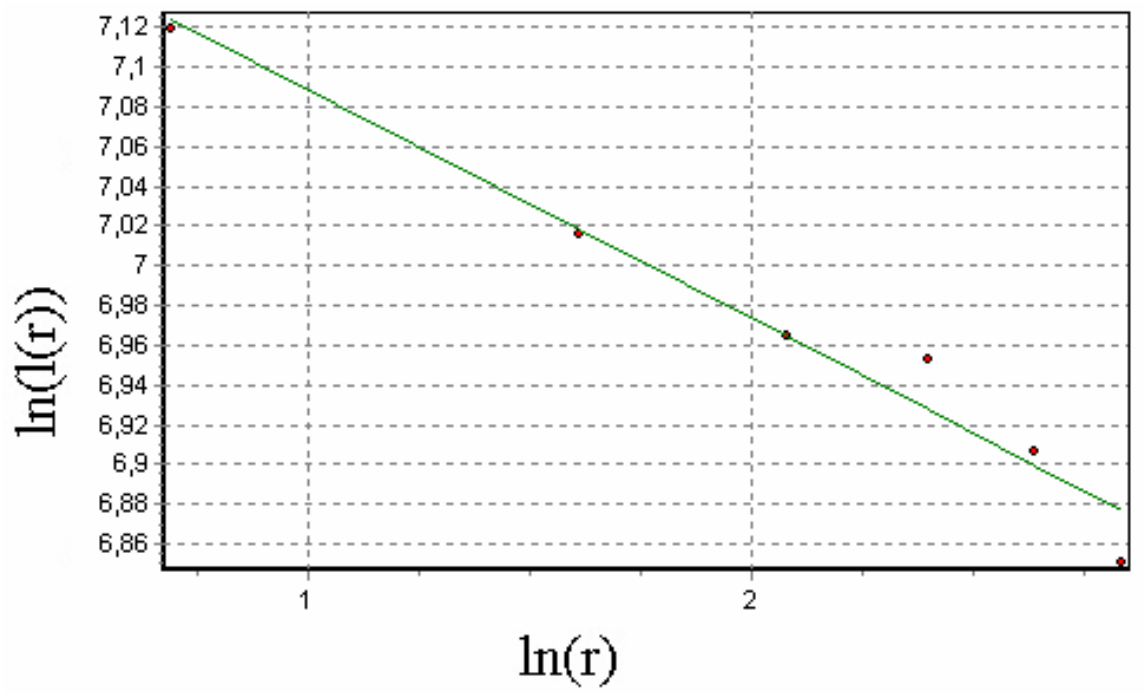

Figura 12 - Cálculo do coeficiente angular no Dividers.

Um dos problemas que este método apresenta é o fato do valor calculado variar dependendo do ponto de início da curva. Para isso, é recomendado que o processo seja repetido para diversos pontos de início na curva (SUGIHARA; MAY 1990). Em alguns casos, o gráfico log-log não possui uma inclinação constante (a Dimensão Fractal não é constante), podendo ser um reflexo da resolução limitada dos dados analisados (HAMILTON et al, 1992) (KENKEL; WALKER, 1993) (GAUTESTAD; MYSTERUD, 1994).

\subsection{Bouligand-Minkowski}

O método de Bouligand-Minkowski ou Dimensão de Minkowski é um dos métodos que produz os resultados mais acurados e consistentes para a Dimensão Fractal (TRICOT, 1995). Isso ocorre por se tratar de um método mais sensível as diferentes mudanças estruturais da forma em análise.

Este método se baseia no estudo da área de influência, criada pela dilatação da forma em questão, por um disco de raio $r$ (Figura 13). Pequenas alterações na forma geram alterações na área de influência calculada (TRICOT, 1995) (SHROEDER, 1996). 


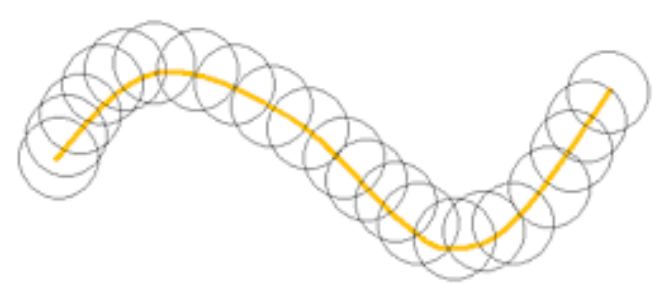

Figura 13 - Dilatação de uma curva com um disco.

Sendo $A \in R^{2}$ a forma analisada, definimos a dilatação de $A, A_{r}$, como o conjunto de pontos em $R^{2}$ que se encontram a uma distância de $A$ menor ou igual a $r$ :

$$
A_{r}=\left\{x \in R^{2}|\exists y \in A:| x-y \leq r \mid\right\}
$$

Essa Dilatação pode também ser definida como:

$$
A_{r}=\bigcup_{x \in A} B_{r}(x),
$$

sendo $B_{r}(x)$ um disco de raio $r$.

Para obter a Dimensão de Minkowski, um disco de raio $r$ é varrido continuamente ao longo dos pixels do contorno (ou de interesse) da imagem, sendo que os centros dos discos correspondem às coordenadas de cada um dos pixels. Os pixels limitados pelo círculo são então somados, fornecendo a área dilatada $A(r)$ da imagem para um raio $r$ (SERRA, 1982). A área dilatada, $A(r)$, e o raio, $r$, obedecem a seguinte relação:

$$
A(r)=\mu r^{2-D} \text {. }
$$

A Dimensão Fractal pode então ser obtida a partir da relação acima, de modo que

$$
D=2-\lim _{r \rightarrow 0} \frac{\ln (A(r))}{\ln (r)},
$$

onde $D$ é a Dimensão Fractal calculada pelo método de Minkowski.

Traçando-se um gráfico log-log de $A(r)$ (área de influência para um raio $r$ ) por $r$ (tamanho do raio de influência), obtém-se a aproximação de uma reta com coeficiente angular $\alpha$, onde $D=2-\alpha$ é Dimensão Fractal de $A$ pelo método de Minkowski (Figura 14). 


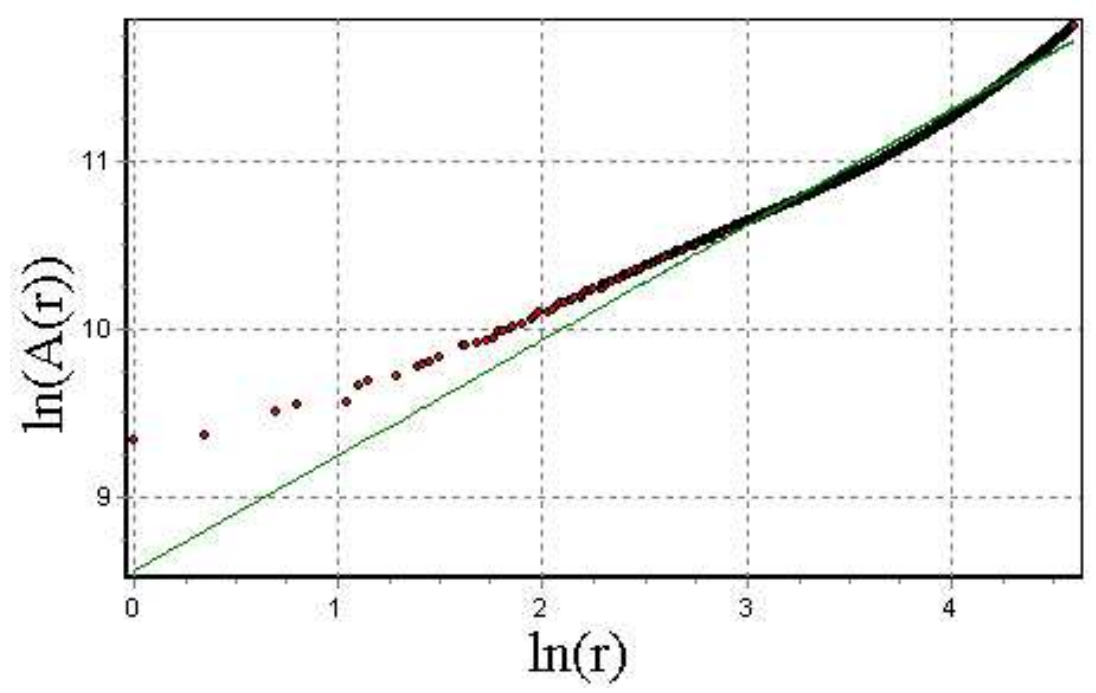

Figura 14 - Cálculo do coeficiente angular no método de Bouligand-Minkowski.

Para otimizar o algoritmo de cálculo da área de influência utiliza-se a Transformada Exata da Distância (TED), que atribui aos pixels de uma imagem binária a distância mínima entre estes pixels e os pixels de fundo. Para o cálculo da TED utiliza-se a Distância Euclidiana, devido a sua propriedade de invariância a rotação (BRUNO; COSTA, 2004).

Dados dois pontos $p, q \in R^{2}$, a distância euclidiana pode ser definida como:

$$
d(p, q)=|q-p|=\sqrt{\left(q_{x}-p_{x}\right)^{2}+\left(q_{y}-p_{y}\right)^{2}} .
$$

Tem-se então que a TED é um conjunto de distâncias Euclidianas únicas, ordenadas e crescentes, que servem de base para as dilatações sucessivas do disco no contorno da imagem (BRUNO; COSTA, 2004).

\subsection{Variações do BoxCounting}

A literatura fornece uma variedade de diferentes técnicas para se estimar a Dimensão Fractal de uma imagem ou objeto. No entanto, vale lembrar que muitas dessas técnicas possuem aplicações limitadas devido ao fato de serem muito específicas, não sendo de grande importância no contexto geral (FALCONER, 1990).

Muitas das técnicas encontradas na literatura são na verdade variações de métodos populares, como por exemplo, o BoxCounting. Ao invés de se dividir uma imagem com uma 
grade de quadrados de lado $r$ e contar o número de quadrados que cubra a imagem (Figura 15a), pode-se cobrir a imagem com quadrados de lado $r$ de forma a obter-se o número mínimo de quadrados (Figura 15b). Outra variação seria cobrir a imagem com círculos de raio $r$ e contá-las, não sendo necessário que essas bolas estejam disjuntas (Figura 15c) (FALCONER, 1990).

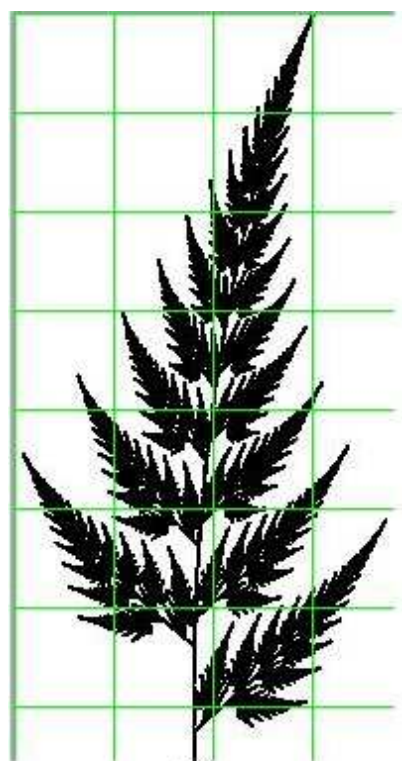

(a)

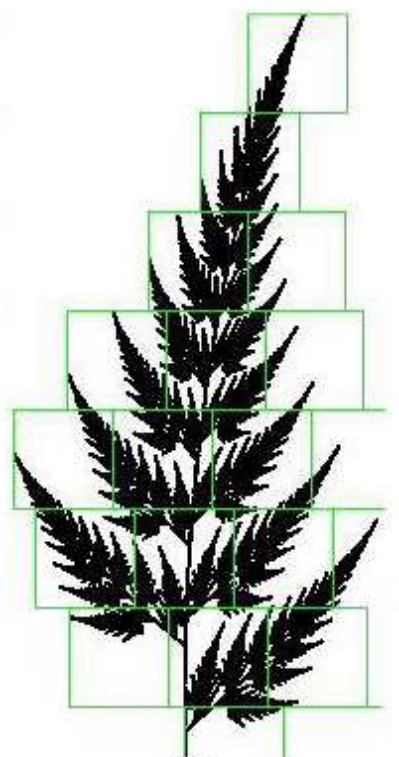

(b)

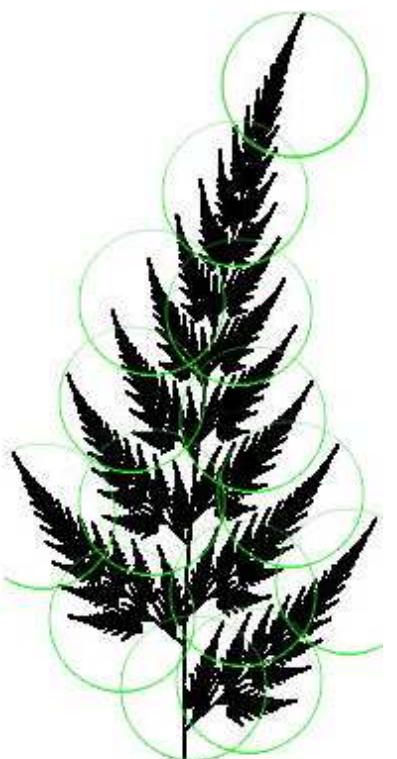

(c)

Figura 15 - variações na implementação do BoxCounting 


\section{Comparação dos Métodos}

\subsection{Análise das Técnicas}

Pode-se observar que os diversos métodos descritos acima são todos baseados em relações entre uma medida realizada e sua distribuição espacial. No entanto, enquanto alguns destes métodos podem ser aplicados a qualquer tipo de estrutura, outros métodos sofrem de certas restrições quanto a sua utilização.

Métodos baseados na medida do comprimento podem ser aplicados apenas a curvas (como membranas celulares, linhas costeiras e limites de terrenos) uma vez que leva em consideração apenas o contorno que descreve o objeto (Figura 16). O método Dividers é um claro exemplo de método baseado no comprimento de curva. Por esse motivo, objetos com contornos semelhantes, mas com diferentes formas interna (como por exemplo, uma área interna não preenchida) são calculados de forma idêntica.

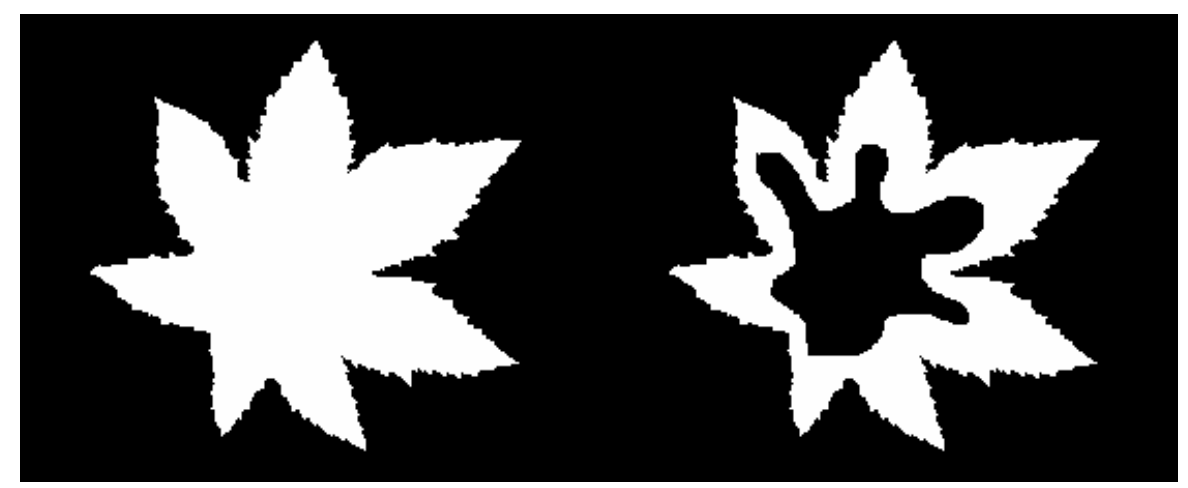

Figura 16 - Método Dividers não leva em consideração a informação interna do objeto. A Dimensão Fractal calculada é a mesma para os dois objetos.

Também o método baseado na análise de intersecções acumulativa possui restrições quanto a sua aplicação. Como seu próprio nome diz, sua análise está baseada na descontinuidade e reentrâncias que a estrutura possui, não fazendo sentido aplicá-lo a uma curva ou a uma estrutura continua, sem reentrâncias. No entanto, esse método pode ser muito bem aplicado ao esqueleto da estrutura (Figura 17). O Esqueleto de uma estrutura pode ser compreendido como a forma de representar imagens através da extração de suas características pelo processo de afinamento, 
resultando os pixels essenciais para composição de segmentos lineares com comprimento, tamanho e direção (SERRA, 1982).

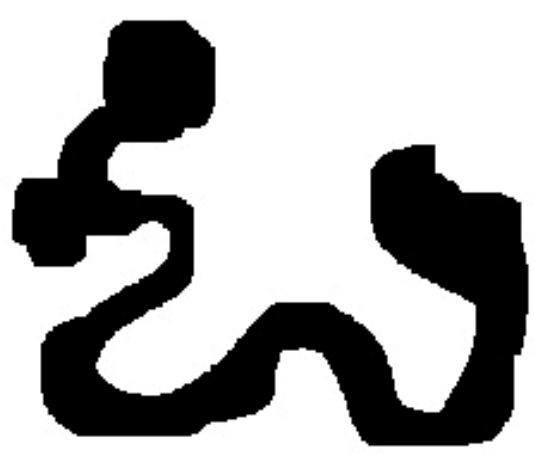

(a)

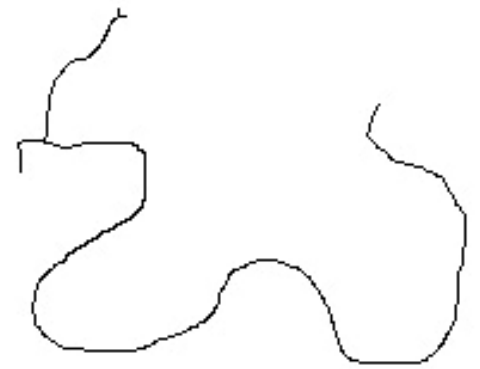

(b)

Figura 17 - (a) Imagem Original; (b) Esqueleto da Imagem Obtido por Afinamentos Sucessivos.

De maneira inversa ao método Dividers, o método Massa-Raio tem a restrição de não ser eficaz quando temos em mãos apenas o contorno de determinada estrutura. Isso ocorre porque tendo apenas o contorno de um objeto, não temos nenhuma informação com relação à massa interna do mesmo (Figura 18). Para a utilização do método de Massa-Raio é necessário que a estrutura esteja preenchida.

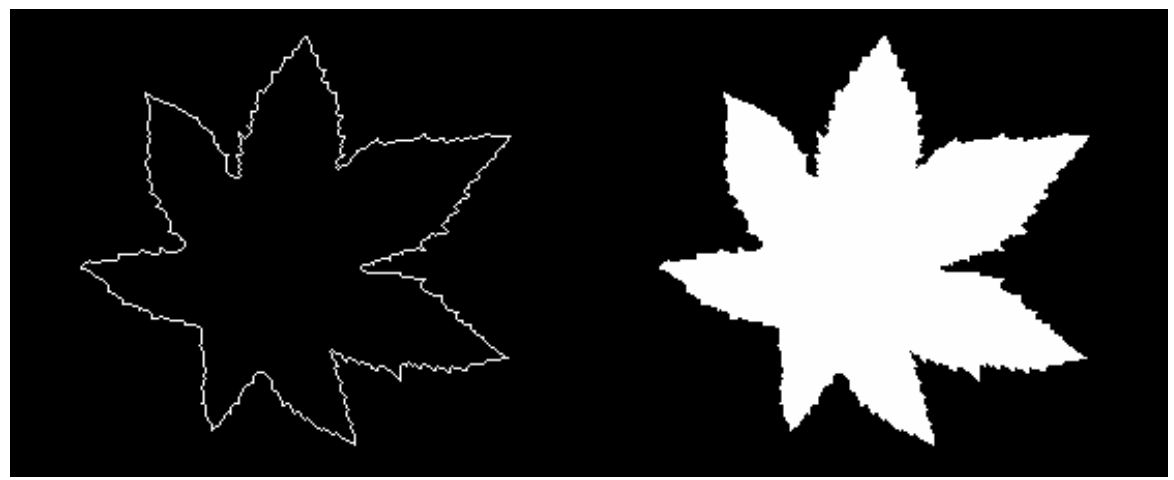

Figura 18 - O Método de Massa-Raio necessita da informação interna do objeto para o cálculo. Apenas o contorno é insuficiente.

Apesar dos métodos descritos possuírem certas restrições quanto a sua utilização, métodos como BoxCounting e Minkowski não apresentaram restrições quanto a classe de imagens a qual podem ser aplicados. 
Outro fator que deve ser considerado nos métodos descritos neste relatório é que a maioria deles pode apresentar certas variações de resultado para uma mesma estrutura medida. Isso se deve ao fato de que vários desses métodos possuem pontos e/ou ajustes iniciais escolhidos para a realização do cálculo. Esse fator de aleatoriedade adiciona ao método uma pequena variação em cada execução, o que pode induzir a certo erro de cálculo da Dimensão Fractal. Este tipo de problema é comum no método BoxCounting.

No método Dividers, a variação da estimativa ocorre devido ao cálculo do comprimento da curva começar a partir de certo ponto escolhido. Se em uma segunda execução outro ponto for escolhido como ponto inicial para o cálculo do comprimento da curva, um resultado diferente do anterior poderá ser encontrado (Figura 19). Uma maneira de diminuir esse erro é calcular o comprimento da curva para vários pontos iniciais distintos e calcular o comprimento médio da curva. A partir dessa média do comprimento da curva é que será calculada a Dimensão Fractal da mesma.

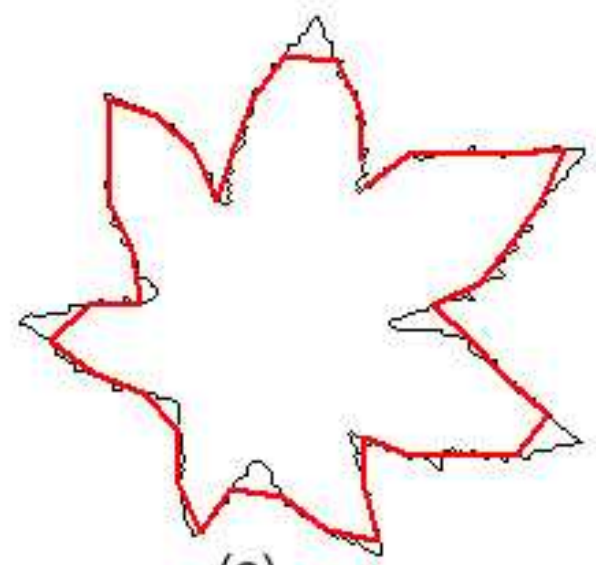

(a)

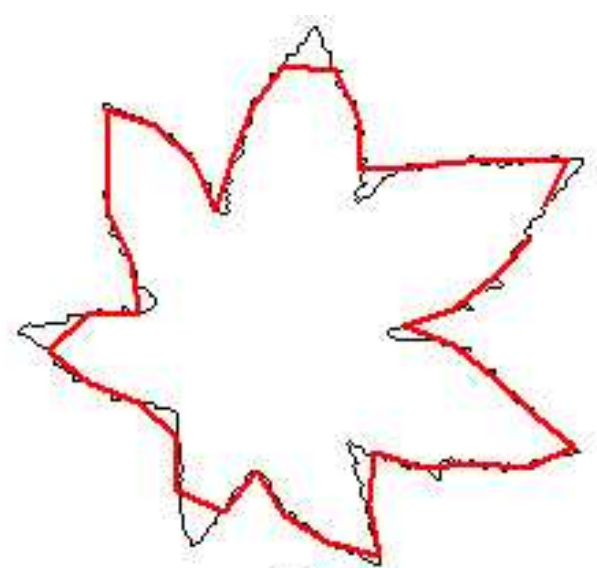

(b)

Figura 19 - (a) e (b) são execuções do Dividers para um mesmo tamanho de régua, mas pontos iniciais distintos.

Já no método BoxCounting, a inconsistência ocorre devido ao posicionamento do grid sobre a imagem. Dependendo de como o grid é posicionado sobre a imagem o número de caixas contadas pode variar, provocando variações no resultado de uma execução para outra (Figura 20). No entanto tais variações podem ser reduzidas alinhando o início do grid com o início da figura a ser analisada, minimizando a porção da imagem delimitada exclusivamente ao plano de fundo. 


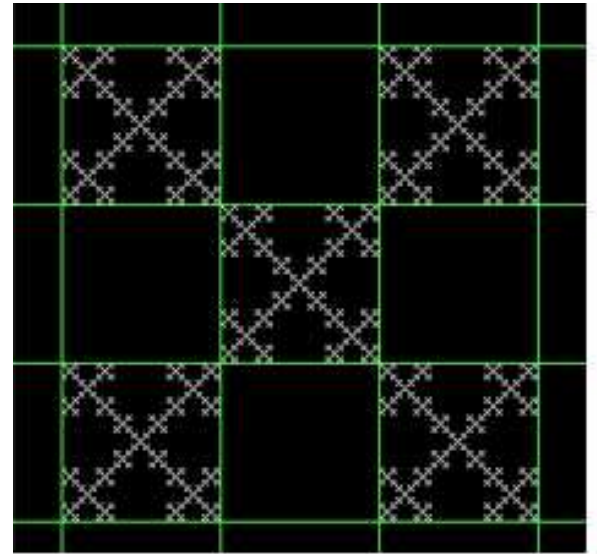

(a)

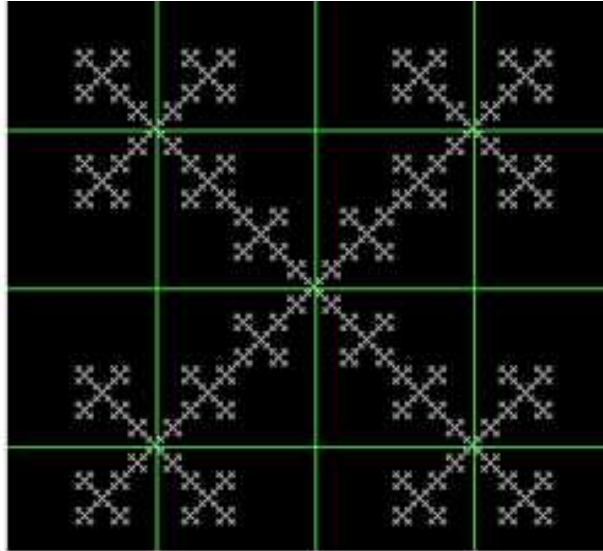

(b)

Figura 20 - (a) Grid alinhado ao início da imagem minimiza a contagem. (b) Grid sem alinhamento.

Ainda, outro problema encontrado no BoxCounting é em relação ao número e ao tamanho de caixas utilizados pelo algoritmo nas iterações do método. Isso se deve ao fato do tamanho da caixa influenciar diretamente no total de caixas necessárias para cobrir a imagem. Pode ser observado que uma mesma imagem apresenta resultados diferentes de Dimensão Fractal para conjuntos diferentes de caixas (Figura 21). Esta variabilidade da Dimensão Fractal quanto ao conjunto de caixas pode ser minimizada usando-se sempre um mesmo conjunto de caixas ou a partir de uma regra que calcule os valores das caixas a partir do tamanho da imagem. Alguns autores consideram uma boa estratégia começar com uma caixa suficientemente grande, de modo que preencha toda imagem e, a cada iteração, diminuir o tamanho da caixa pela metade até possuir uma caixa de tamanho unitário. 


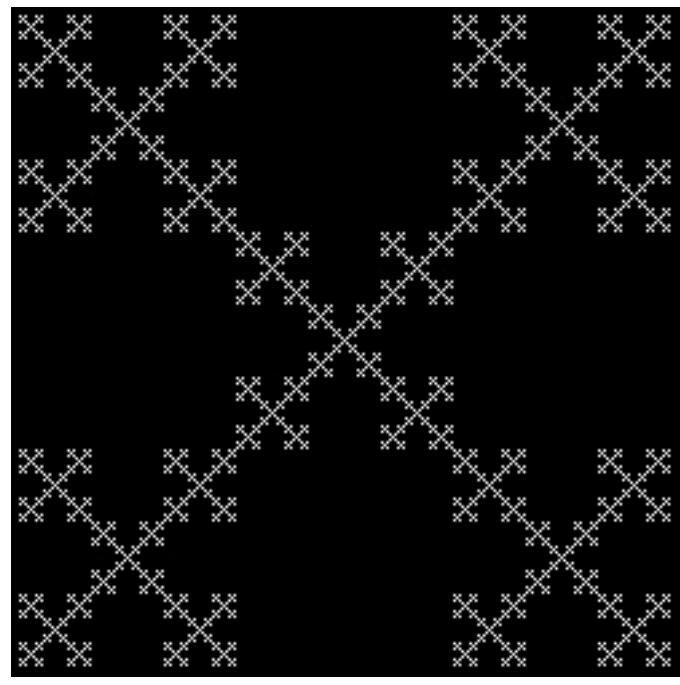

\section{Caixas Usadas:}

$3,9,27,81$

DF: 1,4649735

Caixas Usadas:

$1,2,4,8,15,30,61,122,243$

DF: 1,4997350

Figura 21 - Conjuntos diferentes de caixas geram valores diferentes para a Dimensão Fractal

Os métodos de Massa_Raio e de Intersecções Acumulativas apresentam problemas similares ao do método Dividers. Ambos os métodos dependem de pontos escolhidos como centro dos círculos usados no cálculo. Uma vez que as escolhas podem ser empíricas, provocam variações de resultado de uma execução para outra. Observe que isto ocorre apenas quando são utilizados vários círculos para o cálculo. $\mathrm{O}$ algoritmo apresenta versões que utilizam apenas um círculo, que pode apresentar como centro, o centro de massa da imagem, e reduzir a inconsistência. Assim como no método Dividers, uma saída para minimizar estes erros seria trabalhar com a média de várias execuções para o cálculo da Dimensão Fractal.

O método de Bouligand-Minkowski apresenta resultados mais consistentes, uma vez que não necessita de ajustes iniciais. Confirmando a afirmação de Tricot (TRICOT, 1995) de que este é o método mais preciso e consistente para a estimativa da Dimensão Fractal.

\subsection{Validação dos Métodos}

Visando validar a eficiência dos diversos métodos de estimativa da Dimensão Fractal descritos no Capítulo 3, realizou-se um experimento onde a Dimensão Fractal de diversas formas foi estimada por cada um dos métodos apresentados. 
Para a realização desse experimento, utilizaram-se formas fractais e formas Euclidianas de dimensão já conhecida. A Tabela 1 mostra as formas euclidianas utilizadas, enquanto que a Tabela 2 mostra as formas fractais que foram selecionadas para o experimento.

\begin{tabular}{|c|c|}
\hline Objeto & Dimensão Euclidiana \\
\hline Quadrado & 2 \\
\hline Reta & 1 \\
\hline Ponto & 0 \\
\hline
\end{tabular}

Tabela 1 - Formas Euclidianas

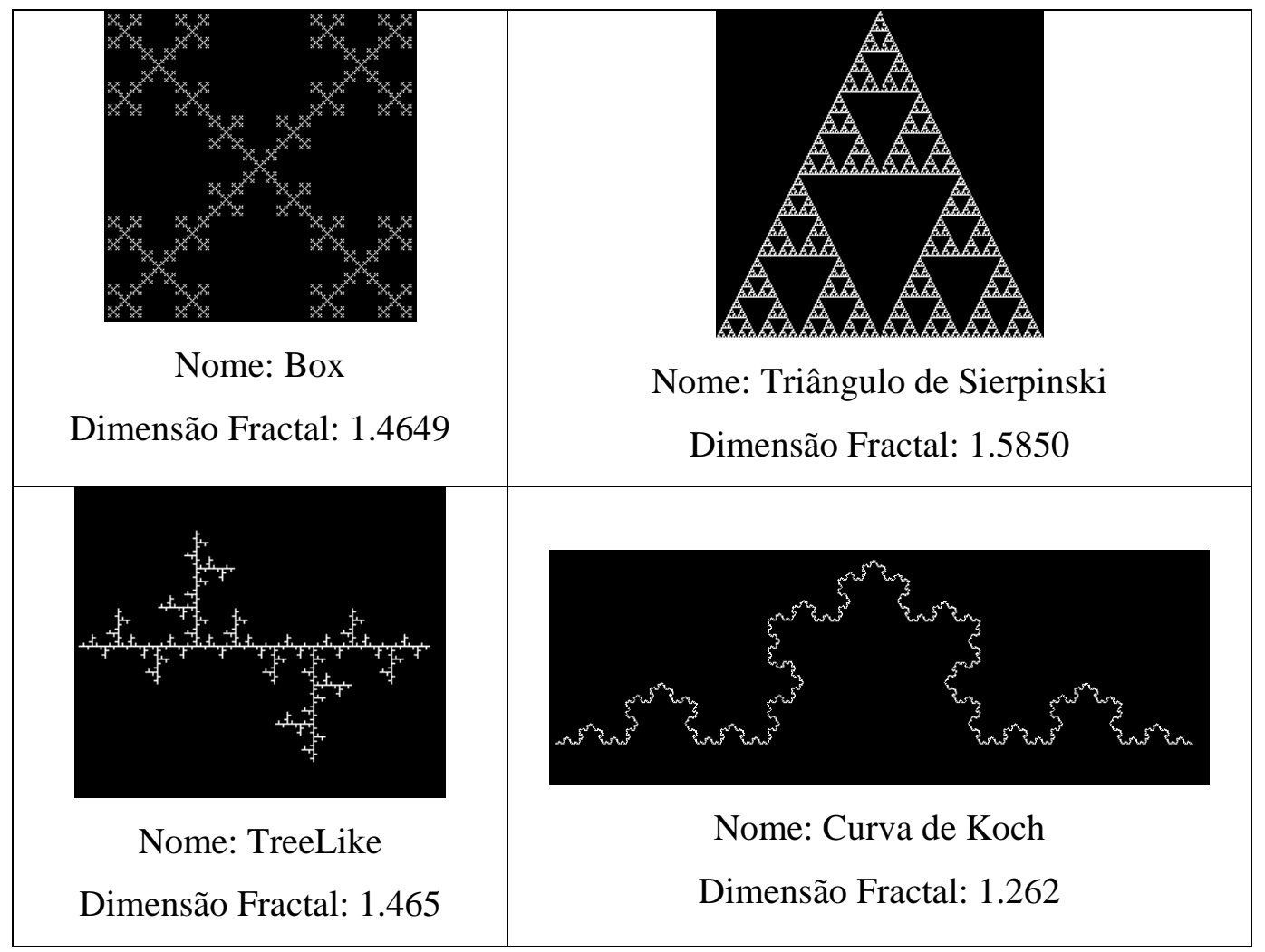

Tabela 2 - Formas Fractais

Partindo-se da definição de cada método anteriormente citado, conclui-se que nem todos os métodos podem ser aplicados de forma satisfatória a todas as formas selecionadas para o experimento. No entanto, alguns métodos podem ser aplicados a qualquer forma, desde que respeitadas certas restrições quanto à sua utilização. Para tanto, os diversos métodos testados foram utilizados conforme as configurações contidas na Tabela 3. Os resultados obtidos foram 
divididos em 3 tabelas: a Tabela 4 contém os resultados obtidos para as formas euclidianas, enquanto que as Tabelas Tabela 5 e Tabela 6 contém os resultados para as formas fractais analisadas. Para os métodos que apresentaram uma alta taxa de variação nos resultados, são também apresentados a média e a variância dos seus resultados.

A partir dos resultados obtidos com o experimento podem-se concluir quais métodos apresentam melhores resultados para cada tipo de forma, e quais os métodos que possuem maior invariância à rotação.

\begin{tabular}{|c|l|}
\hline ID & Configuração do Método \\
\hline A & BoxCounting: Grid \\
\hline B & BoxCounting: Grid Ajustado para menor contagem \\
\hline C & Dividers: Cálculo do Menor Perímetro no Sentido Horário \\
\hline D & Dividers: Cálculo do Menor Perímetro no Sentido Anti-Horário \\
\hline E & Dividers: Cálculo do Total de Rulers utilizados no Sentido Horário \\
\hline F & Dividers: Cálculo do Total de Rulers utilizados no Sentido Anti-Horário \\
\hline G & MassaRaio: Utilizando o Centro de Massa e Raio de Giro \\
\hline H & MassaRaio: Utilizando o vários círculos e raio variável \\
\hline I & Intersecções Acumulativas: Utilizando o Centro de Massa e Raio de Giro \\
\hline J & Intersecções Acumulativas: Utilizando vários círculos e raio variável \\
\hline K & Minkowski: Utilizando raio = 20 \\
\hline L & Minkowski: Utilizando raio = 30 \\
\hline M & Minkowski: Utilizando raio = 40 \\
\hline N & Pico da Derivada de Minkowski: Utilizando raio = 100 e Sigma =10 \\
\hline O & Pico da Derivada de Minkowski: Utilizando raio = 100 e Sigma =15 \\
\hline P & Pico da Derivada de Minkowski: Utilizando raio = 100 e Sigma =20 \\
\hline
\end{tabular}

Tabela 3 - Configurações dos Métodos

O método Dividers mostrou-se incapaz de estimar a Dimensão Fractal da maioria das formas selecionadas devido à sua própria definição. Por se basear no contorno externo, formas que possuíam informação interna (como o triangulo de Sierpinski) ou um contorno indefinido (como o TreeLike) não puderam ser classificados por este método. No entanto ele mostrou-se 
eficiente para formas como uma reta e a curva de Koch (curvas abertas em geral) em suas diversas configurações utilizadas.

O quadrado foi outra forma em que o Dividers mostrou-se ineficiente. Isso ocorre por que o Dividers trabalha sobre o quadrado da mesma maneira que sobre uma curva fechada, ou seja, não existe um ponto inicial para o método. Uma solução para esse problema é escolher diversos pontos de inicio e trabalhar com a média gerada pelas diversas iterações do método. No entanto essa solução acaba gerando uma variação muito alta nos resultados.

Por se trabalhar num espaço discreto, a rotação produz fragmentação dos contornos das formas onde o Dividers anteriormente pôde ser aplicado com sucesso impedindo, na maioria das vezes, a sua aplicação em estruturas que sofreram uma rotação.

O método de Intersecções Acumulativas também se mostrou falho para a grande maioria das formas analisadas, apresentado muitas vezes valores diferentes dos esperados.

O maior problema encontrado para esse método diz respeito ao centro de massa da forma. Alguns centros de massa calculados eram pontos referentes ao fundo e não a forma, o que levava a resultados muito diferentes do esperado (como é o caso do Triângulo de Sierpinski, a Curva de Koch). Uma solução para esse problema é a utilização de vários centros para o cálculo de diversas iterações, e tomando a média dessas iterações como a Dimensão Fractal calculada. Essa solução gera resultados melhores, mas ainda longe dos resultados esperados devido a uma alta margem de variabilidade que o método apresenta.

Já com relação à rotação, o método obteve resultados um pouco acima dos calculados anteriormente (sendo a única exceção a essa regra o quadrado), mas mantendo a mesma taxa de variabilidade.

O método Massa-Raio, ao contrário do método Dividers, tem a restrição de não ser eficaz quando se tem em mãos apenas o contorno de determinada estrutura. Isso ocorre porque apenas com o contorno de um objeto, não se possui nenhuma informação com relação à massa interna do mesmo. Além disso, esse método apresenta o mesmo problema para o cálculo de centro de massa que o método de Intersecções Acumulativas apresenta, sendo a mesma solução apresentada para o método de Intersecções Acumulativas utilizada aqui. 


\begin{tabular}{|c|c|c|c|c|c|}
\hline ID & Ponto & Reta & & Quadrado & \\
\hline & $\mathbf{D F = 0}$ & $\mathbf{D F = 1}$ & Rotação & DF= 2 & Rotação \\
\hline A & 0 & 0,99 & $1,01 \pm 0,019$ & 1,99 & $1,89 \pm 0,075$ \\
\hline B & 0 & 0,99 & $1 \pm 0,009$ & 1,99 & $1,89 \pm 0,073$ \\
\hline C & - & 1 & $1,0006 \pm 0,0006$ & $1,38 \pm 0,17$ & $1,41 \pm 0,13$ \\
\hline D & - & 1 & $1,0006 \pm 0,0006$ & $1,4 \pm 0,15$ & $1,4 \pm 0,14$ \\
\hline E & - & 1,04 & $1,046 \pm 0,018$ & $1,1 \pm 0,017$ & $1,1 \pm 0,029$ \\
\hline F & - & 1,04 & $1,046 \pm 0,018$ & $1,1 \pm 0,017$ & $1,1 \pm 0,028$ \\
\hline G & - & 0,96 & $0,98 \pm 0,0036$ & 1,85 & $1,86 \pm 0,0063$ \\
\hline H & - & $0,88 \pm 0,017$ & $0,93 \pm 0,014$ & $1,82 \pm 0,019$ & $1,81 \pm 0,022$ \\
\hline I & - & 0,99 & $1,077 \pm 0,053$ & 7,81 & $6,38 \pm 1,52$ \\
\hline J & - & $0,94 \pm 0,034$ & $1,078 \pm 0,1$ & $2,097 \pm 0,52$ & $2,037 \pm 0,52$ \\
\hline K & 0,069 & 0,99 & $1,0018 \pm 0,011$ & 1,78 & $1,78 \pm 0,0003$ \\
\hline $\mathbf{L}$ & 0,045 & 0,95 & $0,96 \pm 0,0095$ & 1,7 & $1,7 \pm 0,0001$ \\
\hline $\mathbf{M}$ & 0,032 & 0,91 & $0,92 \pm 0,0082$ & 1,62 & $1,62 \pm 0,0005$ \\
\hline $\mathbf{N}$ & 0,11 & 0,98 & $0,95 \pm 0,018$ & 1,73 & $1,71 \pm 0,016$ \\
\hline $\mathbf{O}$ & 0,078 & 0,93 & $0,93 \pm 0,0048$ & 1,67 & $1,67 \pm 0,0027$ \\
\hline $\mathbf{P}$ & 0,065 & 0,92 & $0,92 \pm 0,0066$ & 1,65 & $1,66 \pm 0,0048$ \\
\hline
\end{tabular}

Tabela 4 - Resultados para as formas euclidianas.

\begin{tabular}{|c|c|c|c|c|}
\hline ID & Box & DF= 1,4649 & Sierpinski & DF= 1,585 \\
\hline & & Rotação & & Rotação \\
\hline $\mathbf{A}$ & 1,5 & $1,42 \pm 0,052$ & 1,58 & $1,57 \pm 0,011$ \\
\hline $\mathbf{B}$ & 1,5 & $1,41 \pm 0,053$ & 1,58 & $1,57 \pm 0,014$ \\
\hline $\mathbf{C}$ & - & - & - & - \\
\hline $\mathbf{D}$ & - & - & - & - \\
\hline $\mathbf{E}$ & - & - & - & - \\
\hline $\mathbf{F}$ & - & - & - & - \\
\hline $\mathbf{G}$ & 1,5 & $1,47 \pm 0,014$ & 2,3 & $2,31 \pm 0,20$ \\
\hline $\mathbf{H}$ & $1,44 \pm 0,028$ & $1,37 \pm 0,054$ & $1,45 \pm 0,028$ & $1,5 \pm 0,02$ \\
\hline $\mathbf{I}$ & 1,47 & $1,49 \pm 0,063$ & 2,44 & $2,51 \pm 0,1$ \\
\hline $\mathbf{J}$ & $1,52 \pm 0,057$ & $1,62 \pm 0,12$ & $1,58 \pm 0,044$ & $1,64 \pm 0,055$ \\
\hline $\mathbf{K}$ & 1,4 & $1,4 \pm 0,0024$ & 1,56 & $1,57 \pm 0,0013$ \\
\hline $\mathbf{L}$ & 1,41 & $1,41 \pm 0,0086$ & 1,55 & $1,55 \pm 0,001$ \\
\hline $\mathbf{M}$ & 1,4 & $1,41 \pm 0,001$ & 1,52 & $1,52 \pm 0,0009$ \\
\hline $\mathbf{N}$ & 1,51 & $1,51 \pm 0,0017$ & 1,54 & $1,54 \pm 0,0007$ \\
\hline $\mathbf{O}$ & 1,5 & $1,5 \pm 0,0014$ & 1,54 & $1,54 \pm 0,0014$ \\
\hline $\mathbf{P}$ & 1,49 & $1,49 \pm 0,0012$ & 1,53 & $1,53 \pm 0,0013$ \\
\hline
\end{tabular}

Tabela 5 - Resultados para as formas fractais Box e Triângulo de Sierpinski. 


\begin{tabular}{|c|c|c|c|c|}
\hline ID & Koch & $\mathbf{D F}=\mathbf{1 , 2 6 2}$ & TreeLike & DF= 1,465 \\
\hline & & Rotação & & Rotação \\
\hline $\mathbf{A}$ & 1,23 & $1,28 \pm 0,0071$ & 1,35 & $1,38 \pm 0,02$ \\
\hline $\mathbf{B}$ & 1,23 & $1,27 \pm 0,0033$ & 1,35 & $1,38 \pm 0,026$ \\
\hline $\mathbf{C}$ & 1,22 & - & - & - \\
\hline $\mathbf{D}$ & 1,22 & - & - & - \\
\hline $\mathbf{E}$ & 1,22 & - & - & - \\
\hline $\mathbf{F}$ & 1,22 & - & - & - \\
\hline $\mathbf{G}$ & 1,52 & $1,49 \pm 0,1$ & 1,4 & $1,4 \pm 0,021$ \\
\hline $\mathbf{H}$ & $1,19 \pm 0,02$ & $1,2 \pm 0,025$ & $1,32 \pm 0,036$ & $1,34 \pm 0,033$ \\
\hline $\mathbf{I}$ & 1,68 & $1,7 \pm 0,027$ & 1,34 & $1,43 \pm 0,076$ \\
\hline $\mathbf{J}$ & $1,39 \pm 0,091$ & $1,39 \pm 0,062$ & $1,36 \pm 0,04$ & $1,56 \pm 1,17$ \\
\hline $\mathbf{K}$ & 1,27 & $1,28 \pm 0,0033$ & 1,37 & $1,37 \pm 0,0035$ \\
\hline $\mathbf{L}$ & 1,26 & $1,26 \pm 0,0026$ & 1,35 & $1,36 \pm 0,0026$ \\
\hline $\mathbf{M}$ & 1,25 & $1,25 \pm 0,0021$ & 1,33 & $1,33 \pm 0,0023$ \\
\hline $\mathbf{N}$ & 1,27 & $1,27 \pm 0,0008$ & 1,38 & $1,39 \pm 0,0019$ \\
\hline $\mathbf{O}$ & 1,26 & $1,26 \pm 0,0017$ & 1,38 & $1,38 \pm 0,0016$ \\
\hline $\mathbf{P}$ & 1,26 & $1,26 \pm 0,0017$ & 1,37 & $1,38 \pm 0,0015$ \\
\hline
\end{tabular}

Tabela 6 - Resultados para as formas fractais Koch e TreeLike.

De modo geral o método de Intersecções Acumulativas apresenta resultados satisfatórios e com uma variabilidade mediana, desde que observadas as restrições acima citadas. Já no caso de se trabalhar com formas que sofreram rotação o método produz resultados semelhantes aos calculados anteriormente, mantendo também o mesmo nível de variação obtido anteriormente, o que garante a esse método uma boa taxa de invariância a rotação com relação às estruturas analisadas.

O método do BoxCounting não apresenta problemas com relação aos tipos de estruturas em que pode ser aplicado. No entanto, devem ser observadas certas restrições impostas durante a sua aplicação para garantir a qualidade dos resultados.

Uma dessas restrições se deve ao alinhamento do grid utilizado na contagem com a estrutura, de modo a minimizar a contagem de caixas. Além disso, o conjunto de caixas utilizados tem influência direta na contagem obtida, sendo por isso utilizada a caixa inicial como o tamanho máximo da estrutura analisada, sendo a caixa seguinte sempre a metade da anterior.

Seguindo estas restrições, o método do BoxCounting apresentou resultados muito próximos dos esperados, sem que esses resultados variassem de uma iteração para a outra.

Já na rotação, alguns resultados tiveram uma pequena tendência de se afastarem dos resultados anteriores. Isso ocorre devido à mudança no conjunto de caixas utilizado quando se 
altera a orientação espacial da estrutura analisada. No entanto, como foi utilizada uma regra para a escolha dessas caixas o resultado ainda se manteve consistente, e apresentou uma variação muito pequena.

O método de Bouligand-Minkowski é outro que também não apresenta problemas para a sua aplicação, sendo possível a sua aplicação a qualquer tipo de estrutura analisada. Além disso, diferente dos métodos anteriormente citados ele não necessita de ajustes iniciais para a sua aplicação, apresentando dessa forma resultados mais consistentes que os demais métodos, e sem variações.

Apesar de não necessitar de ajustes iniciais para a sua aplicação, percebe-se que o raio utilizado no cálculo tem certa influência no resultado final obtido. Raios menores apresentam resultados mais próximos do esperado, apresentando uma tendência a zero conforme o raio aumenta.

No caso da Derivada da curva log-log obtida pelo método de Minkowski o valor do raio utilizado não tem influência sobre o resultado, uma vez que o pico da derivada não varia conforme o raio utilizado. No entanto a Gaussiana utilizada na suavização da curva apresenta um parâmetro sigma que controla o nível de suavização da Derivada (BRIGHAM, 1988).

Esse método se mostra superior a todos os outros com relação à rotação, tanto quando se calcula a inclinação da curva ou o pico da sua derivada, apresentando resultados muito próximos dos anteriores, e com uma taxa de variação muito baixa.

Os resultados obtidos mostram que tanto o método BoxCounting quanto o de Minkowski são capazes de gerar resultados muito próximos do esperado. A fim de determinar qual dentre os dois é o melhor, foi realizado um segundo experimento entre os dois métodos onde fractais antes classificados tiveram um ruído adicionado a sua estrutura para ver qual a influência que esse ruído teria no cálculo da Dimensão Fractal. Esse ruído consistiu-se da adição de uma linha reta como prolongamento da estrutura fractal.

Os Fractais com ruído adicionado utilizados neste novo experimento foram dispostos na Tabela 7. Com este novo experimento foram obtidos novos resultados. Tais resultados estão contidos na Tabela 8.

Apesar de ambos sofrerem uma alteração dos resultados devido ao ruído presente na estrutura, percebe-se que o método de Minkowski sofre menos perturbação durante o cálculo da Dimensão Fractal. 


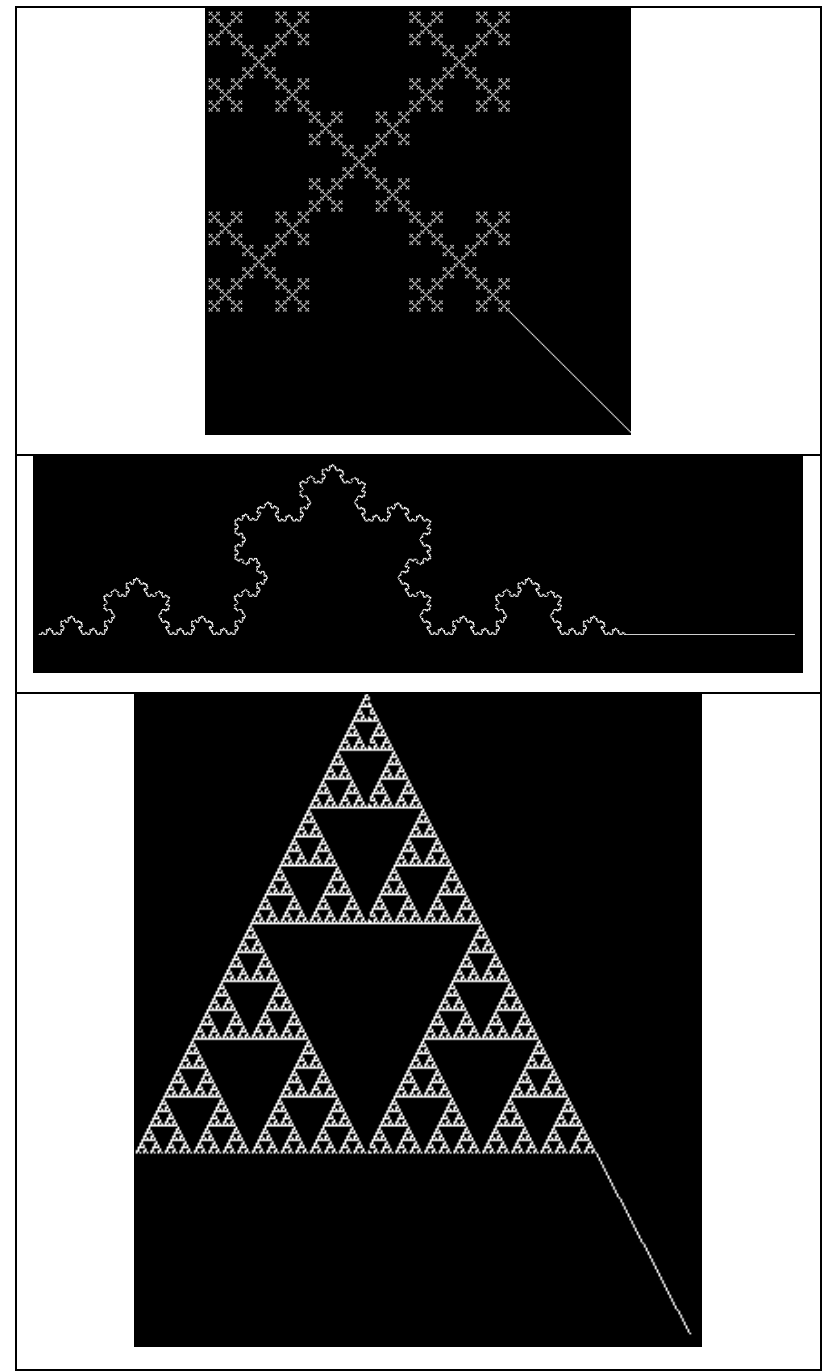

Tabela 7 - Formas Fractais com ruído adicionado

\begin{tabular}{|c|c|c|c|}
\hline ID & $\begin{array}{c}\text { Box com } \\
\text { ruído }\end{array}$ & $\begin{array}{c}\text { Koch com } \\
\text { ruído }\end{array}$ & $\begin{array}{c}\text { Sierpinski } \\
\text { com ruído }\end{array}$ \\
\hline & $\mathbf{D F}=\mathbf{1 , 4 6 4 9}$ & $\mathbf{D F = 1 , 2 6 2}$ & $\mathbf{D F}=\mathbf{1 , 5 8 5}$ \\
\hline $\mathbf{A}$ & 1,43 & 1,26 & 1,50 \\
\hline $\mathbf{B}$ & 1,41 & 1,23 & 1,51 \\
\hline $\mathbf{K}$ & 1,39 & 1,26 & 1,54 \\
\hline $\mathbf{L}$ & 1,4 & 1,24 & 1,52 \\
\hline $\mathbf{M}$ & 1,39 & 1,23 & 1,5 \\
\hline $\mathbf{N}$ & 1,49 & 1,25 & 1,52 \\
\hline $\mathbf{O}$ & 1,5 & 1,24 & 1,51 \\
\hline $\mathbf{P}$ & 1,47 & 1,23 & 1,5 \\
\hline
\end{tabular}

Tabela 8 - Resultados para os fractais com ruído 
A partir da análise comparativa dos principais métodos de estimativa da Dimensão Fractal, onde foram avaliadas características como, precisão, detalhes de implementação e variação de resultados segundo ajustes de parâmetros e orientação, pôde-se concluir que métodos como o BoxCounting e o Bouligand-Minkowski apresentam os melhores resultados, evidenciando a sua capacidade de aferir diferentes estruturas. Comparando esses dois métodos, percebe-se que o método de Bouligand-Minkowski apresenta resultados um pouco superiores ao BoxCounting, uma vez que não necessita de ajustes iniciais e apresenta uma maior invariância à rotação e tolerância a ruídos. 


\section{Dimensão Fractal MultiEscala}

Ao se analisar a curva $\log -\log u(t)$ gerada pelo método de Minkowski para Dimensão Fractal percebe-se que esta possui uma grande riqueza de detalhes em suas diferentes escalas espaciais. Aplicando a essa curva uma Transformação MultiEscala $U(b, a)$, cujo parâmetro $b$ é associado a variável $t$ de $u(t)$ e $a$ a escala de observação, é possível extrair uma função de escala espacial relacionada à curva e não apenas um valor numérico como na Dimensão Fractal tradicional (Figura 22) (EMERSON, 1999) (TRICOT, 1995). A essa função gerada a partir da Transformação MultiEscala dá-se o nome de Dimensão Fractal MultiEscala (DFM).

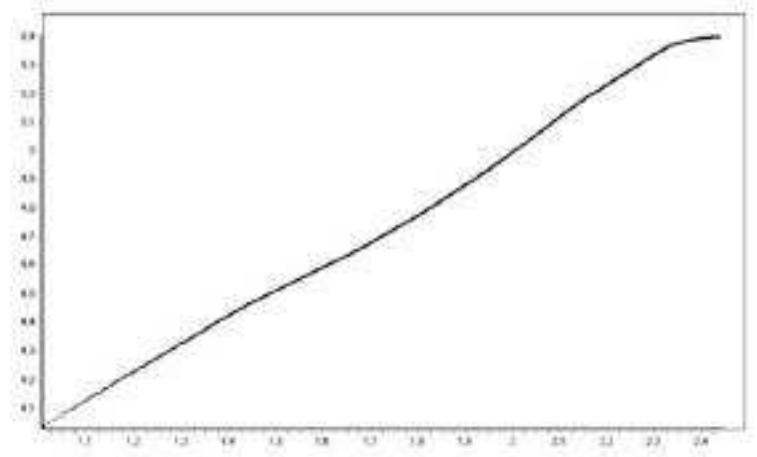

(a)

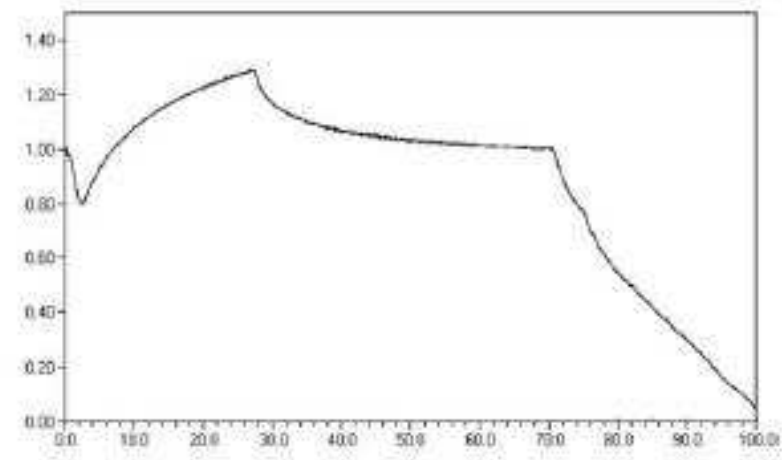

(b)

Figura 22 - (a) gráfico da curva log-log gerada pelo método de Minkowski. (b) gráfico da curva de Dimensão Fractal MultiEscala obtida a partir de (a).

O uso da Tranformação MultiEscala sobre $u(t)$ apresenta uma performance superior quando comparada com a obtida por métodos de interpolação aplicados sobre $u(t)$, os quais são realizados tradicionalmente para o cálculo da Dimensão Fractal. Isso se deve ao fato de um objeto ser agora representado não apenas por um número arbitrário, mas sim por uma função que representa os seus diferentes níveis de fractalidade para as diferentes escalas observadas (EMERSON, 1999) (PLOTZE et. al, 2004).

Basicamente a Curva MultiEscala é obtida a partir da primeira derivada da curva $u(t)$, mais precisamente

$$
D F M=N-\frac{d u(t)}{d t},
$$


onde $D F M$ é a Dimensão Fractal MultiEscala e $N$ é a dimensionalidade do espaço onde o dado está inserido.

\subsection{Transformada Espaço-Escala}

A abordagem espaço-escala para análise de sinais MultiEscala é um dos métodos mais populares desse tipo. Ela está associada à idéia de que as características mais importantes de um sinal estão, geralmente, relacionadas a pontos de máximo ou mínimo local (CESAR; COSTA, 2000) (MARSHALL, 1989) (MOKHTARIAN; MACKWORT, 1986).

Tais pontos de máximo e mínimo local correspondem aos cruzamentos por zero (zerocrossings) da primeira derivada do sinal. Um fato a ser levado em consideração é a tendência a enfatizar ruídos das altas freqüências nos métodos de diferenciação, que pode ser compensado com o uso de filtros de suavização, como o passa-baixa. Como exemplo, utilizaremos o filtro da gaussiana. Neste caso, podemos encontrar o sinal desejado através da convolução da derivada do sinal $u(t)$, representada por $u^{(1)}(t)$, com a Gaussiana $g(t)$, aplicando a propriedade da convolução (BRIGHAM, 1988) (CESAR; COSTA, 2000)

$$
u^{(1)}(t) * g(t)=(u(t) * g(t))^{(1)}=u(t) * g^{(1)}(t)
$$

Os pontos extremos pertencentes ao sinal $u(t)$ podem ser encontrados por meio de uma busca dos zero-crossings em $u^{(1)}(t)$.

É importante salientar que a função gaussiana possui um parâmetro, referente ao desvio padrão, que controla o nível de suavização do filtro. Seja $u(t)$ o sinal a ser analisado, $g_{a}(t)$ é a Gaussiana com desvio padrão $a>0$

$$
g_{a}(t)=\frac{1}{a \sqrt{2 \pi}} \exp \left(\frac{-t^{2}}{2 a^{2}}\right)
$$

A convolução entre $u(t)$ e $g_{a}(t)$ é definida como

$$
U(t, a)=u(t) * g_{a}(t) .
$$

A partir disso, podemos definir o espaço-escala como sendo o conjunto de zero-crossings de $U^{(1)}(t, a)$, onde 


$$
U^{(1)}(t, a)=u(t) * g_{a}^{(1)}(t)
$$

\subsection{Validação da Derivada}

Numa primeira etapa do estudo da técnica de Dimensão Fractal MultiEscala, foi necessário implementar, estudar e validar os dois métodos propostos para obtenção da curva derivada: derivada numérica e derivada no espectro. A validação dos métodos foi então realizada utilizando funções cujas curvas derivadas fossem conhecidas (Figura 23). Desse modo foi possível comparar o resultado obtido pelos métodos com o resultado esperado para aquela curva.

Um detalhe importante sobre esses dois métodos se refere à precisão. Enquanto a derivada numérica utiliza apenas a vizinhança de um ponto para o cálculo da derivada, a derivada no espectro leva em consideração todos os pontos da curva, garantindo uma maior precisão do resultado. Dessa forma, foi definido o uso da derivada obtida no cálculo da Dimensão Fractal MultiEscala.

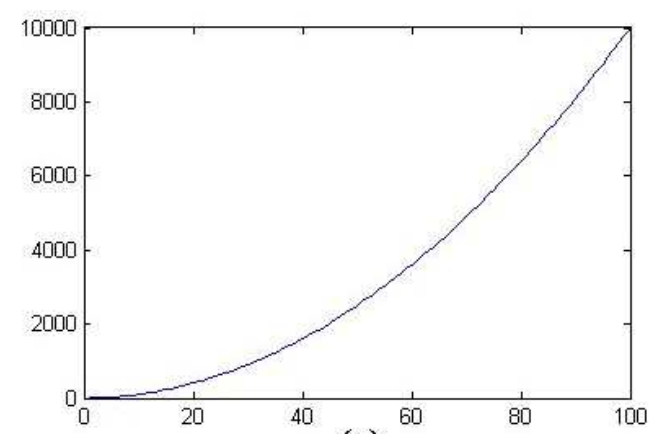

(a)

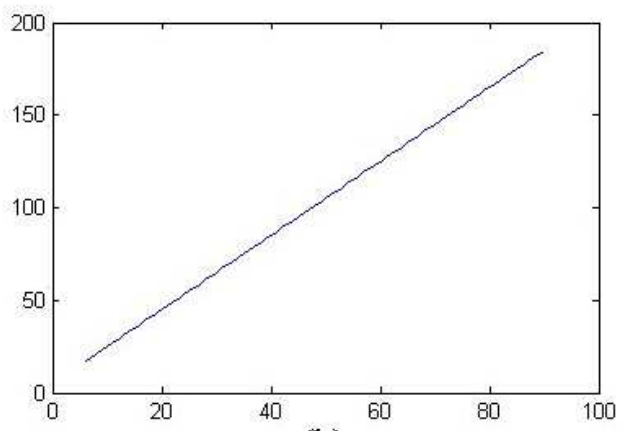

(b)

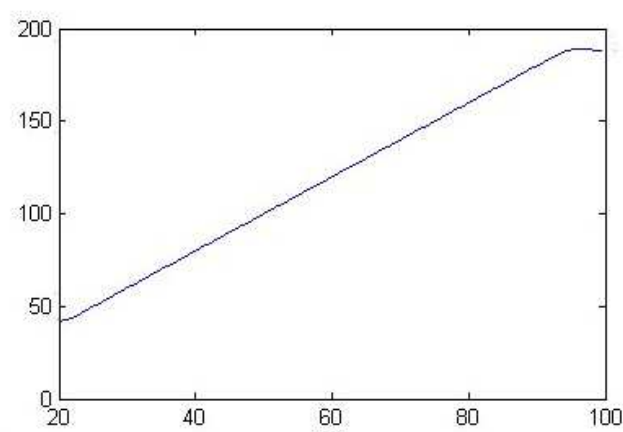

(c)

Figura 23 - Validação das derivadas: (a) curva da função $f(x)=x^{2}$; (b) Derivada Numérica; (c) Derivada calculada por Fourier. 


\subsection{Diferenciação MultiEscala Baseada em Fourier}

A Diferenciação MultiEscala baseada na Transformada de Fourier é um método que nos permite a extração da característica MultiEscala de um sinal por meio da propriedade Derivativa da Transformada de Fourier. Diferente do método de diferenciação baseado em Diferenças Finitas, que leva em consideração apenas a vizinhança do sinal analisado, esse método leva em conta todo o sinal para a diferenciação.

Esse método compreende a Transformada de Fourier da função de área acumulada do método de Minkowski, diferenciada no domínio da freqüência, juntamente com uma suavização gaussiana e a Transformada Inversa de Fourier. Isso pode ser resumido na equação abaixo (BRIGHAM, 1988) (CESAR; COSTA, 2000)

$$
\frac{d h(s)}{d s}=F^{-1}\left\{F\{h(s)\} G_{a}(f)(j 2 \pi f)\right\},
$$

onde $s$ e $h(s)$ são, respectivamente, o logaritmo dos raios e da área acumulada do método de Minkowski, $f$ é a freqüência, $j$ é o número imaginário e $G_{a}(f)$ é a Transformada de Fourier da função Gaussiana de desvio padrão $a$.

Tendo definido o método de extração da primeira derivada, alguns aspectos importantes devem ser considerados de modo a garantir um bom resultado do método. Primeiramente deve se garantir que o sinal analisado possui um espaçamento uniforme e uma boa amostragem. Para garantir uma boa amostragem é necessário desconsiderar os primeiro pontos do sinal, uma vez que a amostragem nesses pontos é muito baixa (Figura 24). Já para garantir o espaçamento uniforme uma interpolação pode ser utilizada para preencher espaços entre cada dois raio exatos, colocando entre esses raios uma média deles. 


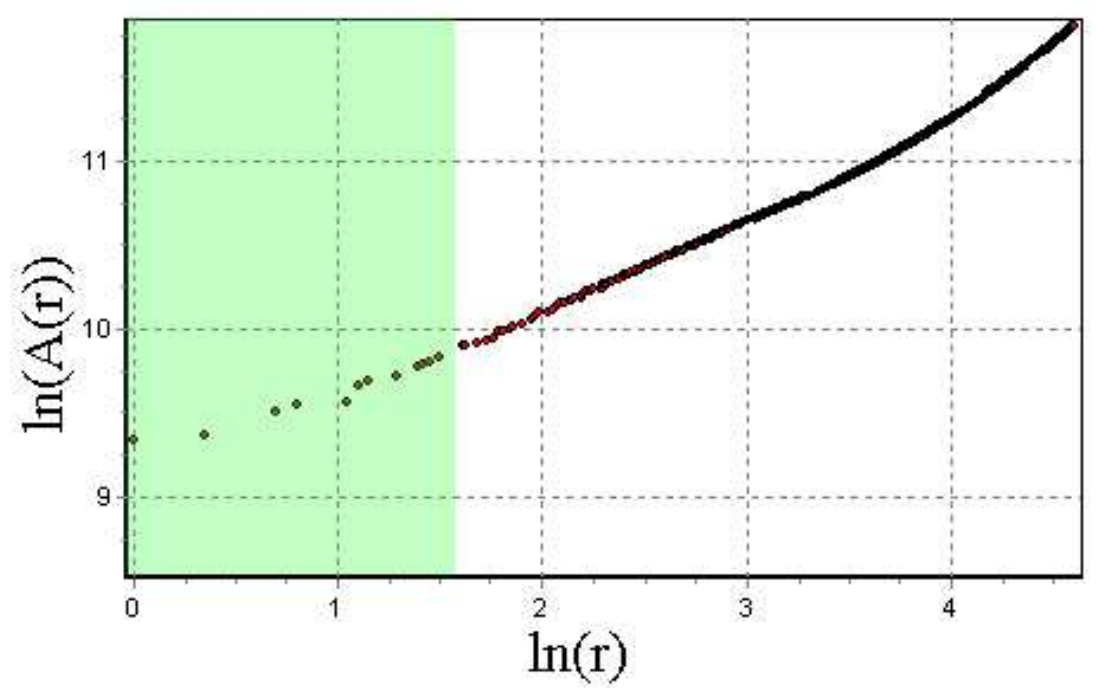

Figura 24 - Região onde os pontos serão desconsiderados

Outro problema com a derivada de Fourier é que ela torna-se descontínua nas suas extremidades do sinal (Figura 25). Esse fenômeno é conhecido com fenômeno de Gibbs (BRIGHAM, 1988). Ele ocorre, pois a transformada de Fourier não converge de modo uniforme nas descontinuidades.
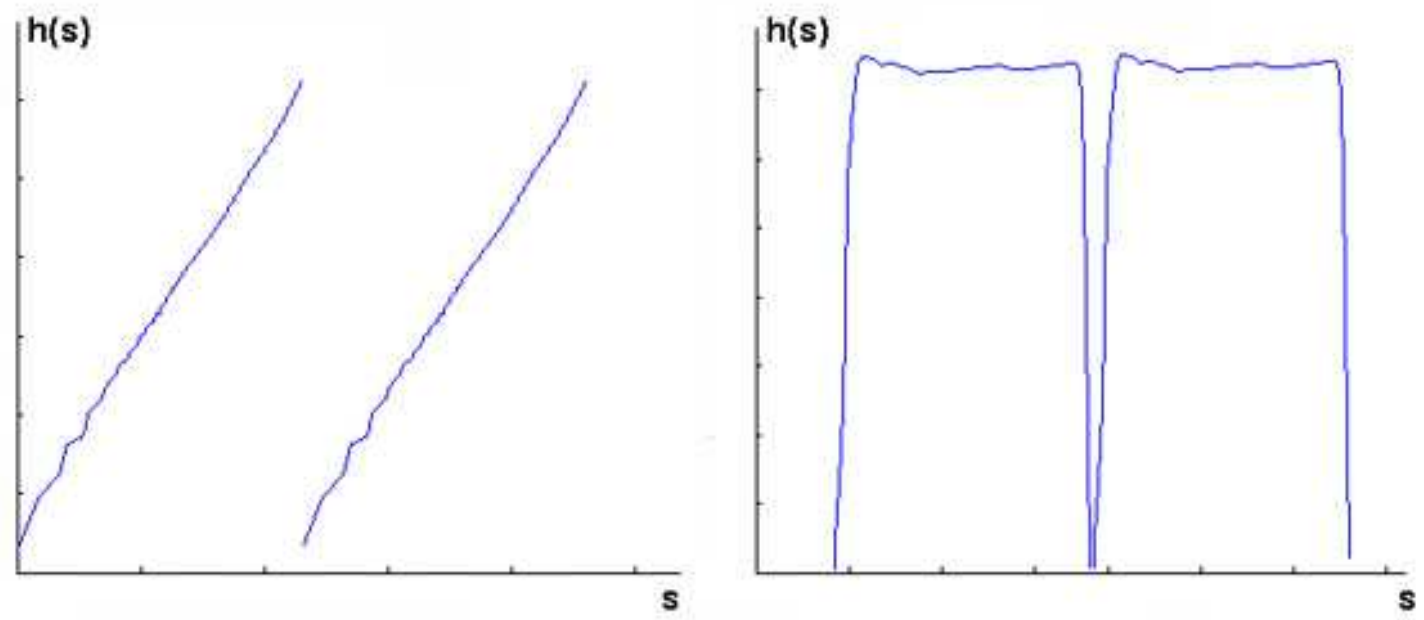

Figura 25 - Fenômeno de Gibbs apresentado nas descontinuidades.

Para resolver tal problema, utiliza-se um esquema de replicação e reflexão do sinal, de modo a fazê-lo contínuo para a transformada discreta de Fourier (Figura 26). Esse esquema garante a continuidade do sinal no intervalo $[2 \mathrm{~N}-1,3 \mathrm{~N}]$. 


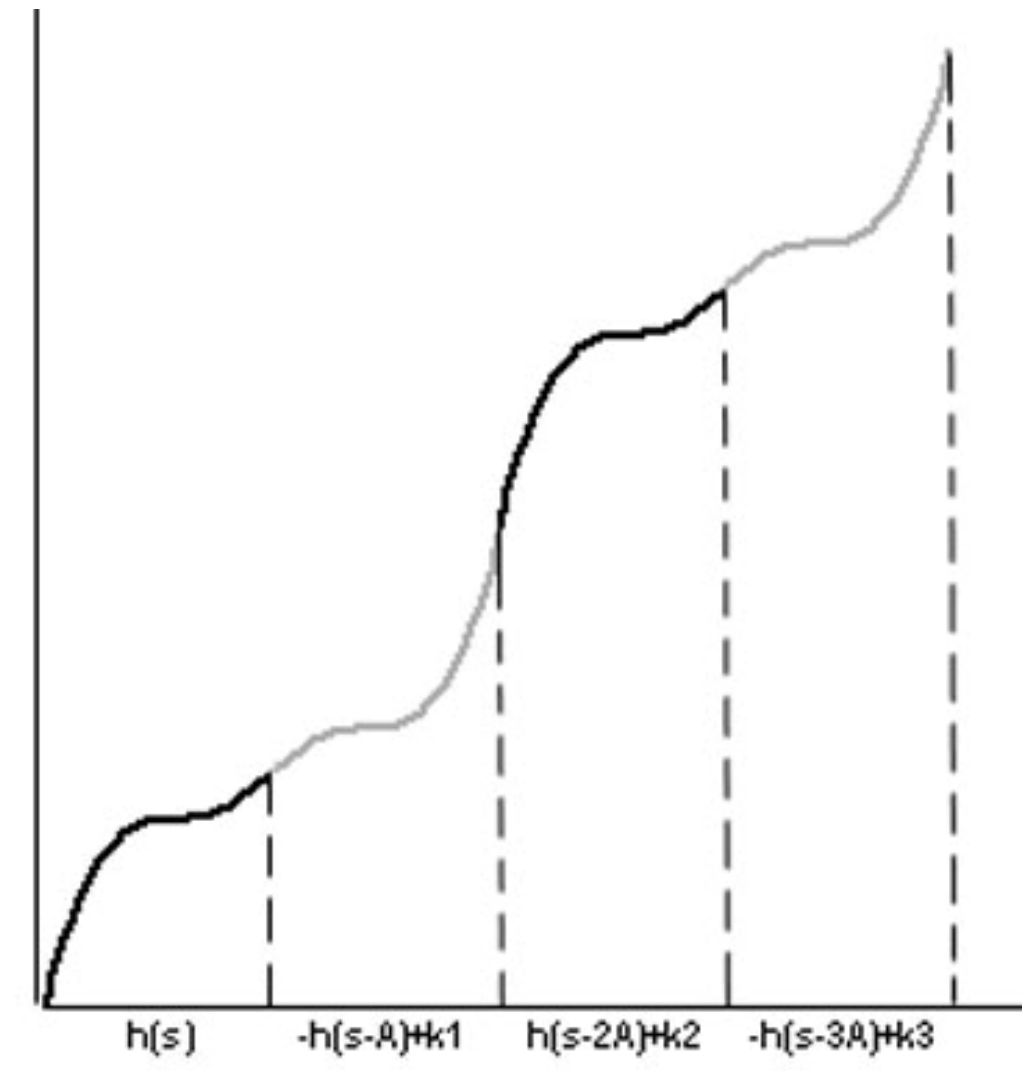

Figura 26 - Esquema de Replicação e Reflexão para tornar o sinal contínuo.

Resolvidos os problemas descritos acima, pode-se então extrair a derivada do sinal pelo método de Fourier, $d h(s) / d s$. A Dimensão Fractal pode ser obtida como sendo

$$
W(s)=n-\frac{d h(s)}{d s},
$$

onde $n$ é a dimensão do espaço a qual os dados estão inseridos, que nesse caso seria 2 (Figura 27). 


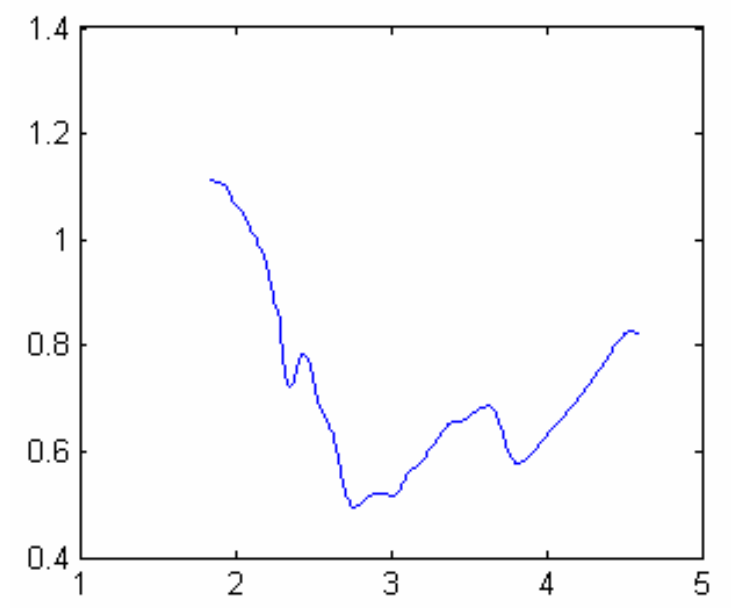

(a)

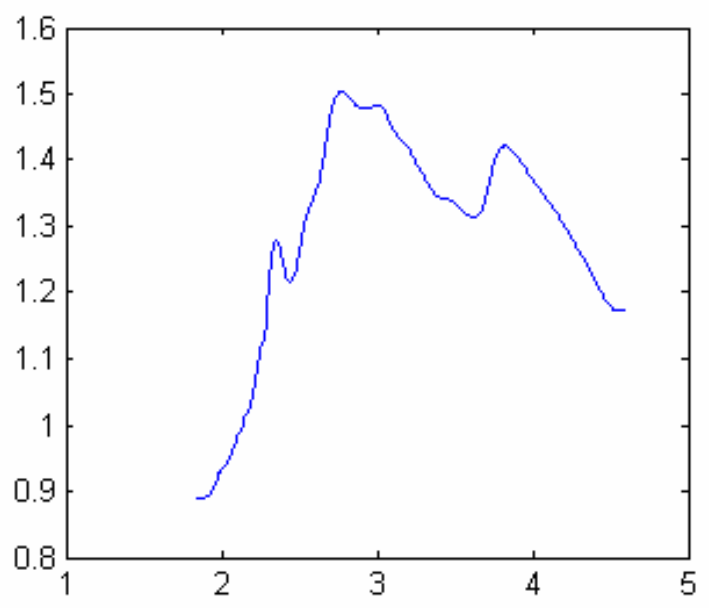

(b)

Figura 27 - (a) curva derivada. (b) curva MultiEscala.

\subsection{Diferenciação MultiEscala por Diferenças Finitas}

A Diferenciação MultiEscala baseada em Diferenças Finitas é um método que nos permite a extração da característica MultiEscala de um sinal por meio da derivada numérica. Diferente da MultiEscala Baseada na Transformada de Fourier, aqui a derivada é calculada com relação a sua vizinhança (SMITH, 1992).

O método de Diferenças Finitas aplica-se a sinais que são igualmente espaçados. Para isso, o início da curva deve ser desconsiderado, pois apresenta uma amostragem muito baixa (figura 24). Além disso, deve-se escolher um valor $L$ para o intervalo de amostragem do sinal e selecionar apenas os pontos do sinal onde $\log (r)$ é múltiplo (ou muito próximo) de $L$.

A Diferenciação Finita é realizada por meio da equação

$$
U^{\prime}(x)=\frac{1}{h}\{U(x)-U(x-h)\},
$$

onde $U^{\prime}(x)$ é o valor da derivada da função $U(x)$ em relação aos pares de pontos $\left(U\left(x_{k}\right), U\left(x_{k-1}\right)\right.$, onde $1 \leq k \leq N$ e $N$ é o número de pontos da amostragem.

A partir do sinal amostrado, o próximo passo seria replicar a função $U(x)$ utilizando o mesmo esquema de replicação e reflexão utilizado no método de diferenciação por Fourier, de modo a evitar que haja distorções no resultado da derivada. 
A partir da derivada do sinal, $U^{\prime}(x)$, podemos obter a curva de Dimensão Fractal MultiEscala, $W(x)$, por meio da relação

$$
W(x)=n-U^{\prime}(x)
$$

onde $n$ é a dimensão do espaço a qual os dados estão inseridos, que nesse caso seria 2 (Figura 28).

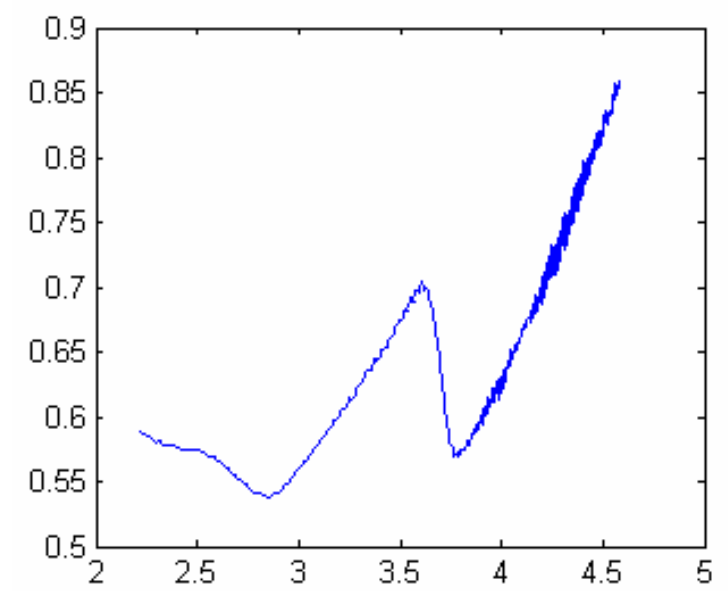

(a)

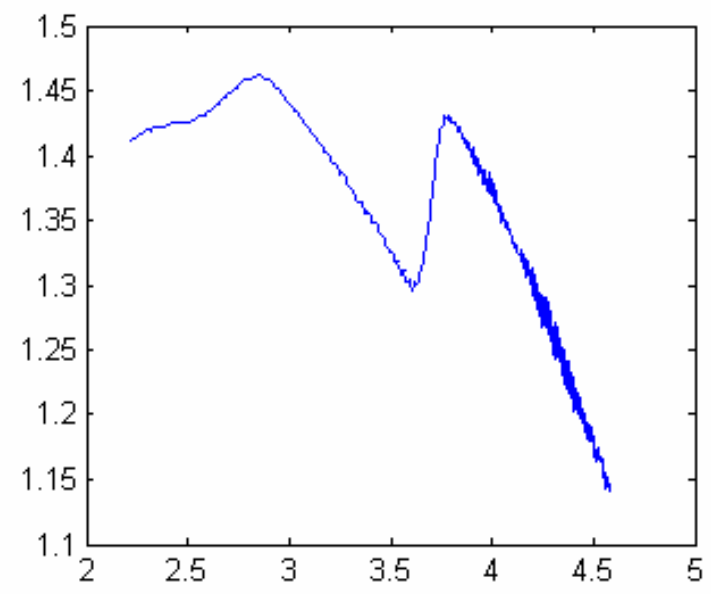

(b)

Figura 28 - (a) curva derivada. (b) curva MultiEscala. 


\section{Análise de Formas}

Nessa etapa do trabalho foi realizada uma análise experimental dos métodos de estimativa da Dimensão Fractal verificando quais deles, além do método de Minkowski, permitem a extração de uma curva de Dimensão Fractal MultiEscala passível de utilização em experimentos de classificação de formas. A partir disso seguiu-se com a análise experimental, de modo a atestar a utilização das curvas de Dimensão Fractal MultiEscala obtidas para cada um dos métodos na análise e classificação de formas. Em alguns momentos do experimento se fez necessário utilizar técnicas como descritores de Fourier e Wavelet, de modo a extrair a informação mais relevante da curva MultiEscala.

A seguir são discutidos os processos de obtenção da curva derivada, dos descritores de Fourier e Wavelet e do conjunto de imagens utilizados no experimento. Além disso, segue também uma descrição da maneira como esses experimentos foram conduzidos, bem como os resultados obtidos para cada método.

\subsection{Descritores de Fourier}

Os Descritores de Fourier são obtidos a partir da aplicação da Transformada de Fourier (BRACEWELL, 2000) sobre um sinal $u(t)$, resultando na obtenção das suas componentes complexas $U(f)$, sendo

$$
U(f)=\int_{-\infty}^{\infty} u(t) e^{-j 2 \pi f t} d t
$$

a representação do sinal $u(t)$ no espectro de frequiências. Essa abordagem através do espectro de freqüências permite separar as diferentes características do sinal analisado em diferentes grupos de frequiências, além de apresentar vantagens como tolerância a ruídos e facilitar a normalização os dados, o que resulta em uma invariância à rotação, translação e escala (CRIMMINS, 1982) (KUHL; GIARDINA, 1982).

Além disso, os coeficientes $U(f)$ localizados na zona de baixa freqüência constituem a zona do espectro onde se encontra a informação mais relevante sobre o comportamento do sinal, enquanto que os coeficientes de alta freqüência possuem informação sobre o detalhe e ruído que 
o sinal apresenta. No caso da curva de Dimensão Fractal MultiEscala, apenas a região de baixa freqüência do espectro é utilizada como descritores.

Os descritores do sinal, $D U(f)$, são obtidos a partir das magnitudes dos coeficientes selecionados, sendo o total de coeficientes selecionados estabelecido pelo usuário,

$$
D U(f)=\|U(f)\|
$$

Faz-se necessária à realização da normalização dos descritores obtidos. Essa normalização pode ser realizada da seguinte maneira:

$$
D U(f)=\left\{\begin{array}{ll}
0 & f=0 \\
D U(f) / D U(1) & f \neq 0
\end{array} .\right.
$$

A normalização adiciona aos descritores selecionados uma maior tolerância a alterações no sinal, como alterações de escala, translação e rotação (CRIMMINS, 1982).

\subsection{Descritores de Wavelet}

Os descritores de Wavelet são produzidos através da aplicação da Transformada de Wavelet sobre o sinal $u(t)$, o que provoca a decomposição do sinal $u(t)$ em duas partes: a Aproximação $(A)$, contendo a maior parte da energia do sinal, e o Detalhe $(D)$, contendo a energia residual do sinal (MALLAT, 1998).

Os sinais de Aproximação são expressos através de funções de escala $\phi_{m n}$ na forma $x_{a}(l)=\sum_{n} a_{n} \phi_{M n}(l)$ e $y_{a}(l)=\sum_{n} c_{n} \phi_{M n}(l)$, onde o sub-índice $M$ significa o nível máximo de decomposição e $n$ o índice de translação. Os sinais de Detalhe são expressos através de funções de escala $\psi_{m n}$ na forma $x_{d m}(l)=\sum_{n} r_{m n} \psi_{m n}(l)$ e $y_{d m}(l)=\sum_{n} d_{m n} \psi_{m n}(l)$ onde o sub índice $m=$ 1,2,...,M significa os níveis de decomposição realizados (MALLAT, 1998) (WICKERHAUSER, 1991). Para cada novo nível calculado pela Transformada de Wavelet, maior a compactação da energia na Aproximação, sendo um novo nível de Detalhe produzido (Figura 29) (WUNSCH; LAINE, 1995). 


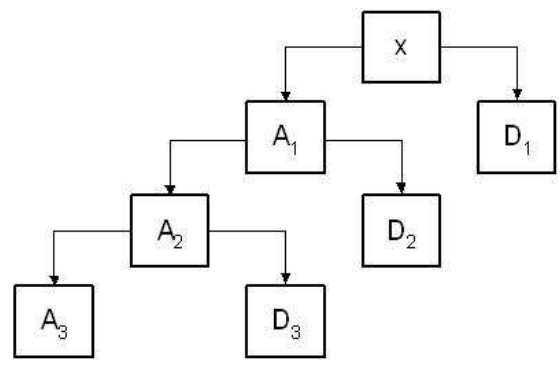

Figura 29 - Transformada Wavelet Multiresolução.

Os descritores de Wavelet são obtidos a partir dos coeficientes $A_{n}$ e $D_{n}$, que representam a Aproximação e o Detalhe do sinal $u(t)$ para um nível de decomposição $n$. Estes coeficientes, após um processo de normalização, adquirem uma tolerância a transformações do tipo escala, rotação e translação, necessária para sua utilização como descritores de $u(t)$.

\subsection{Análise Experimental}

Para este experimento foi utilizado um conjunto de 26 classes de imagens, onde cada classe correspondia a uma letra do alfabeto ocidental (alfabeto latino de 26 letras), em caractere maiúsculo, fonte no estilo Arial com tamanho 72 (Figura 30). Visando obter resultados mais consistentes, cada classe de imagens foi subdividida em quatro conjuntos com igual número de amostras. Para cada um dos conjuntos obtidos, foi realizada a adição de um determinado nível de ruído as suas amostras, de modo a se obter amostras com quatro diferentes níveis de ruído por classe (Figura 31). 


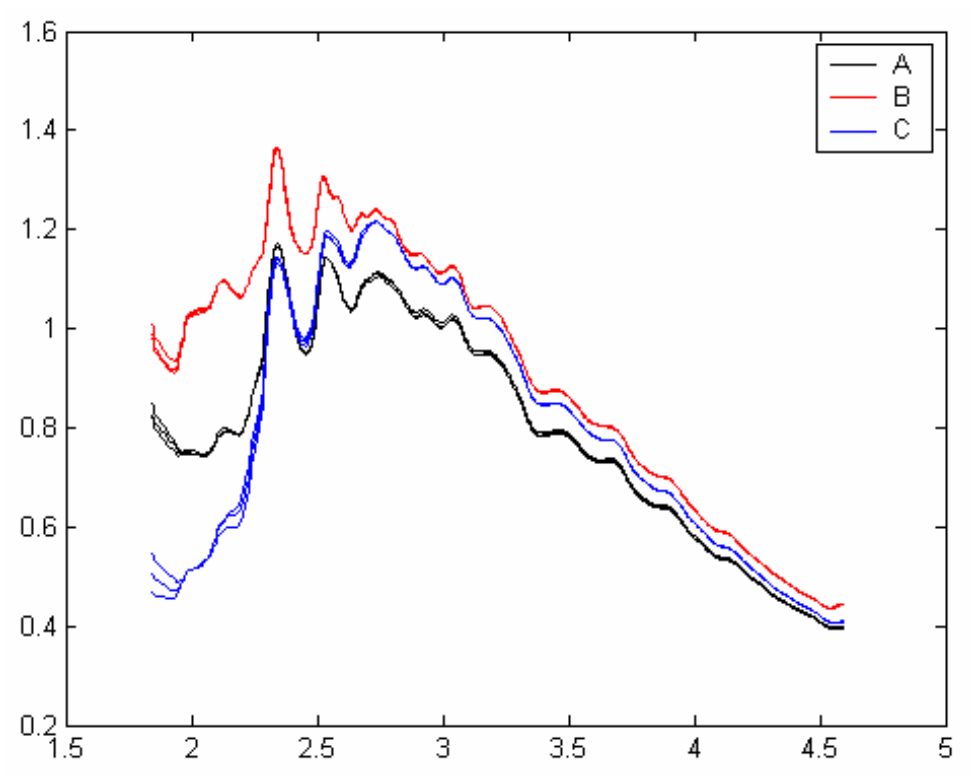

Figura 30 - Exemplo de curvas MultiEscalas para diferentes letras do alfabeto.

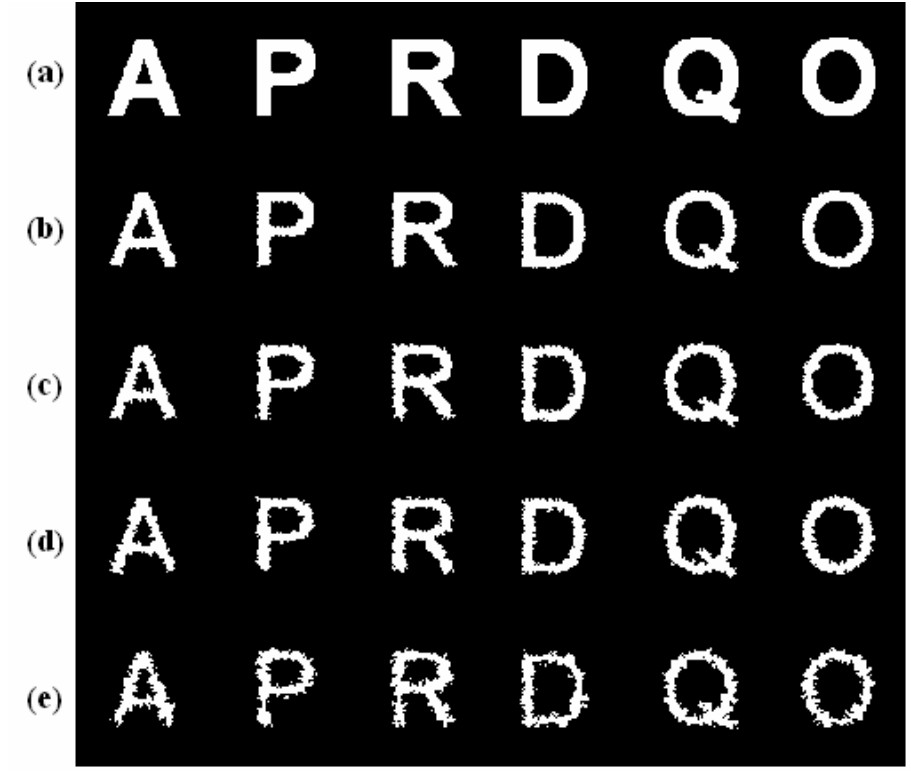

Figura 31 - Imagens com diferentes intensidades de ruído: (a)Imagem Original; (b)Imagem com o $1^{\circ}$ Nível de Ruído; (c)Imagem com o $2^{\circ}$ Nível de Ruído; (d)Imagem com o $3^{\circ}$ Nível de Ruído; (e)Imagem com o $4^{\circ}$ Nível de Ruído.

A adição de ruído às imagens ocorreu de acordo com o seguinte processo: a partir de uma imagem selecionada qualquer (Figura 32a), foi extraído e parametrizado em coordenadas $(x, y)$ os seus contornos externo e interno (caso houvesse), como mostrado na Figura 32b. Para cada 
contorno extraído foi criada uma função aleatória com igual número de pontos (Figura 32c), onde a amplitude de cada ponto variava entre $[-n \ldots n]$ e $n$, variando de 1 à 4 , representava o nível de ruído que seria adicionado à imagem. A soma da função aleatória ao contorno extraído faz com que o mesmo apresente distorções que caracterizam a presença de ruído (Figura 32d). O contorno externo, já com o ruído adicionado, é então desenhado e preenchido com a cor branca sobre um fundo preto (Figura 32e). Caso existam contornos internos, estes são desenhados e preenchidos com a cor preta sobre um fundo branco (Figura 32f). A união da imagem do contorno externo preenchido (Figura 32e) com a imagem dos contornos internos preenchidos, caso eles existam, (Figura 32f), de modo que a cor preta prevaleça sobre a cor branca, reproduz a imagem original distorcida por um certo nível de ruído (Figura 32g).

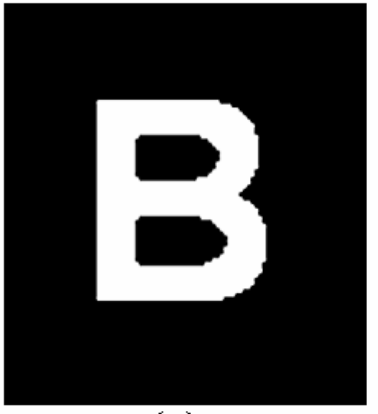

(a)

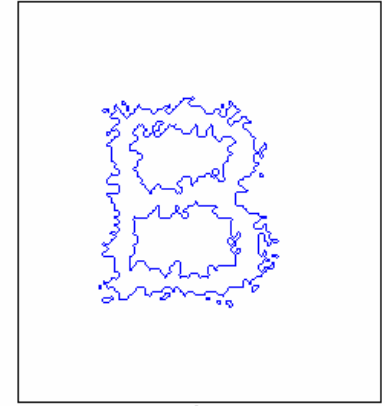

(d)

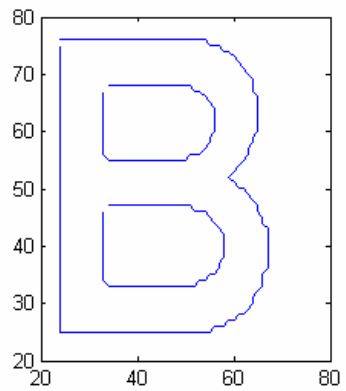

(b)

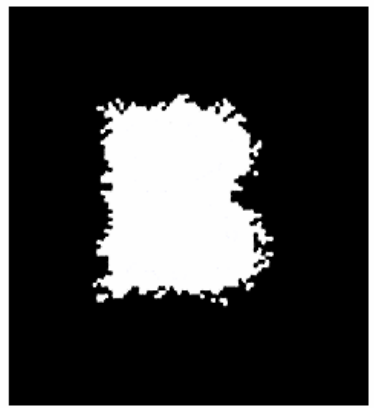

(e)

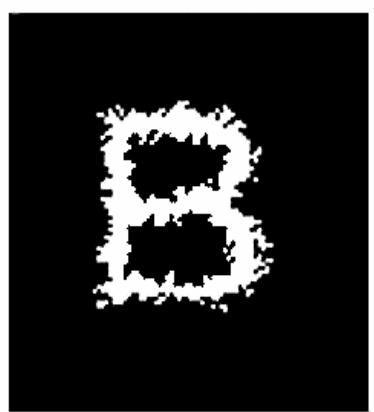

(g)

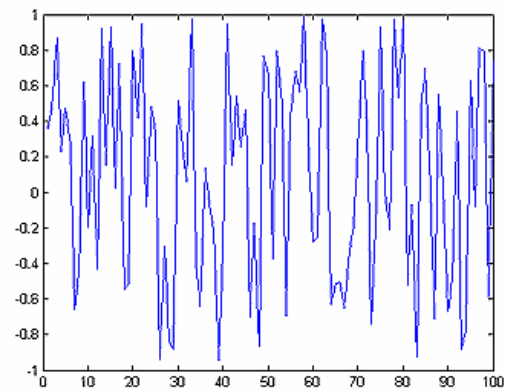

(c)

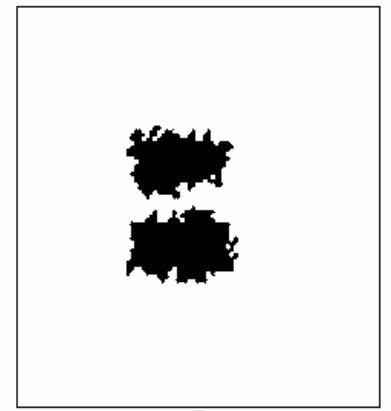

(f)

Figura 32 - Processo de adição de ruído a uma imagem. 
Tendo sido produzidas as amostras para as 26 classes e para os 4 diferentes níveis de ruídos, realizou-se o cálculo das curvas DFM. Para cada amostra, incluindo a amostra original (sem ruído), foram calculadas 4 curvas DFM (Figura 33), cada uma com um diferente valor para o parâmetro de suavização, Sigma $=(10,15,20,25)$, mas utilizando um mesmo valor para o raio de dilatação, $r=100$.
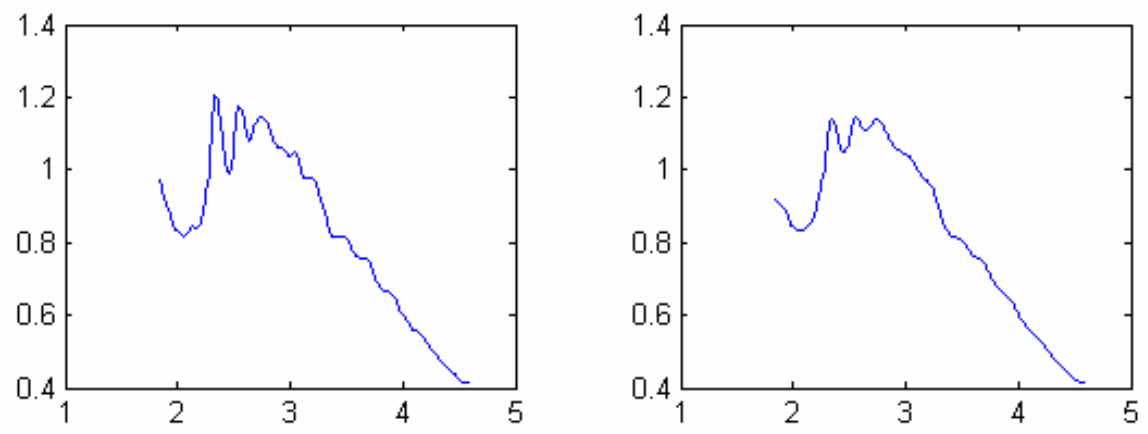

(a)

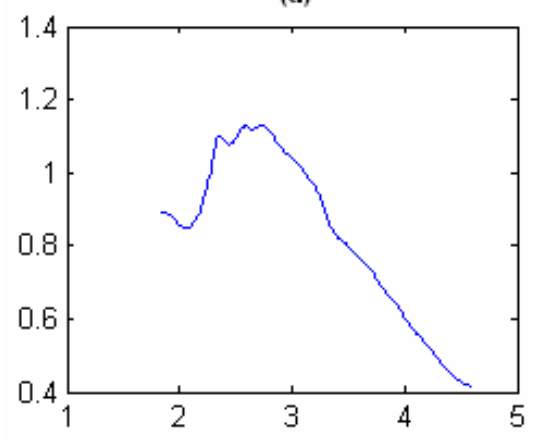

(c)

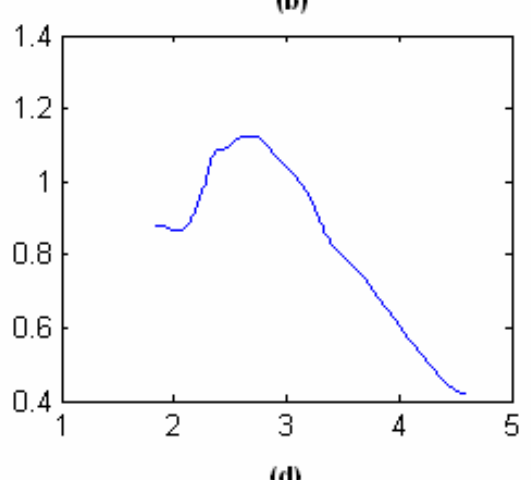

(d)

Figura 33 - Curvas MultiEscala: $($ a) Sigma $=10 ;(b)$ Sigma $=15 ;(c)$ Sigma $=20 ;(d)$ Sigma $=25$.

O experimento de classificação foi então realizado para os conjuntos de amostras com mesmo valor de Sigma. Para cada classe do experimento foi produzida uma curva DFM média, criada a partir de 12 amostras com ruído (sendo 3 amostras de cada nível de ruído) e da amostra original (sem ruído), sendo esse conjunto de curvas posteriormente descartado para não comprometer os resultados (Figura 34). 


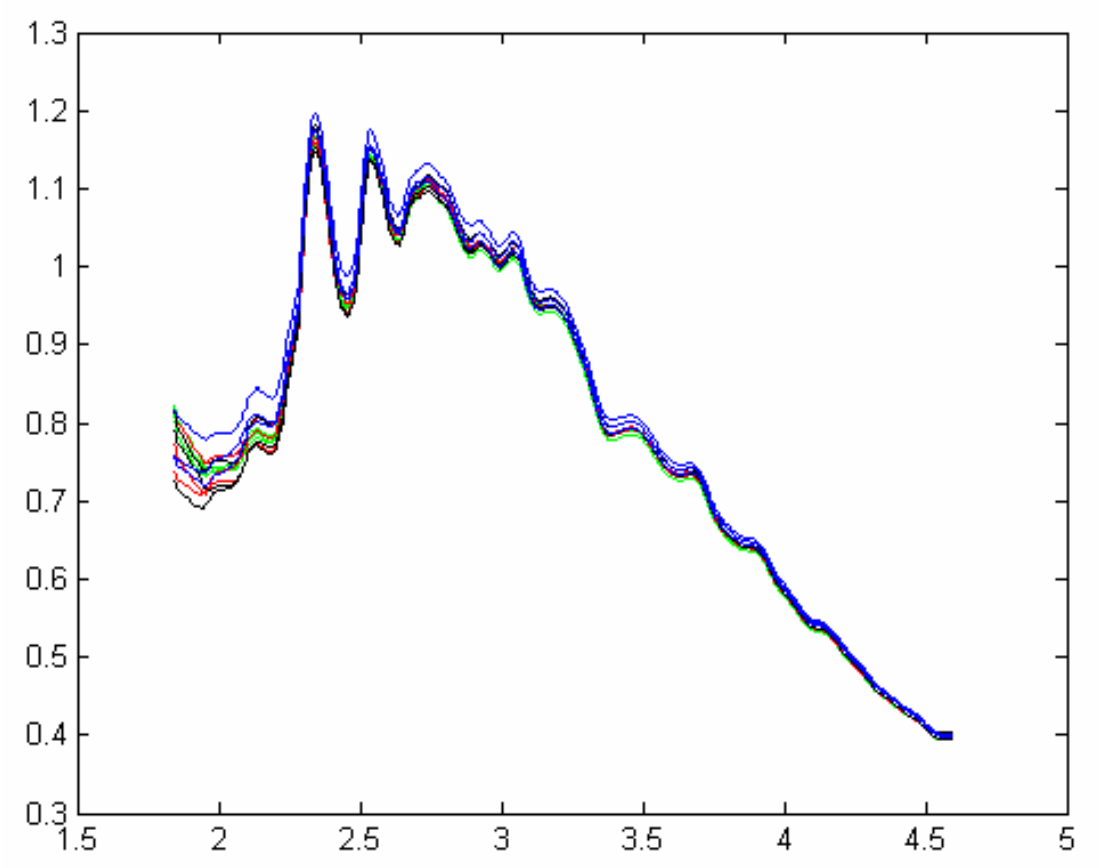

Figura 34 - Demonstração da criação de uma curva Multiescala média.

A classificação das amostras restantes foi realizada verificando a menor distância euclidiana existente entre os descritores obtidos de cada amostra com os descritores das curvas DFM médias. Diversas configurações foram utilizadas no cálculo dos Descritores de Fourier e de Wavelet, visando maximizar o número de acertos na classificação das amostras.

Os resultados obtidos durante o processo de análise e classificação dos descritores foram então organizados em duas tabelas, Tabela 9 e Tabela 10, e dois gráficos, Figura 35 e Figura 36, as quais, respectivamente, agrupam os resultados obtidos com a utilização dos descritores de Wavelet e de Fourier. Em cada uma dessas tabelas são apresentados os coeficientes de suavização (Sigma) utilizados, bem como as configurações utilizadas na obtenção dos descritores (número de descritores selecionados, no caso dos Descritores de Fourier; níveis de Aproximação $A$ e Detalhe $D$ selecionados, no caso dos Descritores de Wavelet), além dos resultados parciais - ou seja, para cada nível de ruído - e totais obtidos no experimento. 


\begin{tabular}{|c|c|c|c|c|c|c|}
\hline \multirow{2}{*}{$\begin{array}{c}\text { Sigma } \\
\text { Utilizado }\end{array}$} & \multirow{2}{*}{$\begin{array}{c}\text { Descritores } \\
\text { Utilizados }\end{array}$} & \multirow{2}{*}{$\begin{array}{c}\text { Total de } \\
\text { Acertos }(\%)\end{array}$} & \multicolumn{4}{|c|}{ Acertos por Nível de Ruído(\%) } \\
\hline & & & $\mathbf{1}^{\mathbf{0}}$ & $\mathbf{2}^{\mathbf{o}}$ & $3^{\circ}$ & $4^{\circ}$ \\
\hline \multirow[t]{8}{*}{10} & $A_{1}$ & 94,7 & 94,6 & 97,7 & 96,2 & 90,4 \\
\hline & $A_{2}$ & 94,3 & 95,0 & 96,5 & 96,2 & 89,6 \\
\hline & $A_{3}$ & 93,8 & 95,8 & 95,0 & 95,8 & 88,8 \\
\hline & $A_{4}$ & 91,7 & 96,2 & 92,7 & 93,5 & 84,6 \\
\hline & $A_{4}+D_{4}$ & 91,7 & 96,5 & 92,7 & 93,1 & 84,6 \\
\hline & $A_{5}+D_{5}$ & 87,2 & 92,7 & 90,0 & 85,8 & 80,4 \\
\hline & $A_{5}+D_{5}+D_{4}$ & 87,3 & 93,5 & 90,0 & 85,8 & 80,0 \\
\hline & $A_{6}+D_{6}+D_{5}+D_{4}$ & 81,3 & 88,1 & 86,2 & 78,1 & 73,1 \\
\hline \multirow[t]{8}{*}{15} & $A_{1}$ & 93,6 & 93,8 & 97,3 & 96,2 & 86,9 \\
\hline & $A_{2}$ & 93,6 & 94,6 & 96,9 & 95,8 & 86,9 \\
\hline & $A_{3}$ & 93,1 & 94,2 & 96,2 & 95,4 & 86,5 \\
\hline & $A_{4}$ & 91,9 & 93,8 & 94,6 & 93,8 & 85,4 \\
\hline & $A_{4}+D_{4}$ & 91,9 & 93,8 & 94,6 & 93,8 & 85,4 \\
\hline & $A_{5}+D_{5}$ & 88,5 & 91,5 & 90,8 & 91,2 & 80,4 \\
\hline & $A_{5}+D_{5}+D_{4}$ & 88,5 & 91,5 & 90,8 & 91,2 & 80,4 \\
\hline & $A_{6}+D_{6}+D_{5}+D_{4}$ & 84,1 & 89,6 & 86,9 & 85,0 & 75,0 \\
\hline \multirow[t]{8}{*}{20} & $A_{l}$ & 93,0 & 93,1 & 96,5 & 95,8 & 86,5 \\
\hline & $A_{2}$ & 93,1 & 93,5 & 97,3 & 95,8 & 85,8 \\
\hline & $A_{3}$ & 93,0 & 93,8 & 96,9 & 95,4 & 85,8 \\
\hline & $A_{4}$ & 92,8 & 95,0 & 95,4 & 94,6 & 86,2 \\
\hline & $A_{4}+D_{4}$ & 92,8 & 95,0 & 95,4 & 94,6 & 86,2 \\
\hline & $A_{5}+D_{5}$ & 89,6 & 91,5 & 93,5 & 91,5 & 81,9 \\
\hline & $A_{5}+D_{5}+D_{4}$ & 89,6 & 91,5 & 93,5 & 91,5 & 81,9 \\
\hline & $A_{6}+D_{6}+D_{5}+D_{4}$ & 86,2 & 90,4 & 89,2 & 87,3 & 77,7 \\
\hline \multirow[t]{8}{*}{25} & $A_{1}$ & 92,5 & 91,9 & 96,2 & 95,4 & 86,5 \\
\hline & $A_{2}$ & 92,7 & 92,3 & 96,5 & 95,4 & 86,5 \\
\hline & $A_{3}$ & 92,1 & 92,7 & 96,2 & 95,0 & 84,6 \\
\hline & $A_{4}$ & 92,2 & 93,8 & 95,0 & 94,2 & 85,8 \\
\hline & $A_{4}+D_{4}$ & 92,2 & 93,8 & 95,0 & 94,2 & 85,8 \\
\hline & $A_{5}+D_{5}$ & 90,2 & 91,9 & 93,5 & 92,3 & 83,1 \\
\hline & $A_{5}+D_{5}+D_{4}$ & 90,2 & 91,9 & 93,5 & 92,3 & 83,1 \\
\hline & $A_{6}+D_{6}+D_{5}+D_{4}$ & 88,1 & 91,9 & 91,2 & 90,0 & 79,2 \\
\hline
\end{tabular}

Tabela 9 - Resultados para os descritores de Wavelet. 


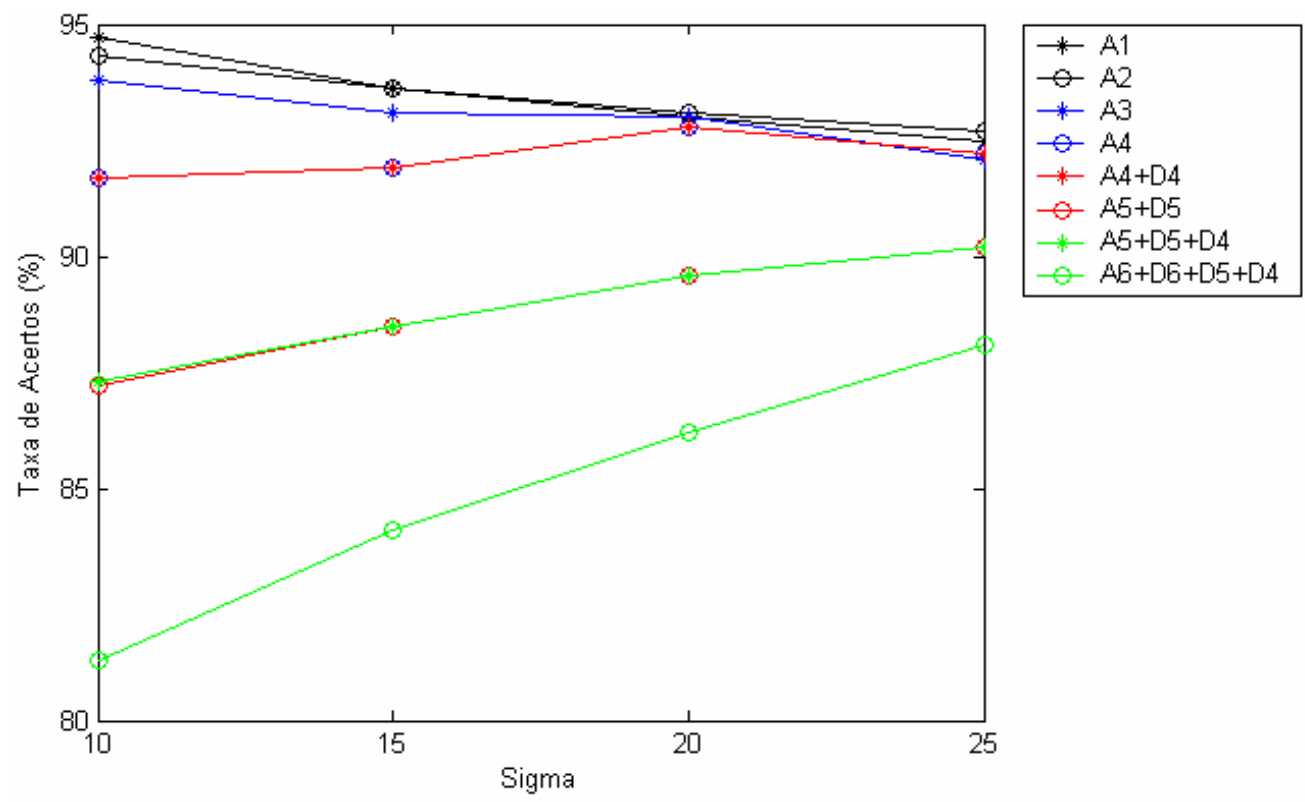

Figura 35 - Comparação dos resultados para os descritores de Wavelet

\begin{tabular}{|c|c|c|c|c|c|c|}
\hline \multirow{2}{*}{$\begin{array}{c}\text { Sigma } \\
\text { Utilizado }\end{array}$} & \multirow{2}{*}{$\begin{array}{l}\text { Número de } \\
\text { Descritores }\end{array}$} & \multirow{2}{*}{$\begin{array}{c}\text { Total de } \\
\text { Acertos }(\%)\end{array}$} & \multicolumn{4}{|c|}{ Acertos por Nível de Ruído(\%) } \\
\hline & & & $\mathbf{1}^{\mathbf{0}}$ & $2^{\circ}$ & $3^{\mathbf{o}}$ & $4^{\circ}$ \\
\hline \multirow[t]{5}{*}{10} & 10 & 88,6 & 95,8 & 95,0 & 90,8 & 73,1 \\
\hline & 15 & 91,9 & 97,3 & 96,5 & 92,7 & 81,2 \\
\hline & 20 & 92,1 & 96,5 & 96,5 & 93,1 & 82,3 \\
\hline & 25 & 92,5 & 96,9 & 97,3 & 93,8 & 82,3 \\
\hline & 40 & 92,8 & 96,5 & 96,9 & 95,0 & 82,7 \\
\hline \multirow[t]{5}{*}{15} & 10 & 89,3 & 95,0 & 95,8 & 91,5 & 75,0 \\
\hline & 15 & 91,1 & 96,5 & 96,2 & 92,7 & 79,2 \\
\hline & 20 & 91,4 & 96,5 & 96,2 & 93,1 & 80,0 \\
\hline & 25 & 91,5 & 96,5 & 96,2 & 93,1 & 80,4 \\
\hline & 40 & 92,1 & 96,9 & 96,5 & 93,1 & 81,9 \\
\hline \multirow[t]{5}{*}{20} & 10 & 89,5 & 95,0 & 95,8 & 93,1 & 74,2 \\
\hline & 15 & 90,1 & 95,8 & 96,2 & 93,5 & 75,4 \\
\hline & 20 & 90,9 & 96,2 & 95,8 & 94,6 & 77,3 \\
\hline & 25 & 91,0 & 96,2 & 96,2 & 94,6 & 77,3 \\
\hline & 40 & 91,1 & 96,2 & 96,2 & 94,2 & 77,7 \\
\hline \multirow[t]{5}{*}{25} & 10 & 89,5 & 95,0 & 95,8 & 93,5 & 73,8 \\
\hline & 15 & 90,0 & 95,4 & 95,8 & 93,8 & 75,4 \\
\hline & 20 & 90,0 & 95,0 & 95,8 & 94,2 & 75,0 \\
\hline & 25 & 90,0 & 95,0 & 95,4 & 94,2 & 75,4 \\
\hline & 40 & 89,8 & 95,0 & 95,4 & 93,8 & 75,0 \\
\hline
\end{tabular}

Tabela 10 - Resultados para os descritores de Fourier. 


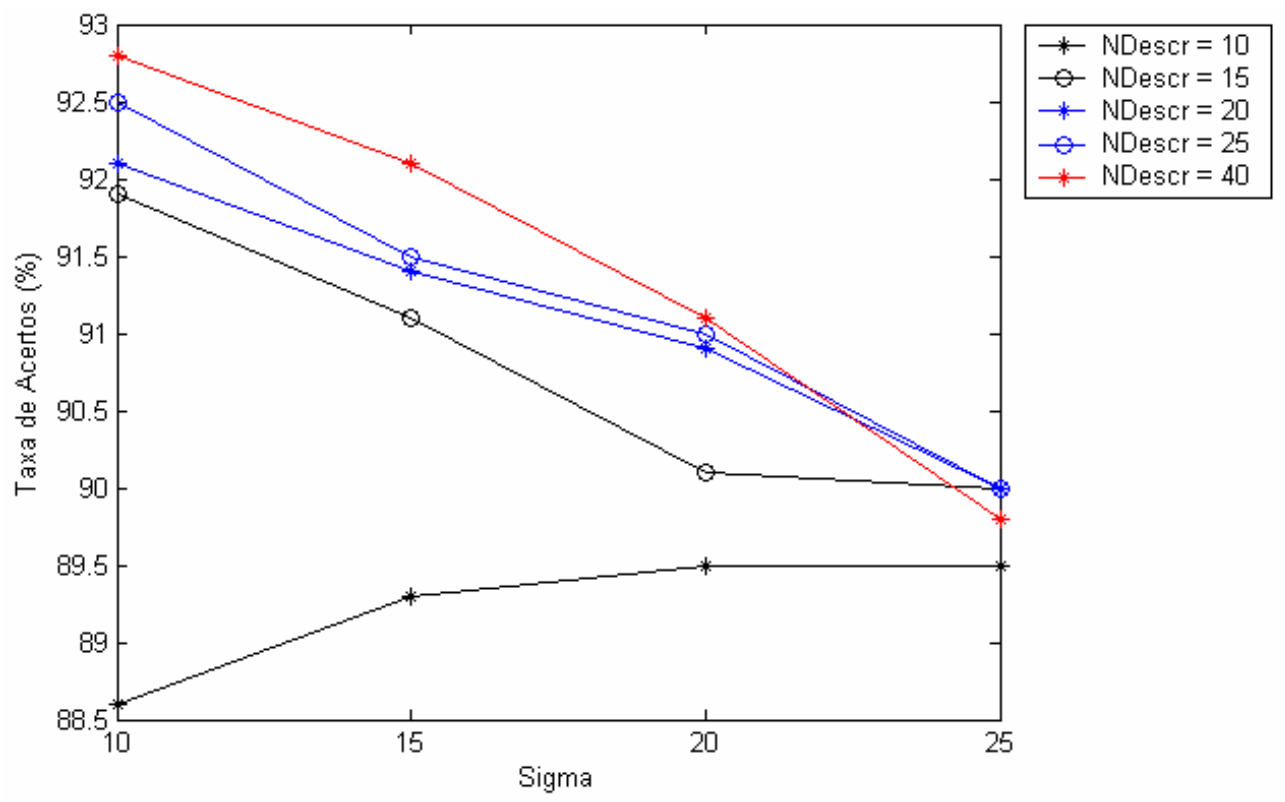

Figura 36 - Comparação dos resultados para os descritores de Fourier

A partir dos resultados obtidos com o experimento podem-se concluir quais configurações, da curva MultiEscala e dos descritores, apresentam melhores resultados e maior tolerância a ruídos.

Num primeiro olhar sobre os resultados é possível notar que a taxa de acerto tende a diminuir conforme a intensidade do ruído aplicado aumenta. Isso acontece, pois o ruído tende a alterar as características geométricas das letras, dificultando os processos de reconhecimento das mesmas. No entanto esta não é uma regra absoluta, uma vez que para certas configurações de descritores, em especial os descritores de Wavelet $A_{1}, A_{2}$ e $A_{3}$, apresentam taxas de acerto maiores para o segundo e terceiros níveis de ruído.

Outro fator de influência presente nos resultados é o parâmetro de suavização, Sigma, escolhido. É possível notar que a taxa de acertos tende a diminuir conforme o valor de Sigma aumenta. Isso ocorre uma vez que altos valores de Sigma provocam suavização excessiva da curva MultiEscala, reduzindo a quantidade de informação disponível para os processos de análise e classificação das curvas (Figura 33).

As curvas MultiEscala obtidas durante o experimento utilizaram um raio de dilatação $r=100$, o que confere a curva MultiEscala 817 pontos de informação. O uso de descritores tem como finalidade principal a compactação da informação e extração das informações mais relevantes presente na curva MultiEscala. Desse modo, é de se esperar que ocorra uma 
diminuição considerável no tamanho dos dados após a aplicação de descritores sobre eles. Além disso, uma alta taxa de compactação da informação não pode comprometer os resultados, de modo que se faz necessário encontrar uma configuração onde o número de descritores seja minimizado ao mesmo tempo em que se maximiza a taxa de acertos.

Quando observado esse quesito, percebe-se que os descritores de Fourier são superiores aos descritores de Wavelet na compactação e extração de informações mais relevantes da curva MultiEscala. Apesar de certas configurações dos descritores de Wavelet apresentarem taxas de acerto maiores, a redução do tamanho do vetor característica é mínima. Isso pode ser comprovado quando se verifica a quantidade de pontos presente nas diferentes configurações utilizadas dos descritores de Wavelet (Tabela 11) (Figura 37).

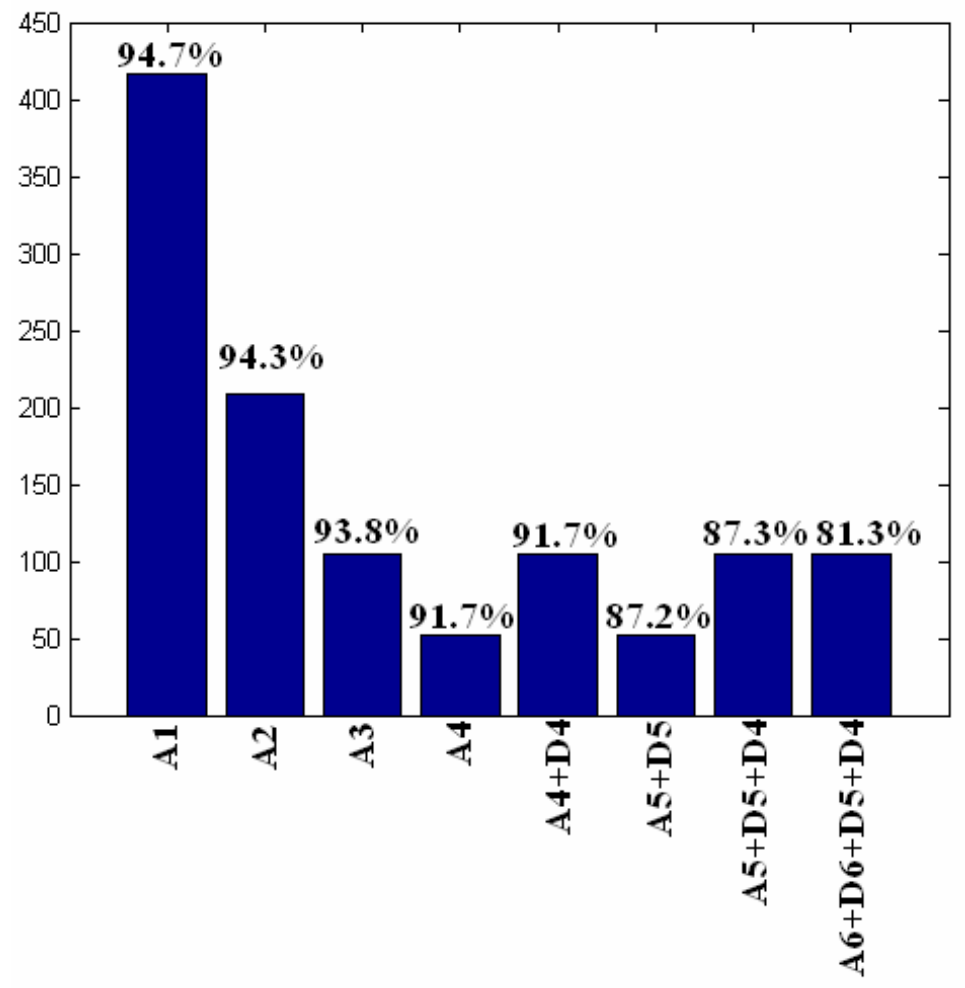

Figura 37 - Comparação entre o número de descritores Wavelet utilizados e a taxa de acertos alcançada. 


\begin{tabular}{|l|c|}
\hline \multicolumn{1}{|c|}{$\begin{array}{c}\text { Descritores } \\
\text { Utilizados }\end{array}$} & $\begin{array}{c}\text { Total de } \\
\text { Pontos }\end{array}$ \\
\hline $\mathrm{A}_{1}$ & 416 \\
\hline $\mathrm{A}_{2}$ & 208 \\
\hline $\mathrm{A}_{3}$ & 104 \\
\hline $\mathrm{A}_{4}$ & 52 \\
\hline $\mathrm{A}_{4}+\mathrm{D}_{4}$ & 104 \\
\hline $\mathrm{A}_{5}+\mathrm{D}_{5}$ & 52 \\
\hline $\mathrm{A}_{5}+\mathrm{D}_{5}+\mathrm{D}_{4}$ & 104 \\
\hline $\mathrm{A}_{6}+\mathrm{D}_{6}+\mathrm{D}_{5}+\mathrm{D}_{4}$ & 104 \\
\hline
\end{tabular}

Tabela 11 - Quantidade de pontos presentes nas diversas configurações dos descritores de Wavelet utilizados.

A partir da análise comparativa dos resultados obtidos com a classificação de imagens através do uso da curva de Dimensão Fractal MultiEscala e descritores de Fourier e Wavelet, onde foram avaliadas características como, precisão, tolerância a ruídos e variação dos resultados segundo ajustes de parâmetros, pôde-se concluir que a curva de Dimensão Fractal MultiEscala quando associada aos descritores de Fourier apresenta os melhores resultados, evidenciando a sua capacidade de aferir diferentes estruturas e grande tolerância a ruídos, servindo como excelente ferramenta em processos de análise e classificação de imagens.

\subsection{Análise da Propriedade MultiEscala em outros Métodos}

Técnicas recentes têm demonstrado importantes resultados quando comparadas aos métodos clássicos (PLOTZE et. al, 2004), como é o caso da Dimensão MultiEscala. Um exemplo disso pode ser encontrado em experimentos com identificação de espécies arbóreas, onde a Dimensão MultiEscala de Minkowsi apresentou um resultado melhor do que os outros métodos existentes (PLOTZE et. al, 2004).

Originalmente, a Dimensão Fractal MultiEscala é calculada a partir do gráfico log-log obtido pelo método de Minkowski. Nessa fase do projeto realizou-se um estudo sobre a possibilidade de se calcular a Dimensão Fractal MultiEscala a partir do gráfico log-log gerado pelos seguintes métodos: Massa-Raio, Intersecções Acumulativas, BoxCounting e Dividers. Nesse estudo, realizou-se um experimento visando averiguar a possibilidade de uso dessas novas curvas MultiEscala como classificadores de formas, além de suas vantagens e desvantagens quando comparados seus resultados com os resultados obtidos com a curva MultiEscala obtida a partir do método de Minkowski. 
Para a realização desse experimento, fez-se uso do conjunto de imagens previamente preparado e utilizado nos experimentos com a curva MultiEscala de Minkowski. Tal conjunto de imagens foi reutilizado, assim como a metodologia do experimento, a fim de manter uma base de comparação com os resultados obtidos com a MultiEscala de Minkowski.

De posse do conjunto de imagens, realizou-se o cálculo das curvas DFM. Para cada amostra, incluindo a amostra original (sem ruído), foram calculadas 4 curvas $D F M$, cada uma com um diferente valor para o parâmetro de suavização, Sigma $=(1.5,2.0,2.5,3.0)$. Esse processo foi realizado para cada um dos métodos analisados (Massa-Raio, Intersecções Acumulativas, BoxCounting e Dividers), respeitando as limitações de cada método.

Um fato relevante quanto ao processo de obtenção da curva MultiEscala diz respeito à quantidade de pontos presentes nas curvas log-log utilizadas. Os métodos sob análise produzem curvas log-log com menos informações que a curva log-log obtida pelo método de Minkowski. Desse modo, faz-se necessário utilizar um parâmetro de suavização menor do que o utilizado na validação da Dimensão Fractal MultiEscala de Minkowski. Além disso, o uso de um parâmetro de suavização maior acarreta uma suavização excessiva da curva MultiEscala, suprimindo informações sobre a forma analisada.

O experimento de classificação foi então realizado para cada um dos métodos estudados. Neles, o processo de classificação das amostras foi realizado para os conjuntos de amostras com mesmo valor de Sigma. Para cada classe do experimento foi produzida uma curva DFM média, criada a partir de 12 amostras com ruído (sendo 3 amostras de cada nível de ruído) e da amostra original (sem ruído), sendo esse conjunto de curvas posteriormente descartado para não comprometer os resultados.

A classificação das amostras restantes foi realizada verificando a menor distância euclidiana existente entre as curvas DFM obtidas para cada amostra e as curvas DFM médias. Diferente do experimento de validação da Dimensão Fractal MultiEscala de Minkowski, aqui não foram utilizados descritores de Fourier e de Wavelet. $\mathrm{O}$ uso dos descritores não se fez necessário, pois as curvas DFM obtidas possuíam uma quantidade muito menor de pontos que as curvas DFM obtidas com base no método de Minkowski.

Os resultados obtidos durante o processo de análise e classificação das curvas $D F M$ foram então organizados e agrupados segundo o método utilizado na obtenção da curva MultiEscala. A seguir são apresentadas as análises referentes a cada um dos quatro métodos utilizados, os 
coeficientes de suavização (Sigma) utilizados, bem como as configurações utilizadas em cada método, além dos resultados parciais - ou seja, para cada nível de ruído - e totais obtidos no experimento.

\subsubsection{Método Massa-Raio}

A utilização do método Massa-Raio no conjunto de amostras anteriormente definido somente foi possível após observarem certas restrições que o método apresenta. Tais restrições se referem principalmente à escolha dos centros dos círculos utilizados no cálculo. Essa escolha pode ser um processo empírico, o que por sua vez provoca variações nos resultados de uma execução para outra. Uma solução para isso é a utilização de apenas um círculo, que apresente como centro, o centro de massa da imagem, reduzindo a inconsistência. No entanto, certas letras do alfabeto apresentam aberturas internas, de modo que o seu centro de massa seja um ponto não pertencente à imagem, o que impossibilita o cálculo do método a partir desse ponto (Figura 38).

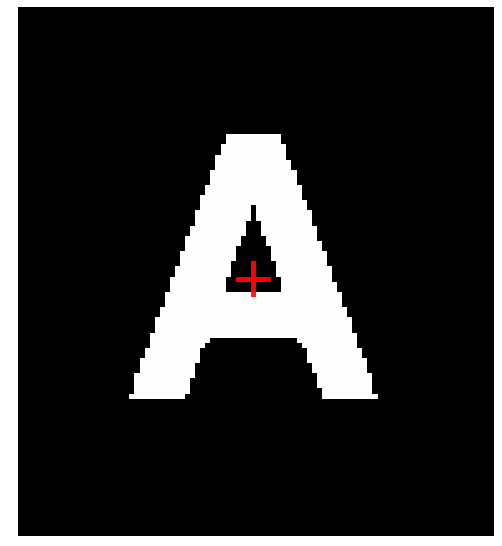

Figura 38 - Letra com abertura interna. Seu centro de massa é um ponto pertencente ao fundo da imagem.

Visando solucionar esse problema, optou-se pela utilização de vários círculos durante o cálculo da massa, sendo a massa final obtida como sendo a média das várias execuções realizadas.

Devido à utilização de vários círculos durante o cálculo do método, evitou-se utilizar o raio de giro da imagem como raio máximo, $r_{\max }$, de crescimento dos círculos, optando-se por testar diferentes valores para o $r_{\max }$ durante o experimento. Isso por que o uso raio de giro apresenta melhores resultados quando o método é utilizado com apenas um círculo disposto no centro de massa da imagem. 
Tendo sido definido a maneira como o método seria utilizado, seguiram-se os experimentos cujos resultados podem ser vistos na Tabela 12 e na Figura 39.

A partir dos resultados obtidos com o experimento pode-se concluir que o método sofre influência direta do número de círculos utilizados, bem como do $r_{\max }$ utilizado no crescimento dos círculos. É possível notar um aumento na taxa de acerto à medida que o número de círculos utilizados aumenta. Esse aumento na taxa de acertos também pode ser notado quando se aumenta o valor de $r_{\max }$. Isso ocorre uma vez que o aumento do número de círculos utilizados durante o cálculo, aliada a um aumento no $r_{\max }$ provoca uma melhor amostragem da distribuição de massa da forma, conseqüentemente melhorando a caracterização da mesma.

Partindo-se dos resultados obtidos para cada um dos quatro níveis de ruído, pode-se notar que a curva MultiEscala obtida a partir do método de Massa-Raio apresenta uma alta tolerância a ruídos presentes na forma analisada. No entanto, certas configurações apresentam uma tolerância menor ao ruído, de modo que a taxa de acertos diminui acentuadamente à medida que o nível de ruído aplicado à forma aumenta.

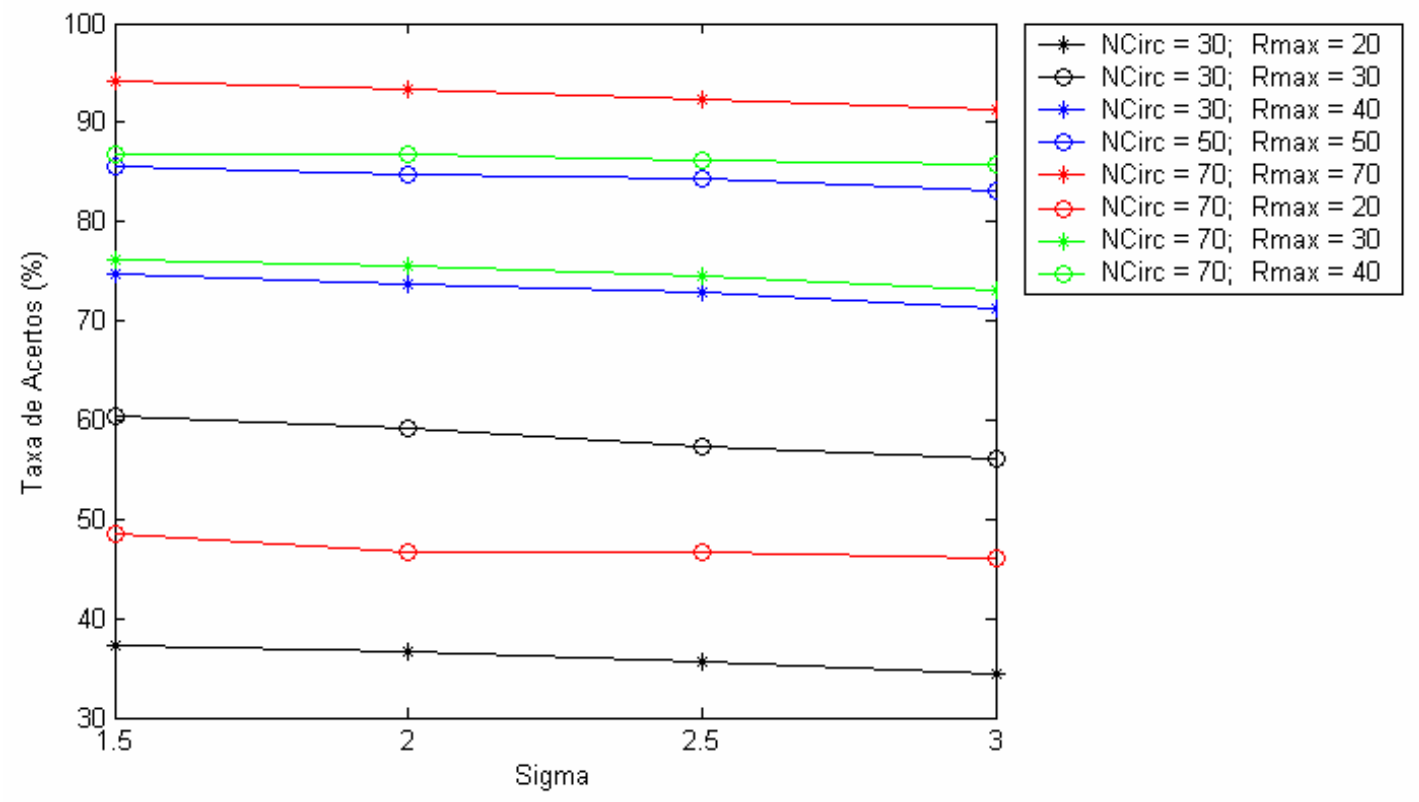

Figura 39 - Comparação dos resultados obtidos para o método Massa-Raio. 


\begin{tabular}{|c|c|c|c|c|c|c|c|}
\hline \multirow{2}{*}{$\begin{array}{l}\text { Círculos } \\
\text { Utilizados }\end{array}$} & \multirow[b]{2}{*}{$r_{\max }$} & \multirow{2}{*}{$\begin{array}{c}\text { Sigma } \\
\text { Utilizado }\end{array}$} & \multirow{2}{*}{$\begin{array}{c}\text { Total de } \\
\text { Acertos }(\%)\end{array}$} & \multicolumn{4}{|c|}{ Acertos por Nível de Ruído(\%) } \\
\hline & & & & $\mathbf{1}^{\mathbf{0}}$ & $\mathbf{2}^{\mathbf{0}}$ & $3^{\circ}$ & $4^{\circ}$ \\
\hline \multirow[t]{4}{*}{10} & \multirow[t]{4}{*}{20} & 1,5 & 22,40 & 26,15 & 23,85 & 22,69 & 16,92 \\
\hline & & 2,0 & 21,92 & 26,15 & 22,69 & 22,69 & 16,15 \\
\hline & & 2,5 & 21,92 & 27,69 & 22,31 & 23,08 & 14,62 \\
\hline & & 3,0 & 21,92 & 26,92 & 22,69 & 23,08 & 15,00 \\
\hline \multirow[t]{4}{*}{20} & \multirow[t]{4}{*}{20} & 1,5 & 32,02 & 33,08 & 35,77 & 32,31 & 26,92 \\
\hline & & 2,0 & 31,92 & 33,08 & 35,00 & 32,69 & 26,92 \\
\hline & & 2,5 & 31,44 & 30,00 & 35,38 & 33,08 & 27,31 \\
\hline & & 3,0 & 31,92 & 29,62 & 34,62 & 33,08 & 30,38 \\
\hline \multirow[t]{4}{*}{30} & \multirow[t]{4}{*}{20} & 1,5 & 37,21 & 40,00 & 40,00 & 36,15 & 32,69 \\
\hline & & 2,0 & 36,63 & 40,38 & 38,08 & 36,15 & 31,92 \\
\hline & & 2,5 & 35,77 & 39,62 & 37,31 & 37,31 & 28,85 \\
\hline & & 3,0 & 34,42 & 37,69 & 36,92 & 35,77 & 27,31 \\
\hline \multirow[t]{4}{*}{30} & \multirow[t]{4}{*}{30} & 1,5 & 60,38 & 63,08 & 62,31 & 57,69 & 58,46 \\
\hline & & 2,0 & 59,23 & 61,92 & 61,15 & 56,92 & 56,92 \\
\hline & & 2,5 & 57,40 & 60,00 & 60,38 & 55,38 & 53,85 \\
\hline & & 3,0 & 56,06 & 57,31 & 58,08 & 53,85 & 55,00 \\
\hline \multirow[t]{4}{*}{30} & \multirow[t]{4}{*}{40} & 1,5 & 74,81 & 78,08 & 72,69 & 76,54 & 71,92 \\
\hline & & 2,0 & 73,75 & 76,54 & 71,54 & 77,31 & 69,62 \\
\hline & & 2,5 & 72,88 & 75,00 & 70,77 & 76,54 & 69,23 \\
\hline & & 3,0 & 71,25 & 74,62 & 70,38 & 71,92 & 68,08 \\
\hline \multirow[t]{4}{*}{50} & \multirow[t]{4}{*}{50} & 1,5 & 85,58 & 89,23 & 87,31 & 87,31 & 78,46 \\
\hline & & 2,0 & 84,71 & 87,31 & 86,15 & 86,92 & 78,46 \\
\hline & & 2,5 & 84,33 & 87,69 & 86,92 & 85,77 & 76,92 \\
\hline & & 3,0 & 83,17 & 88,08 & 83,85 & 84,23 & 76,54 \\
\hline \multirow[t]{4}{*}{70} & \multirow[t]{4}{*}{70} & 1,5 & 94,23 & 95,38 & 95,77 & 93,85 & 91,92 \\
\hline & & 2,0 & 93,46 & 94,23 & 95,38 & 93,85 & 90,38 \\
\hline & & 2,5 & 92,31 & 93,46 & 94,62 & 91,54 & 89,62 \\
\hline & & 3,0 & 91,44 & 92,69 & 94,23 & 89,23 & 89,62 \\
\hline \multirow[t]{4}{*}{70} & \multirow[t]{4}{*}{20} & 1,5 & 48,56 & 55,00 & 53,08 & 49,23 & 36,92 \\
\hline & & 2,0 & 46,73 & 52,31 & 50,38 & 47,69 & 36,54 \\
\hline & & 2,5 & 46,73 & 52,31 & 49,23 & 47,69 & 37,69 \\
\hline & & 3,0 & 46,15 & 51,15 & 48,85 & 46,54 & 38,08 \\
\hline \multirow[t]{4}{*}{70} & \multirow[t]{4}{*}{30} & 1,5 & 76,25 & 78,46 & 81,15 & 76,15 & 69,23 \\
\hline & & 2,0 & 75,67 & 77,69 & 80,77 & 75,38 & 68,85 \\
\hline & & 2,5 & 74,52 & 76,92 & 79,62 & 75,00 & 66,54 \\
\hline & & 3,0 & 73,17 & 77,31 & 76,92 & 72,69 & 65,77 \\
\hline \multirow[t]{4}{*}{70} & 40 & 1,5 & 86,83 & 87,31 & 90,77 & 87,69 & 81,54 \\
\hline & & 2,0 & 86,73 & 88,46 & 89,62 & 87,31 & 81,54 \\
\hline & & 2,5 & 86,15 & 89,23 & 88,46 & 87,31 & 79,62 \\
\hline & & 3,0 & 85,87 & 88,85 & 88,08 & 86,92 & 79,62 \\
\hline
\end{tabular}

Tabela 12 - Configurações e resultados obtidos para o método Massa-Raio. 
Além das configurações referentes à quantidade de círculos e $r_{\max }$ utilizados, nota-se que o valor do parâmetro Sigma também exerce certa influência sobre os resultados de classificação obtidos. Esse valor é referente ao coeficiente de suavização da curva MultiEscala, o qual é responsável por uma presença maior ou menor de detalhes na curva (Figura 40). Nota-se que valores maiores para o parâmetro Sigma provocam uma suavização excessiva da curva MultiEscala, suprimindo detalhes, as vezes, importantes, acarretando uma diminuição na taxa de acerto dos resultados.

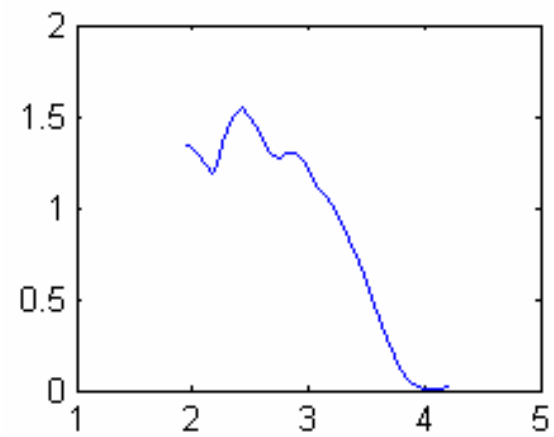

(a)

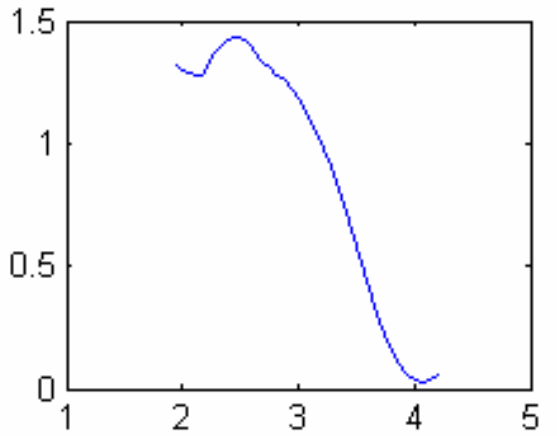

(c)

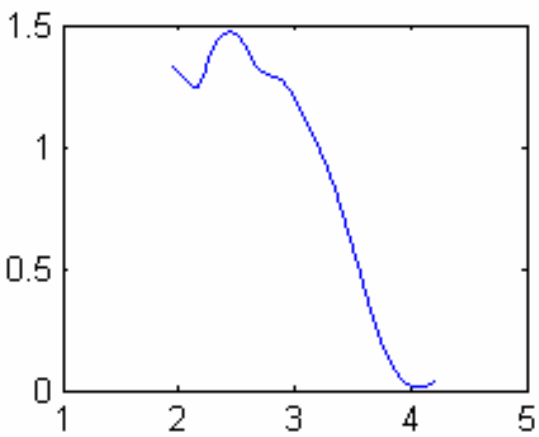

(b)

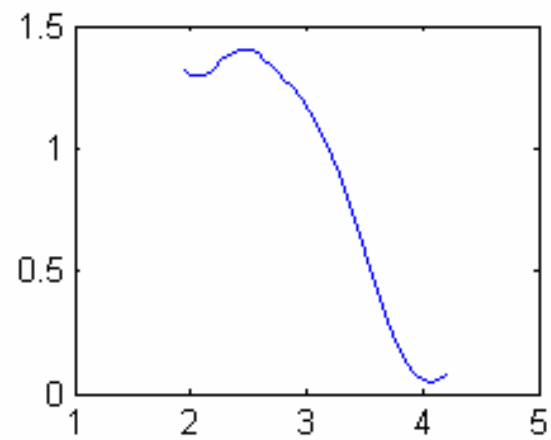

(d)

Figura 40 - Curvas MultiEscala obtidas pelo método Massa-Raio: (a)Sigma = 1,5; (b)Sigma = 2,0; $($ c)Sigma = 2,5; (d)Sigma $=3,0$.

De modo geral esse método apresenta resultados mais que satisfatórios desde que observadas as restrições acima citadas.

\subsubsection{Método de Intersecções Acumulativas}

A utilização do método Intersecções Acumulativas no conjunto de amostras anteriormente definido somente foi possível depois de observadas certas restrições que o método apresenta. 
Essas restrições se referem principalmente à escolha dos centros dos círculos utilizados no cálculo do método e a quantidade de círculos utilizados.

O método de Intersecções Acumulativas se assemelha ao método de Massa-Raio, uma vez que ambos os métodos se baseiam no crescimento de círculos para o cálculo de suas respectivas curvas log-log. Dessa maneira, o método de Intersecções Acumulativas acaba sofrendo dos mesmos problemas de utilização que o método de Massa-Raio. Felizmente, as mesmas estratégias utilizadas para o método de Massa-Raio e que permitiram a sua utilização no conjunto de imagens do experimento puderam ser utilizadas aqui. Sendo assim, aqui também se optou pela utilização de vários círculos durante o cálculo das intersecções, sendo o total de intersecções final obtida como sendo a média das várias execuções realizadas.

Como no método de Massa-Raio, aqui também se evitou utilizar o raio de giro da imagem como raio máximo, $r_{\max }$, de crescimento dos círculos, optando-se por testar diferentes valores para o raio máximo durante o experimento. Isso por que o uso do raio de giro apresenta melhores resultados quando o método é utilizado com apenas um círculo disposto no centro de massa da imagem.

Tendo sido definido a maneira como o método seria utilizado, seguiram-se os experimentos cujos resultados podem ser vistos na Tabela 13 e na Figura 41.

A partir dos resultados obtidos com o experimento pode-se concluir que o método sofre influência direta do número de círculos utilizados, bem como do $r_{\max }$ utilizado no crescimento dos círculos. Como nos resultados obtidos utilizando o método Massa-Raio, aqui também é possível notar um aumento na taxa de acerto à medida que o número de círculos utilizados aumenta. Esse aumento na taxa de acertos também pode ser notado quando se aumenta o valor de $r_{\max }$. Isso ocorre uma vez que o aumento do número de círculos utilizados durante o cálculo, aliada a um aumento no $r_{\max }$ provoca uma melhor amostragem da distribuição das intersecções presentes na forma, conseqüentemente melhorando a caracterização da mesma. 


\begin{tabular}{|c|c|c|c|c|c|c|c|}
\hline \multirow{2}{*}{$\begin{array}{l}\text { Círculos } \\
\text { Utilizados }\end{array}$} & \multirow[b]{2}{*}{$r_{\max }$} & \multirow{2}{*}{$\begin{array}{c}\text { Sigma } \\
\text { Utilizado }\end{array}$} & \multirow{2}{*}{$\begin{array}{c}\text { Total de } \\
\text { Acertos }(\%)\end{array}$} & \multicolumn{4}{|c|}{ Acertos por Nível de Ruído(\%) } \\
\hline & & & & $\mathbf{1}^{\mathbf{0}}$ & $\mathbf{2}^{\mathbf{o}}$ & $3^{\circ}$ & $4^{0}$ \\
\hline \multirow[t]{4}{*}{10} & \multirow[t]{4}{*}{20} & 1,5 & 19,04 & 21,15 & 21,15 & 16,54 & 17,31 \\
\hline & & 2,0 & 18,56 & 20,77 & 20,77 & 15,77 & 16,92 \\
\hline & & 2,5 & 18,65 & 18,85 & 20,77 & 17,69 & 17,31 \\
\hline & & 3,0 & 18,56 & 18,85 & 20,38 & 18,08 & 16,92 \\
\hline \multirow[t]{4}{*}{20} & \multirow[t]{4}{*}{20} & 1,5 & 23,56 & 24,23 & 25,77 & 23,85 & 20,38 \\
\hline & & 2,0 & 23,27 & 22,69 & 26,54 & 23,85 & 20,00 \\
\hline & & 2,5 & 22,79 & 22,69 & 25,00 & 24,23 & 19,23 \\
\hline & & 3,0 & 22,31 & 23,08 & 25,00 & 24,62 & 16,54 \\
\hline \multirow[t]{4}{*}{30} & \multirow[t]{4}{*}{20} & 1,5 & 26,83 & 26,54 & 27,69 & 25,77 & 27,31 \\
\hline & & 2,0 & 26,25 & 26,92 & 26,92 & 25,38 & 25,77 \\
\hline & & 2,5 & 25,77 & 26,15 & 26,92 & 24,23 & 25,77 \\
\hline & & 3,0 & 26,44 & 26,15 & 28,85 & 24,62 & 26,15 \\
\hline \multirow[t]{4}{*}{30} & \multirow[t]{4}{*}{30} & 1,5 & 49,13 & 50,00 & 51,54 & 49,23 & 45,77 \\
\hline & & 2,0 & 47,69 & 46,92 & 52,31 & 46,54 & 45,00 \\
\hline & & 2,5 & 46,25 & 46,54 & 49,23 & 46,54 & 42,69 \\
\hline & & 3,0 & 45,00 & 45,77 & 48,85 & 45,00 & 40,38 \\
\hline \multirow[t]{4}{*}{30} & \multirow[t]{4}{*}{40} & 1,5 & 67,69 & 66,54 & 70,00 & 69,62 & 64,62 \\
\hline & & 2,0 & 65,87 & 63,85 & 69,62 & 68,85 & 61,15 \\
\hline & & 2,5 & 63,65 & 62,31 & 67,31 & 66,54 & 58,46 \\
\hline & & 3,0 & 61,63 & 60,38 & 66,54 & 64,23 & 55,38 \\
\hline \multirow[t]{4}{*}{50} & \multirow[t]{4}{*}{50} & 1,5 & 78,17 & 77,69 & 82,31 & 77,69 & 75,00 \\
\hline & & 2,0 & 76,25 & 75,38 & 81,15 & 76,92 & 71,54 \\
\hline & & 2,5 & 74,23 & 72,69 & 80,00 & 74,23 & 70,00 \\
\hline & & 3,0 & 72,31 & 70,77 & 77,69 & 72,31 & 68,46 \\
\hline \multirow[t]{4}{*}{70} & \multirow[t]{4}{*}{70} & 1,5 & 86,25 & 85,00 & 89,23 & 88,46 & 82,31 \\
\hline & & 2,0 & 84,90 & 83,08 & 87,31 & 88,08 & 81,15 \\
\hline & & 2,5 & 83,46 & 80,77 & 86,92 & 86,15 & 80,00 \\
\hline & & 3,0 & 81,15 & 77,31 & 86,15 & 84,62 & 76,54 \\
\hline \multirow[t]{4}{*}{70} & \multirow[t]{4}{*}{20} & 1,5 & 33,94 & 38,08 & 34,62 & 32,69 & 30,38 \\
\hline & & 2,0 & 32,98 & 35,00 & 33,85 & 33,85 & 29,23 \\
\hline & & 2,5 & 32,50 & 33,85 & 34,23 & 34,23 & 27,69 \\
\hline & & 3,0 & 30,96 & 33,08 & 31,15 & 33,85 & 25,77 \\
\hline \multirow[t]{4}{*}{70} & \multirow[t]{4}{*}{30} & 1,5 & 62,02 & 63,46 & 69,23 & 64,62 & 50,77 \\
\hline & & 2,0 & 59,71 & 62,31 & 65,77 & 64,23 & 46,54 \\
\hline & & 2,5 & 57,12 & 61,54 & 63,46 & 58,46 & 45,00 \\
\hline & & 3,0 & 53,85 & 56,92 & 61,15 & 55,00 & 42,31 \\
\hline \multirow[t]{4}{*}{70} & 40 & 1,5 & 80,19 & 79,23 & 86,15 & 81,92 & 73,46 \\
\hline & & 2,0 & 78,65 & 77,69 & 84,23 & 80,00 & 72,69 \\
\hline & & 2,5 & 74,81 & 75,77 & 81,15 & 76,15 & 66,15 \\
\hline & & 3,0 & 71,15 & 73,08 & 77,31 & 72,31 & 61,92 \\
\hline
\end{tabular}

Tabela 13 - Configurações e resultados obtidos para o método Intersecções Acumulativas. 


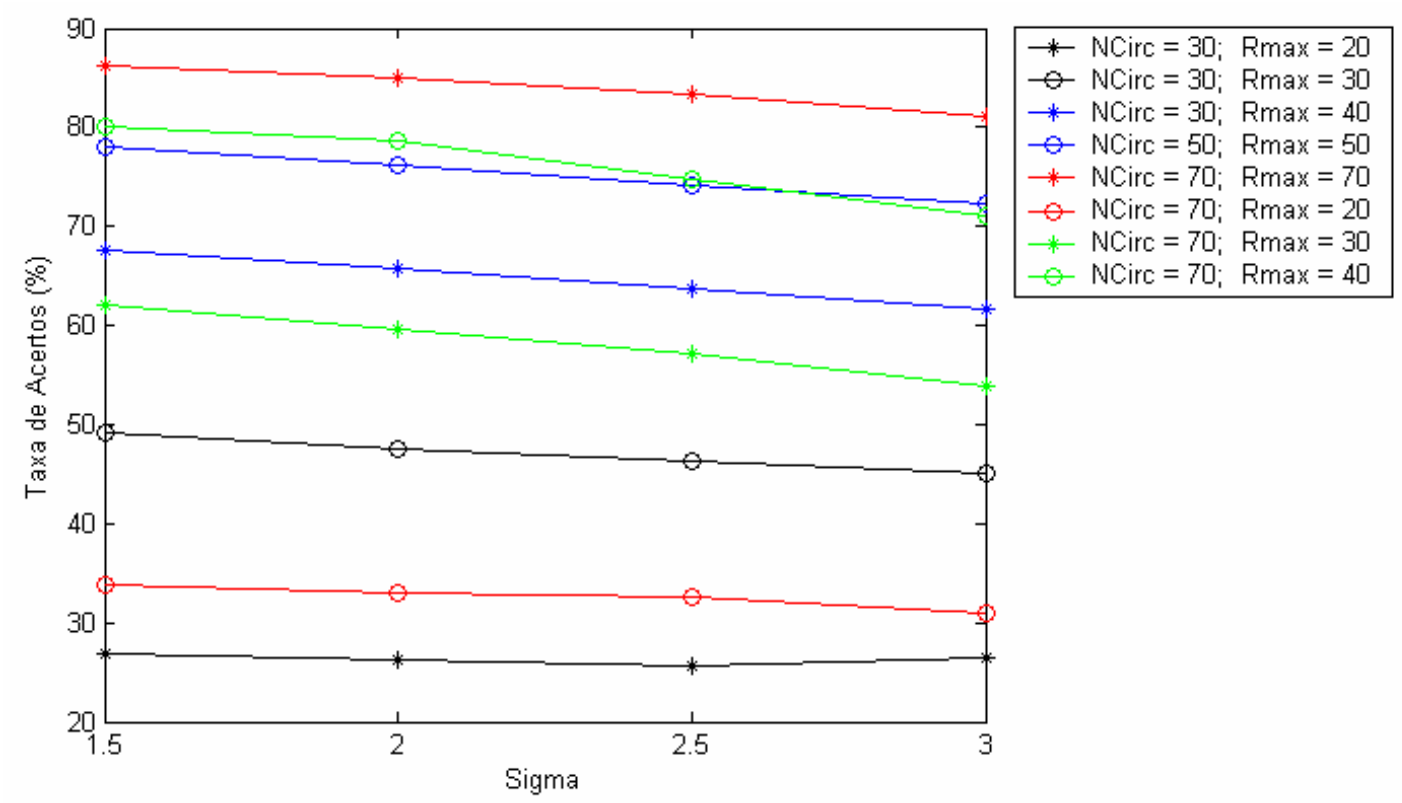

Figura 41 - Comparação dos resultados obtidos para o método Intersecções Acumulativas.

Partindo-se dos resultados obtidos para cada um dos quatro níveis de ruído, pode-se notar que a curva MultiEscala obtida a partir do método de Intersecções Acumulativas apresenta uma certa tolerância a ruídos presentes na forma analisada. No entanto, certas configurações apresentam uma diminuição nessa tolerância ao ruído, de modo que a taxa de acertos diminui acentuadamente à medida que o nível de ruído aplicado à forma aumenta.

Além das configurações referentes à quantidade de círculos e $r_{\text {max }}$ utilizados, nota-se que o valor do parâmetro Sigma também exerce uma certa influência sobre os resultados de classificação obtidos. Esse valor é referente ao coeficiente de suavização da curva MultiEscala, o qual é responsável por uma presença maior ou menor de detalhes na curva (Figura 42). Nota-se que valores maiores para o parâmetro Sigma provocam uma suavização excessiva da curva MultiEscala, suprimindo detalhes, as vezes, importantes, acarretando uma diminuição na taxa de acerto dos resultados. 


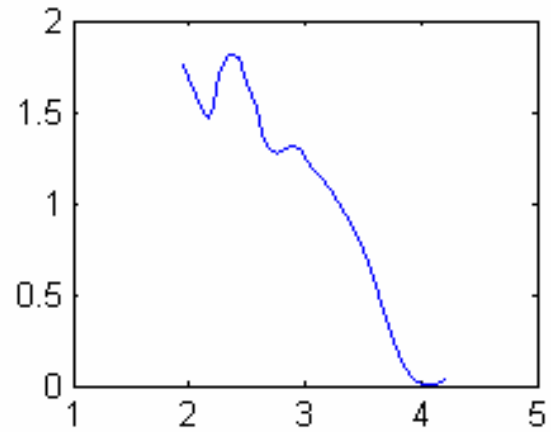

(a)

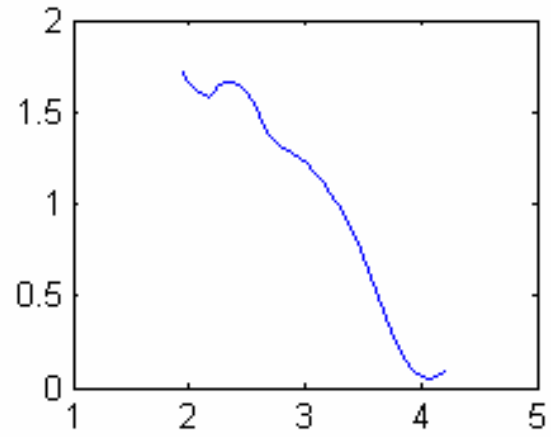

(c)

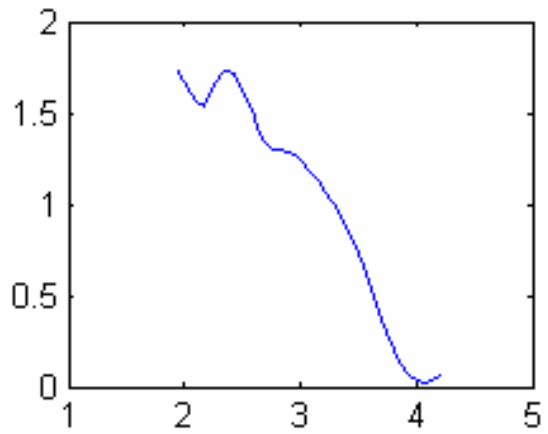

(b)

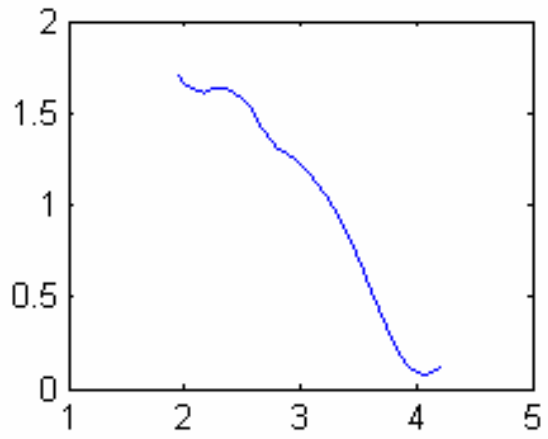

(d)

Figura 42 - Curvas MultiEscala obtidas pelo método Intersecções Acumulativas: $(\mathrm{a})$ Sigma = 1,5; $(\mathrm{b})$ Sigma = 2,0; (c)Sigma = 2,5; (d)Sigma = 3,0.

De modo geral esse método apresenta resultados satisfatórios, desde que observadas as restrições acima citadas.

\subsubsection{Método BoxCounting}

A utilização do método BoxCounting no conjunto de amostras anteriormente definido somente foi possível após observarem certas restrições que o método apresenta. Tais restrições se referem principalmente ao conjunto de caixas utilizados pelo algoritmo nas diversas iterações do método, já que o tamanho da caixa influencia diretamente o total de caixas necessárias para cobrir a imagem. Essa escolha pode ser um processo empírico, o que por sua vez provoca variações nos resultados de uma execução para outra. Uma solução para isso é a utilização de uma caixa inicial com o tamanho da imagem, reduzindo o tamanho dessa caixa pela metade a cada nova iteração, até que se chegue numa caixa de largura um. No entanto, apesar dessa 
estratégia ser muito útil no cálculo da Dimensão Fractal da imagem, ela produz uma quantidade muito pequena de pontos, o que torna inviável o cálculo da curva MultiEscala (Figura 43).

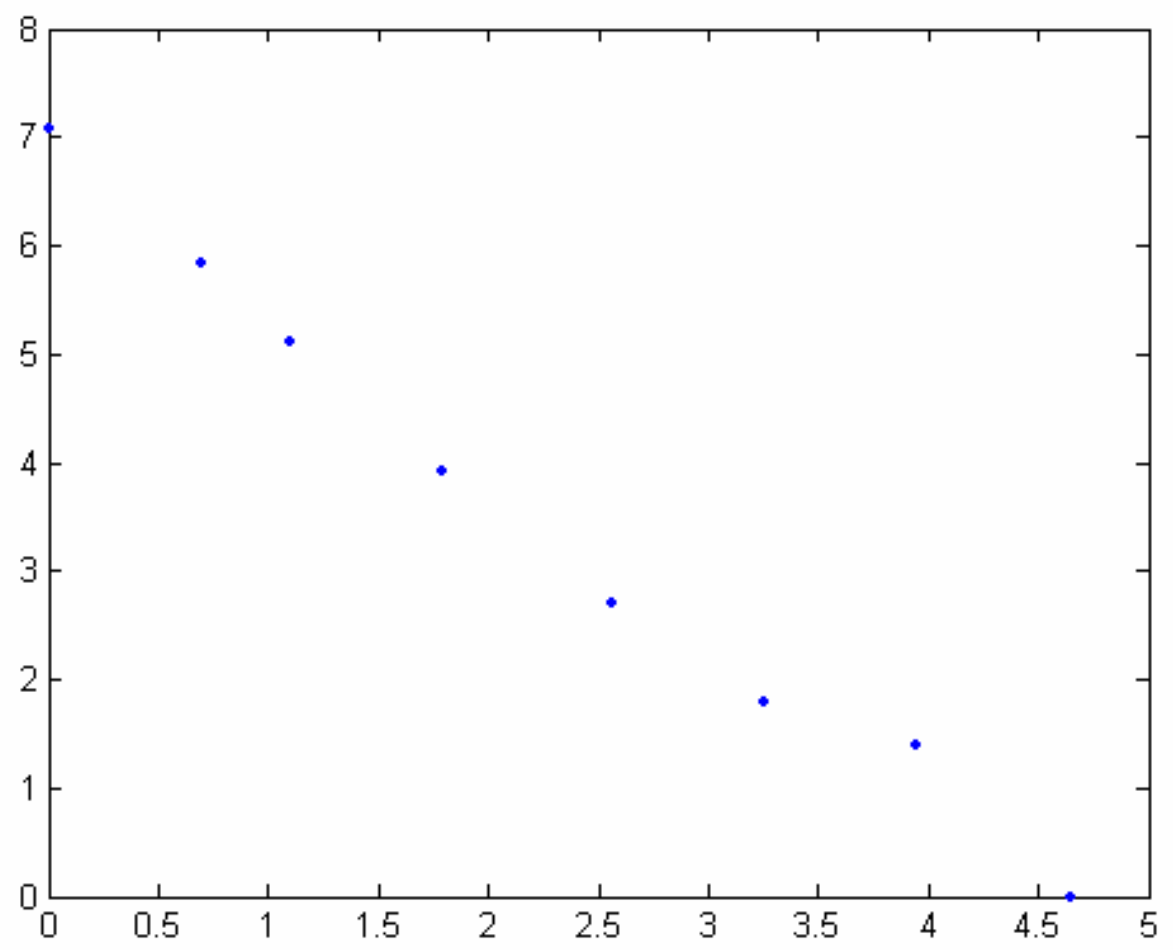

Figura 43 - Curva log-log com poucos pontos. Insuficiente para gerar uma curva de Dimensão Fractal MultiEscala sa tisfatória.

Visando solucionar esse problema, optou-se pela utilização de um conjunto maior de caixas, de modo que o método foi calculado para uma caixa inicialmente com largura 1, sendo essa largura incrementada a cada nova iteração, até atingir uma largura limite $L_{\max }$.

Outro problema relativo à utilização do método do BoxCounting se refere ao posicionamento das caixas sobre a imagem. Dependendo de como o grid é posicionado sobre a imagem, o número de caixas contadas pode variar, provocando variações no resultado de uma execução para outra. De modo a evitar tais variações, optou-se por realizar dois tipos de alinhamento das caixas com relação a imagem:

- grid, onde um grid de quadrados é sobreposto à imagem, de modo que o início desse grid esteja alinhado com o início da figura a ser analisada, minimizando a porção da imagem delimitada exclusivamente ao plano de fundo (Figura 44a); 
- caixas ajustadas, onde as caixas foram sobrepostas individualmente sobre a imagem, sem sobreposição, de modo a minimizar o número de caixas necessário para cobrir a imagem (Figura $44 b)$.

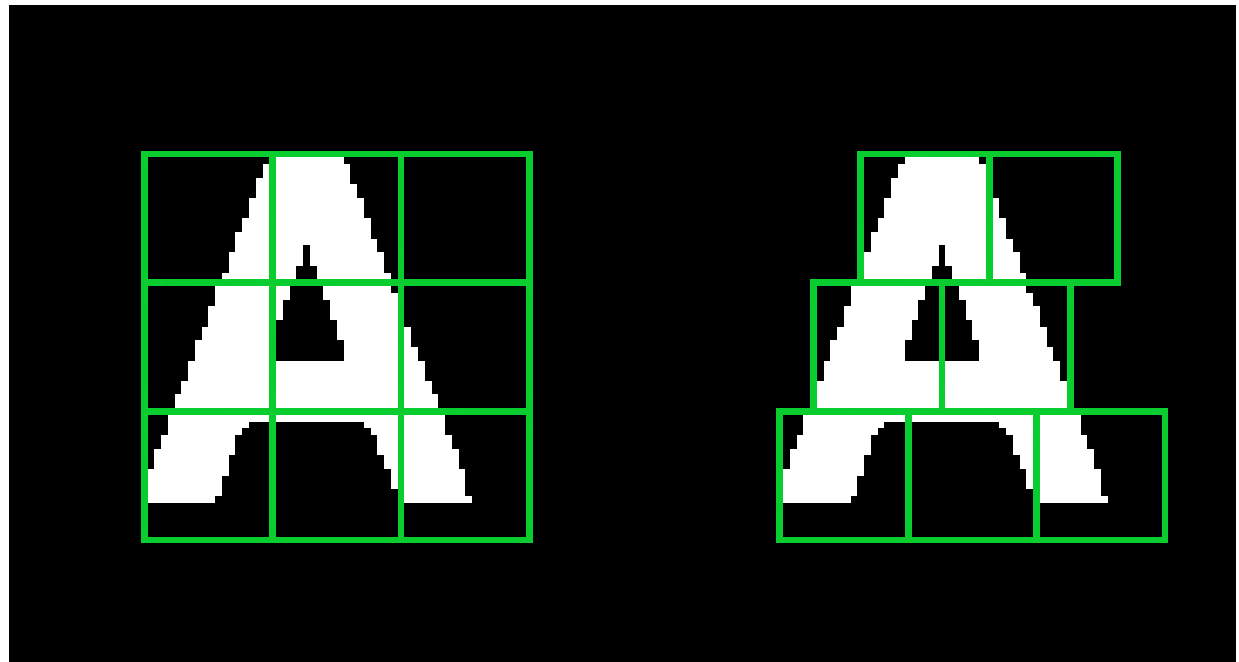

(a)

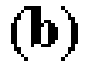

Figura 44 - Sobreposição das caixas sobre a imagem: (a) grid; (b) caixas ajustadas.

Tendo sido definido a maneira como o método seria utilizado, seguiram-se os experimentos cujos resultados podem ser vistos na Tabela 14 e na Figura 45.

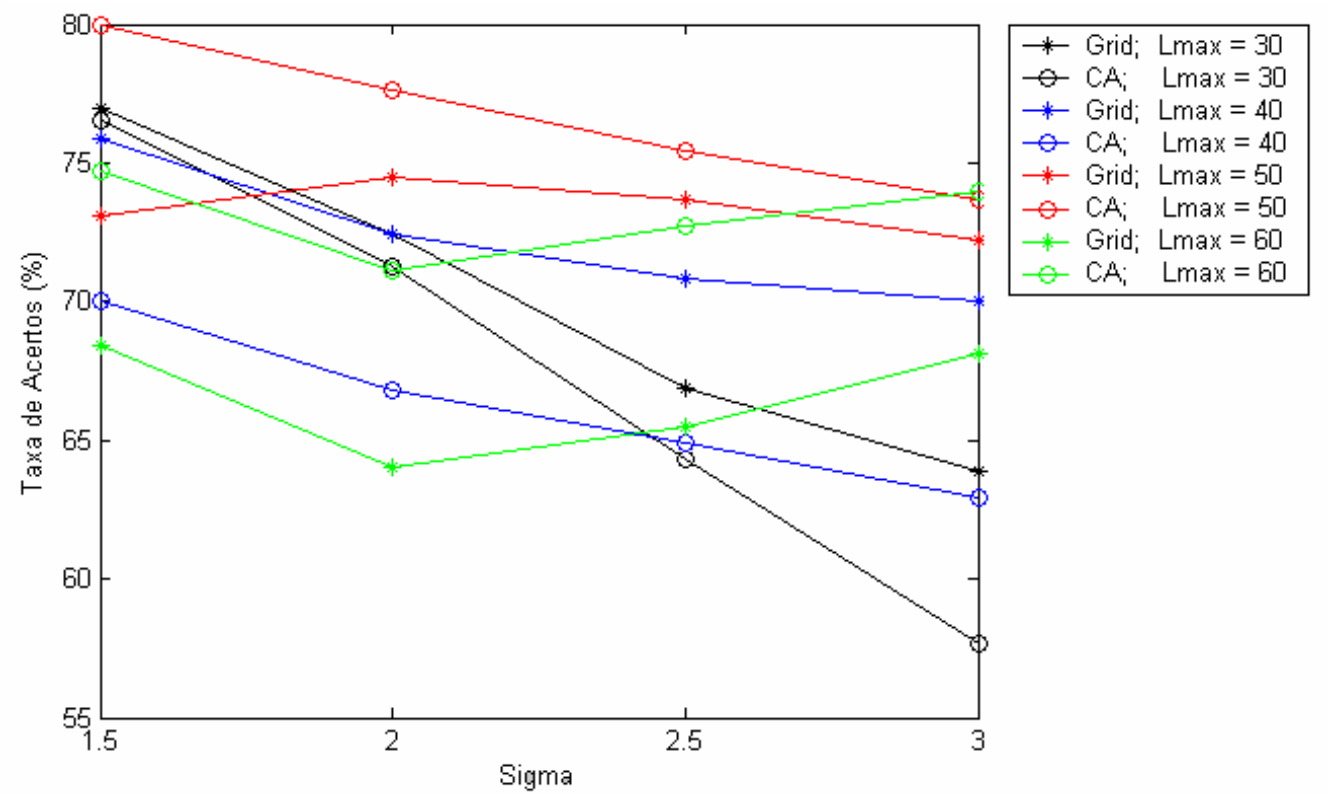

Figura 45 - Comparação dos resultados obtidos para o método BoxCounting. 


\begin{tabular}{|c|c|c|c|c|c|c|c|}
\hline \multirow{2}{*}{$\begin{array}{c}\text { Método } \\
\text { Utilizado }\end{array}$} & \multirow[b]{2}{*}{$L_{\max }$} & \multirow{2}{*}{$\begin{array}{c}\text { Sigma } \\
\text { Utilizado }\end{array}$} & \multirow{2}{*}{$\begin{array}{c}\text { Média de } \\
\text { Acertos(\%) }\end{array}$} & \multicolumn{4}{|c|}{ Acertos por Nível de Ruído(\%) } \\
\hline & & & & $\mathbf{1}^{\mathbf{0}}$ & $\mathbf{2}^{\mathbf{0}}$ & $3^{\mathbf{0}}$ & $4^{\circ}$ \\
\hline \multirow[t]{4}{*}{ Grid } & \multirow[t]{4}{*}{20} & 1,5 & 53,65 & 52,69 & 63,85 & 64,62 & 33,46 \\
\hline & & 2,0 & 50,10 & 43,85 & 62,69 & 62,69 & 31,15 \\
\hline & & 2,5 & 53,65 & 52,69 & 63,85 & 64,62 & 33,46 \\
\hline & & 3,0 & 45,48 & 40,38 & 57,31 & 54,62 & 29,62 \\
\hline \multirow[t]{4}{*}{ Caixas Ajustadas } & \multirow[t]{4}{*}{20} & 1,5 & 54,52 & 70,77 & 63,85 & 55,77 & 27,69 \\
\hline & & 2,0 & 47,40 & 53,46 & 57,31 & 55,00 & 23,85 \\
\hline & & 2,5 & 43,46 & 47,31 & 53,08 & 52,31 & 21,15 \\
\hline & & 3,0 & 38,85 & 36,92 & 47,69 & 48,85 & 21,92 \\
\hline \multirow[t]{4}{*}{ Grid } & \multirow[t]{4}{*}{30} & 1,5 & 77,02 & 88,46 & 86,92 & 82,69 & 50,00 \\
\hline & & 2,0 & 72,40 & 76,15 & 87,31 & 80,38 & 45,77 \\
\hline & & 2,5 & 66,92 & 63,85 & 85,77 & 77,69 & 40,38 \\
\hline & & 3,0 & 63,94 & 56,92 & 83,08 & 76,54 & 39,23 \\
\hline \multirow[t]{4}{*}{ Caixas Ajustadas } & \multirow[t]{4}{*}{30} & 1,5 & 76,54 & 84,23 & 85,77 & 84,62 & 51,54 \\
\hline & & 2,0 & 71,35 & 73,85 & 83,08 & 83,46 & 45,00 \\
\hline & & 2,5 & 64,33 & 59,23 & 78,46 & 78,46 & 41,15 \\
\hline & & 3,0 & 57,79 & 44,62 & 74,23 & 73,85 & 38,46 \\
\hline \multirow[t]{4}{*}{ Grid } & \multirow[t]{4}{*}{40} & 1,5 & 75,96 & 83,46 & 84,23 & 80,38 & 55,77 \\
\hline & & 2,0 & 72,40 & 79,23 & 81,15 & 76,92 & 52,31 \\
\hline & & 2,5 & 70,87 & 73,85 & 81,15 & 77,31 & 51,15 \\
\hline & & 3,0 & 70,00 & 72,31 & 79,62 & 78,08 & 50,00 \\
\hline \multirow[t]{4}{*}{ Caixas Ajustadas } & \multirow[t]{4}{*}{40} & 1,5 & 70,00 & 74,62 & 76,54 & 74,23 & 54,62 \\
\hline & & 2,0 & 66,83 & 73,46 & 71,92 & 71,92 & 50,00 \\
\hline & & 2,5 & 64,90 & 68,85 & 71,15 & 71,15 & 48,46 \\
\hline & & 3,0 & 62,98 & 66,92 & 69,23 & 70,77 & 45,00 \\
\hline \multirow[t]{4}{*}{ Grid } & \multirow[t]{4}{*}{50} & 1,5 & 73,17 & 70,00 & 81,15 & 83,46 & 58,08 \\
\hline & & 2,0 & 74,52 & 76,15 & 81,92 & 81,15 & 58,85 \\
\hline & & 2,5 & 73,75 & 76,92 & 83,46 & 80,38 & 54,23 \\
\hline & & 3,0 & 72,21 & 72,69 & 82,69 & 80,38 & 53,08 \\
\hline \multirow[t]{4}{*}{ Caixas Ajustadas } & \multirow[t]{4}{*}{50} & 1,5 & 80,10 & 91,54 & 86,15 & 85,38 & 57,31 \\
\hline & & 2,0 & 77,69 & 85,00 & 83,85 & 81,92 & 60,00 \\
\hline & & 2,5 & 75,48 & 78,46 & 83,08 & 81,92 & 58,46 \\
\hline & & 3,0 & 73,75 & 76,54 & 83,08 & 81,15 & 54,23 \\
\hline \multirow[t]{4}{*}{ Grid } & \multirow[t]{4}{*}{60} & 1,5 & 68,46 & 62,31 & 81,92 & 79,62 & 50,00 \\
\hline & & 2,0 & 64,04 & 51,54 & 77,69 & 75,77 & 51,15 \\
\hline & & 2,5 & 65,58 & 54,62 & 77,69 & 76,92 & 53,08 \\
\hline & & 3,0 & 68,17 & 60,38 & 80,38 & 77,69 & 54,23 \\
\hline \multirow[t]{4}{*}{ Caixas Ajustadas } & 60 & 1,5 & 74,71 & 69,23 & 86,54 & 83,85 & 59,23 \\
\hline & & 2,0 & 71,15 & 57,69 & 85,00 & 83,08 & 58,85 \\
\hline & & 2,5 & 72,79 & 63,08 & 86,15 & 82,69 & 59,23 \\
\hline & & 3,0 & 74,04 & 66,54 & 86,92 & 83,46 & 59,23 \\
\hline
\end{tabular}

Tabela 14 - Configurações e resultados obtidos para o método BoxCounting. 
A partir dos resultados obtidos com o experimento pode-se concluir que o método sofre influência direta do $L_{\max }$ utilizado e, conseqüentemente, do conjunto de caixas estipulado. É possível notar um aumento na taxa de acerto à medida que o valor de $L_{\max }$ aumenta. No entanto, esta não é uma regra, uma vez que também é possível notar que a taxa de acerto pode às vezes diminuir ao se aumentar o valor de $L_{\max }$.

Ao se aumentar o valor de $L_{\max }$, ocorre uma aumento na informação contida na curva MultiEscala, uma vez que o método é calculado para um conjunto maior de caixas. No entanto, a partir de certo valor de $L_{\max }$, a curva de $\log$-log tende a se tornar constante, não oferecendo nenhuma nova informação útil para a caracterização da imagem. Essa região de derivada igual a zero presente na curva diminui a diferença existente entre curvas distintas, provocando possíveis classificações incorretas, conseqüentemente diminuindo a taxa de acertos (Figura 46).

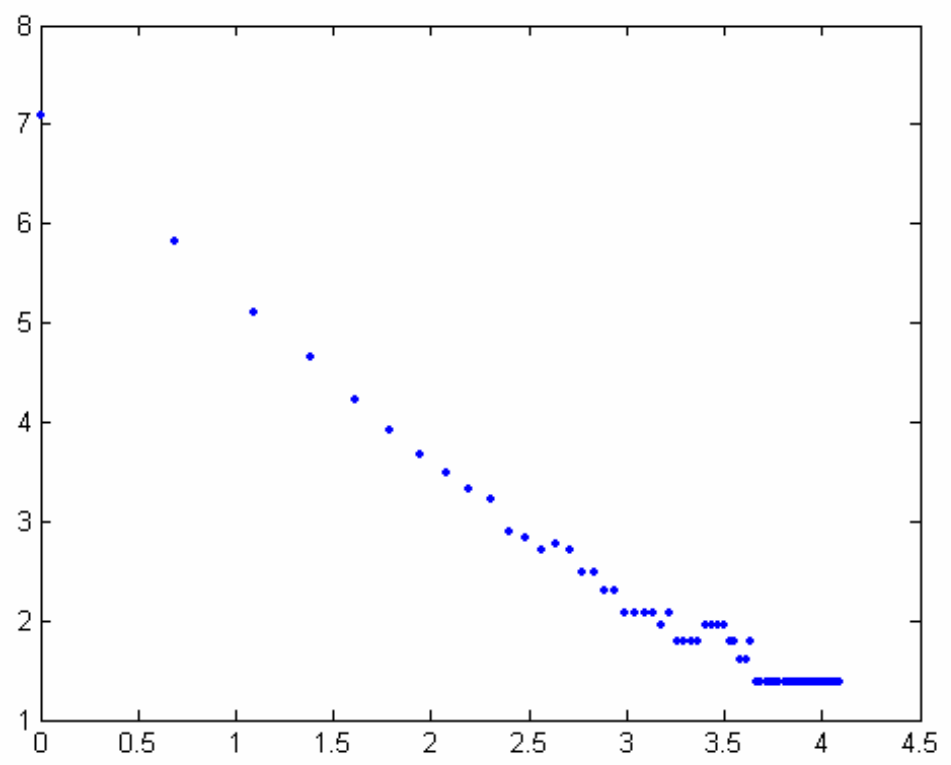

Figura 46 - Curva log-log com trechos constantes, onde a derivada é igual a zero.

Partindo-se dos resultados obtidos para cada um dos quatro níveis de ruído, pode-se notar que a curva MultiEscala obtida a partir do método BoxCounting apresenta tolerância a certos níveis de ruído presentes na forma analisada. Percebe-se que certas configurações apresentam essa tolerância reduzida, e que, de modo geral, a taxa de acertos diminui acentuadamente no $4^{\circ}$ nível de ruído. 
Com relação à disposição das caixas sobre a imagem, não se pôde concluir qual dos dois tipos de alinhamentos apresenta melhores resultados. Isso porque ambos os tipos de alinhamentos apresentaram resultados próximos, sendo um tipo de alinhamento um pouco melhor que o outro, dependendo do valor de $L_{\max }$ utilizado.

Além das configurações referentes à disposição das caixas e ao $L_{\max }$ utilizados, nota-se que o valor do parâmetro Sigma também exerce certa influência sobre os resultados de classificação obtidos. Esse valor é referente ao coeficiente de suavização da curva MultiEscala, o qual é responsável por uma presença maior ou menor de detalhes na curva (Figura 47). Nota-se que valores maiores para o parâmetro Sigma provocam uma suavização excessiva da curva MultiEscala, suprimindo detalhes, as vezes, importantes, acarretando uma diminuição na taxa de acerto dos resultados.

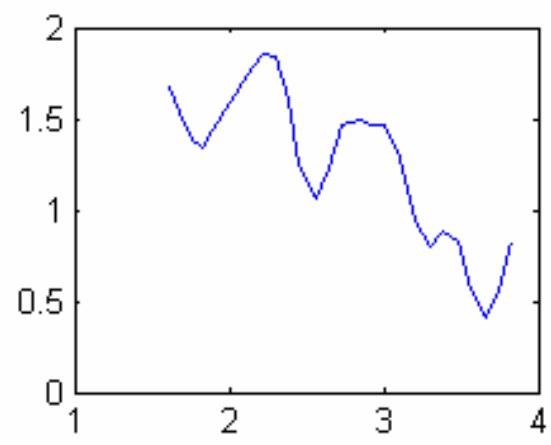

(a)

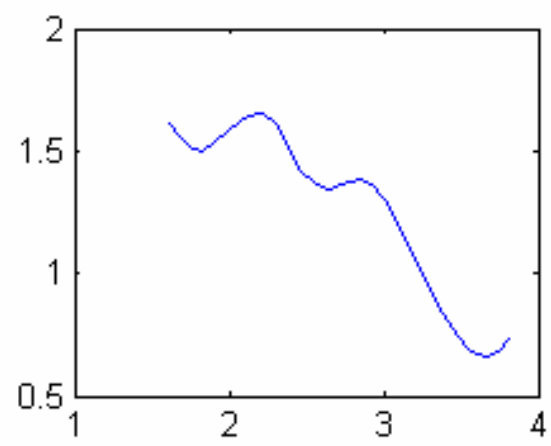

(c)

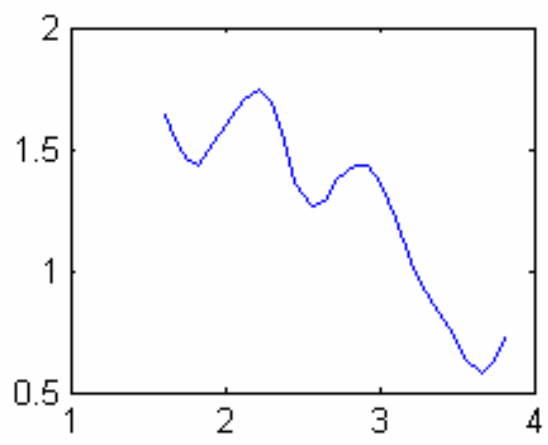

(b)

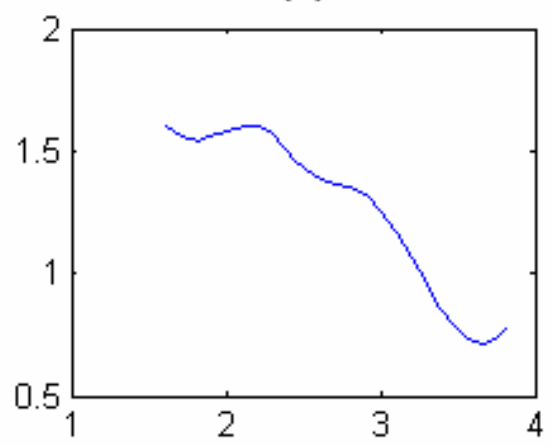

(d)

Figura 47 - Curvas MultiEscala obtidas pelo método BoxCounting: (a)Sigma = 1,5; (b)Sigma = 2,0; (c)Sigma = 2,5; (d)Sigma = 3,0.

De modo geral esse método apresenta resultados satisfatórios, mas inferiores aos obtidos com os métodos Massa-Raio e Intersecções Acumulativas. Além disso, tais resultados apenas são obtidos se observadas as restrições acima citadas. 


\subsubsection{Método Dividers}

Como os demais métodos analisados, o método Dividers também apresenta certas restrições que devem ser respeitadas para sua utilização no conjunto de amostras previamente selecionado para análise. Tais restrições se referem principalmente à escolha do ponto inicial para o cálculo do comprimento da curva. Em curvas abertas, esse ponto pode ser tomado como o ponto inicial da curva. No entanto, em curvas fechadas como os contornos de formas, essa escolha pode ser um processo empírico, o que por sua vez provoca variações nos resultados de uma execução para outra (Figura 48).

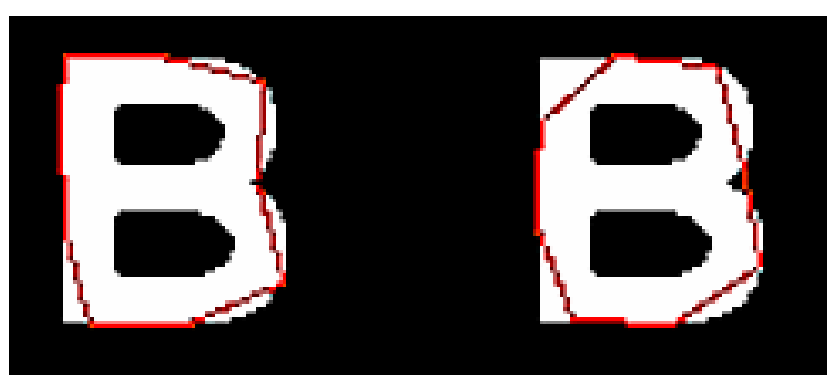

Figura 48 - Execuções do Dividers para um mesmo tamanho de ruler, mas pontos iniciais distintos.

Uma solução para isso é a utilização de vários pontos iniciais para o cálculo do comprimento, sendo o comprimento final do contorno obtido como sendo a média das várias execuções realizadas.

Outro problema encontrado para a utilização desse método se refere ao conjunto de rulers a serem utilizados no cálculo das diversas iterações do método. Como no método BoxCounting, a utilização de um conjunto muito pequeno de rulers produz uma curva log-log com poucos pontos, o que torna inviável o cálculo da curva MultiEscala. Sendo assim, optou-se aqui também por definir um conjunto maior de rulers, sendo o método calculado inicialmente para um ruler de comprimento igual a 2, sendo esse comprimento incrementado a cada nova iteração, até atingir um comprimento máximo $R_{\max }$.

Apenas para manter uma configuração padrão do método durante todo o processo de análise, o comprimento do contorno da forma foi medido sempre no sentido horário, uma vez que contornos fechados permitem essa medição em ambos os sentidos: horário e anti-horário. 
Tendo sido definida a maneira como o método seria utilizado, seguiram-se os experimentos cujos resultados podem ser vistos na Tabela 15 e na Figura 49.

\begin{tabular}{|c|c|c|c|c|c|c|c|}
\hline \multirow{2}{*}{$\begin{array}{l}\text { Pontos } \\
\text { Iniciais }\end{array}$} & \multirow[b]{2}{*}{$\boldsymbol{R}_{\max }$} & \multirow{2}{*}{$\begin{array}{c}\text { Sigma } \\
\text { Utilizado } \\
\end{array}$} & \multirow{2}{*}{$\begin{array}{c}\text { Média de } \\
\text { Acertos }(\%)\end{array}$} & \multicolumn{4}{|c|}{ Acertos por Nível de Ruído(\%) } \\
\hline & & & & $\mathbf{1}^{\mathbf{0}}$ & $2^{\circ}$ & $3^{\circ}$ & $4^{\circ}$ \\
\hline \multirow[t]{4}{*}{1} & \multirow[t]{4}{*}{30} & 1,5 & 21,15 & 22,31 & 23,85 & 21,92 & 16,54 \\
\hline & & 2,0 & 22,02 & 24,62 & 23,46 & 23,08 & 16,92 \\
\hline & & 2,5 & 21,54 & 24,23 & 21,15 & 23,08 & 17,69 \\
\hline & & 3,0 & 21,44 & 23,46 & 18,08 & 25,00 & 19,23 \\
\hline \multirow[t]{4}{*}{10} & \multirow[t]{4}{*}{30} & 1,5 & 44,33 & 47,69 & 46,15 & 47,31 & 36,15 \\
\hline & & 2,0 & 45,29 & 48,85 & 48,08 & 47,31 & 36,92 \\
\hline & & 2,5 & 45,67 & 48,08 & 48,08 & 49,62 & 36,92 \\
\hline & & 3,0 & 45,67 & 47,69 & 45,00 & 51,92 & 38,08 \\
\hline \multirow[t]{4}{*}{20} & \multirow[t]{4}{*}{30} & 1,5 & 49,42 & 53,85 & 58,46 & 50,00 & 35,38 \\
\hline & & 2,0 & 53,17 & 57,69 & 62,69 & 53,08 & 39,23 \\
\hline & & 2,5 & 54,90 & 60,00 & 62,69 & 55,00 & 41,92 \\
\hline & & 3,0 & 54,23 & 60,77 & 62,31 & 53,46 & 40,38 \\
\hline \multirow[t]{4}{*}{1} & \multirow[t]{4}{*}{40} & 1,5 & 15,87 & 15,38 & 15,77 & 15,77 & 16,54 \\
\hline & & 2,0 & 17,98 & 16,92 & 14,62 & 20,00 & 20,38 \\
\hline & & 2,5 & 18,17 & 17,31 & 14,62 & 20,00 & 20,77 \\
\hline & & 3,0 & 17,88 & 17,69 & 13,46 & 20,38 & 20,00 \\
\hline \multirow[t]{4}{*}{10} & \multirow[t]{4}{*}{40} & 1,5 & 32,60 & 34,62 & 33,08 & 34,23 & 28,46 \\
\hline & & 2,0 & 32,60 & 33,08 & 33,08 & 35,00 & 29,23 \\
\hline & & 2,5 & 32,60 & 32,69 & 32,31 & 34,23 & 31,15 \\
\hline & & 3,0 & 32,40 & 32,31 & 34,23 & 33,46 & 29,62 \\
\hline \multirow[t]{4}{*}{20} & \multirow[t]{4}{*}{40} & 1,5 & 46,15 & 51,54 & 48,46 & 45,77 & 38,85 \\
\hline & & 2,0 & 47,40 & 50,77 & 50,38 & 46,92 & 41,54 \\
\hline & & 2,5 & 48,37 & 53,46 & 50,00 & 48,46 & 41,54 \\
\hline & & 3,0 & 48,94 & 53,46 & 49,62 & 50,38 & 42,31 \\
\hline \multirow[t]{4}{*}{1} & \multirow[t]{4}{*}{50} & 1,5 & 10,00 & 10,38 & 10,38 & 11,15 & 8,08 \\
\hline & & 2,0 & 9,81 & 11,15 & 10,38 & 10,00 & 7,69 \\
\hline & & 2,5 & 9,71 & 11,15 & 10,38 & 9,23 & 8,08 \\
\hline & & 3,0 & 10,96 & 12,69 & 11,92 & 9,62 & 9,62 \\
\hline \multirow[t]{4}{*}{10} & \multirow[t]{4}{*}{50} & 1,5 & 28,17 & 27,69 & 29,23 & 29,62 & 26,15 \\
\hline & & 2,0 & 29,81 & 30,38 & 31,15 & 33,08 & 24,62 \\
\hline & & 2,5 & 30,87 & 32,31 & 31,54 & 33,08 & 26,54 \\
\hline & & 3,0 & 30,58 & 30,77 & 29,23 & 33,46 & 28,85 \\
\hline \multirow[t]{4}{*}{20} & \multirow[t]{4}{*}{50} & 1,5 & 29,23 & 35,00 & 33,08 & 29,23 & 19,62 \\
\hline & & 2,0 & 30,87 & 35,00 & 35,00 & 32,31 & 21,15 \\
\hline & & 2,5 & 31,15 & 35,00 & 35,00 & 32,69 & 21,92 \\
\hline & & 3,0 & 32,88 & 35,77 & 38,85 & 33,46 & 23,46 \\
\hline
\end{tabular}

Tabela 15 - Configurações e resultados obtidos para o método Dividers. 


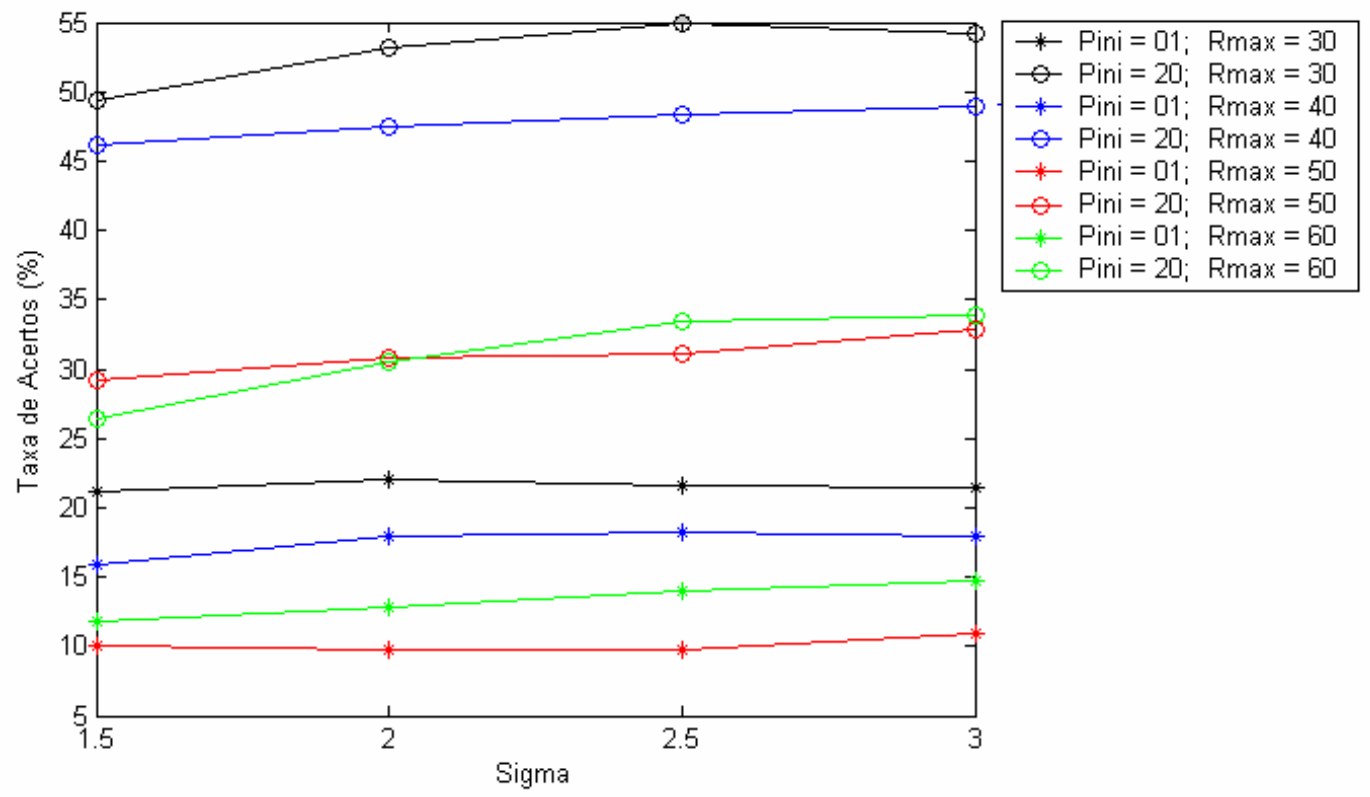

Figura 49 - Comparação dos resultados obtidos para o método Dividers.

A partir dos resultados obtidos com o experimento pode-se concluir que o método sofre influência direta do $R_{\max }$ utilizado e, conseqüientemente, do conjunto de rulers estipulado. É possível notar um aumento na taxa de acerto à medida que o valor de $R_{\max }$ aumenta. No entanto, esta não é uma regra, uma vez que também é possível notar que a taxa de acerto pode às vezes diminuir ao se aumentar o valor de $R_{\max }$.

Ao se aumentar o valor de $R_{\max }$, ocorre uma aumento na informação contida na curva MultiEscala, uma vez que o método é calculado para um conjunto maior de rulers. No entanto, a partir de certo valor de $R_{\max }$ a medição do contorno torna-se falha, pois o ruler torna-se muito grande para medir certas características presentes no contorno. Tais características são ignoradas pelo método, que acaba produzindo uma simplificação do contorno, o que pode provocar possíveis classificações incorretas e, conseqüentemente diminuir a taxa de acertos (Figura 50).

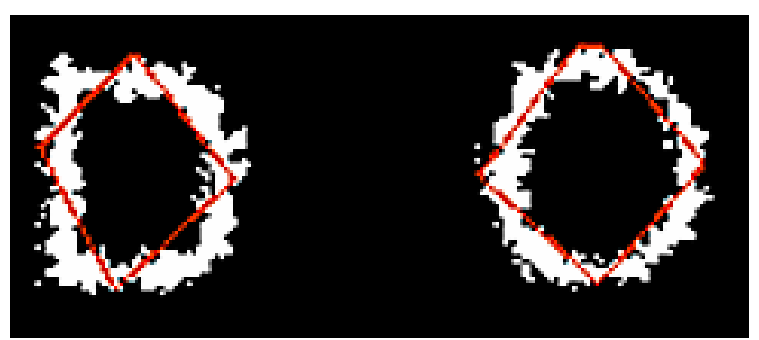

Figura 50 - Simplificação do contorno provocada pelo uso de um ruler muito grande no método Dividers. 
Outro aumento na taxa de acertos também pode ser notado quando se aumenta o número de pontos iniciais para a execução do método. Isso porque, o aumento no número de pontos iniciais provoca uma melhor amostragem do comportamento do contorno da forma, conseqüentemente melhorando a caracterização da mesma.

Partindo-se dos resultados obtidos para cada um dos quatro níveis de ruído, pode-se notar que a curva MultiEscala obtida a partir do método Dividers apresenta uma baixa tolerância a ruídos presentes na forma analisada. Isso ocorre, principalmente, por que o método Dividers utiliza apenas a informação do contorno externo da forma para a caracterização da mesma, ignorando outras informações como, por exemplo, o contorno interno que certas formas apresentam. Além disso, esse método acentua o fenômeno de Gibbs (BRIGHAM, 1988) provocado pela derivada de Fourier, tornando a curva descontinua nas suas extremidades (Figura $51)$.

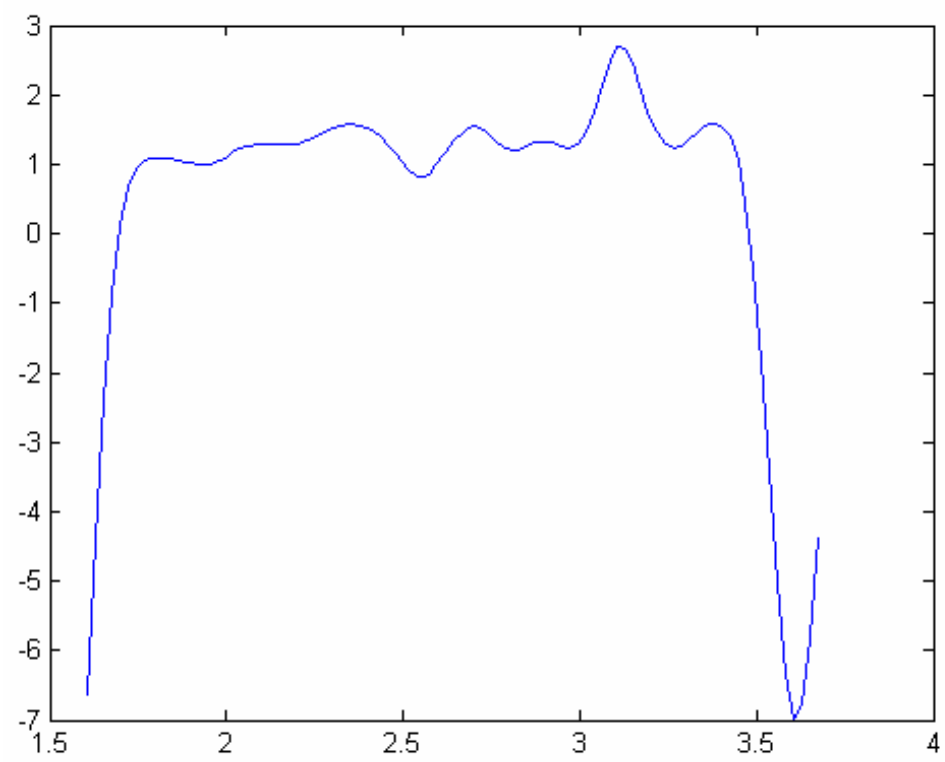

Figura 51 - Descontinuidade provocada pelo fenômeno de Gibbs na curva MultiEscala obtida pelo método Dividers.

Além das configurações referentes ao número de pontos iniciais e $R_{\max }$ utilizados, nota-se que o valor do parâmetro Sigma também exerce uma certa influência sobre os resultados de classificação obtidos. Esse valor é referente ao coeficiente de suavização da curva MultiEscala, o qual é responsável por uma presença maior ou menor de detalhes na curva (Figura 52). Diferentes 
das outras curvas MultiEscala obtidas, nota-se que valores maiores para o parâmetro Sigma provocam uma suavização maior da curva MultiEscala, suprimindo uma maior taxa de ruído, provocando um aumentando na taxa de acerto dos resultados.

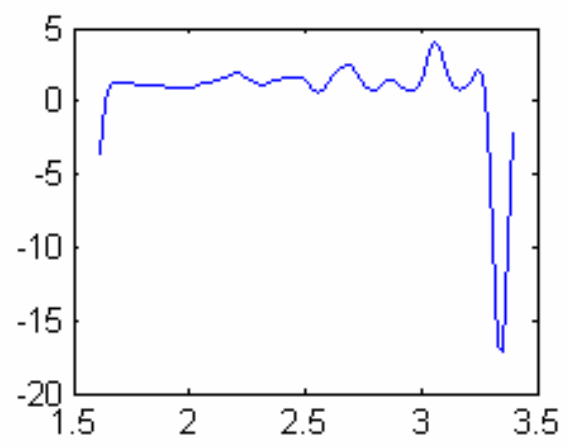

(a)

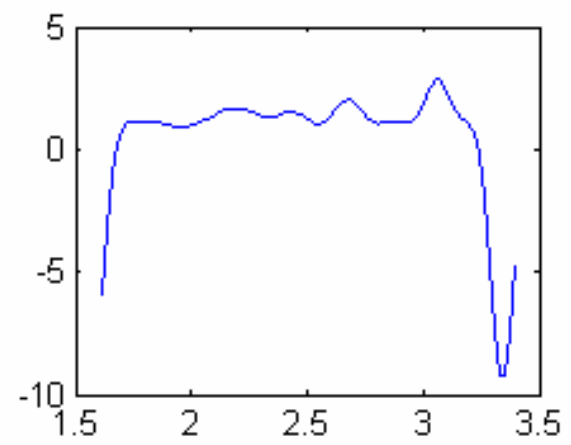

(c)

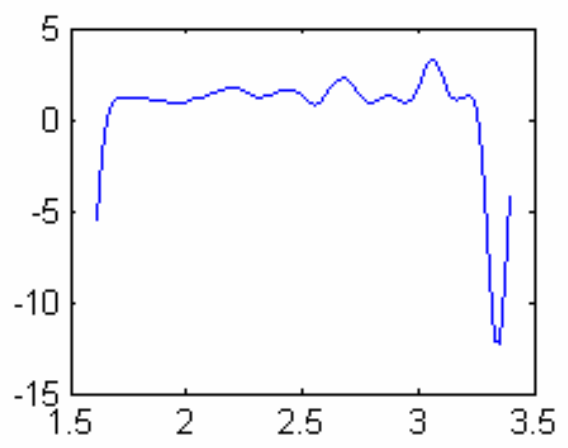

(b)

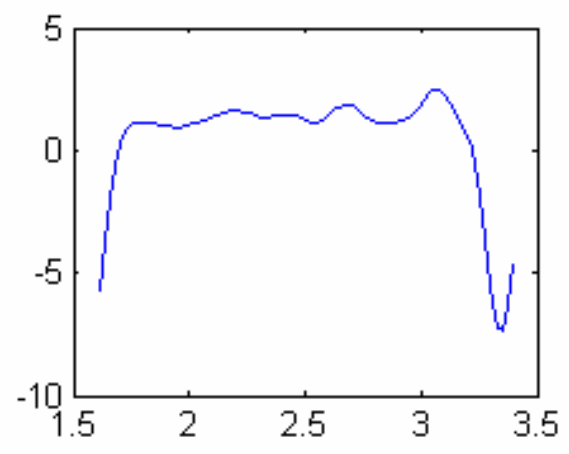

(d)

Figura 52 - Curvas MultiEscala obtidas pelo método Dividers: (a)Sigma = 1,5; (b)Sigma = 2,0; (c)Sigma = 2,5; (d)Sigma $=\mathbf{3 , 0}$.

De modo geral, o método apresentou resultados abaixo das expectativas, devido, principalmente, aos problemas relacionados à configuração do método e ao conjunto de imagens selecionado para análise.

\subsection{Comparação dos Métodos}

A partir dos experimentos de análise e classificação de imagens realizados com base nos métodos anteriormente discutidos (Minkowski, Massa-Raio, Intersecções Acumulativas, BoxCounting e Dividers) pôde-se constatar que a curva de Dimensão Fractal MultiEscala possui 
um grande potencial para a análise de formas, apresentando uma alta taxa de acertos além de grande tolerância a ruídos de diversas intensidades (Tabela 16) (Figura 53).

Com base nos resultados obtidos, pode-se concluir que os métodos que se baseiam em dilatações de círculos para a realização de seu cálculo (Minkowski, Massa-Raio e Intersecções Acumulativas) apresentam resultados mais consistentes e menos suscetíveis a ruídos. Percebe-se ainda que dentre esses métodos, os que são baseados em medidas de massa (Minkowski e MassaRaio) apresentam maior taxa de acerto. O método de Minkowski, já utilizado na literatura como base para o cálculo da curva MultiEscala, apresentou uma menor tolerância a ruídos de maior intensidade, apresentando um resultado inferior ao método Massa-Raio.

\begin{tabular}{|l|c|c|c|c|c|}
\hline \multirow{2}{*}{ Método Utilizado } & Total de & \multicolumn{4}{c|}{ Acertos por Nível de Ruído } \\
\cline { 3 - 6 } & Acertos & $\mathbf{1}^{\mathbf{0}}$ & $\mathbf{2}^{\mathbf{0}}$ & $\mathbf{3}^{\mathbf{0}}$ & $\mathbf{4}^{\mathbf{0}}$ \\
\hline Minkowski & 92,80 & 96,50 & 96,90 & 95,00 & 82,70 \\
\hline Massa-Raio & 94,23 & 95,38 & 95,77 & 93,85 & 91,92 \\
\hline Intersecções Acumulativas & 86,25 & 85,00 & 89,23 & 88,46 & 82,31 \\
\hline BoxCounting & 80,10 & 91,54 & 86,15 & 85,38 & 57,31 \\
\hline Dividers & 54,90 & 60,00 & 62,69 & 55,00 & 41,92 \\
\hline
\end{tabular}

Tabela 16 - Melhores resultados obtidos para cada método.

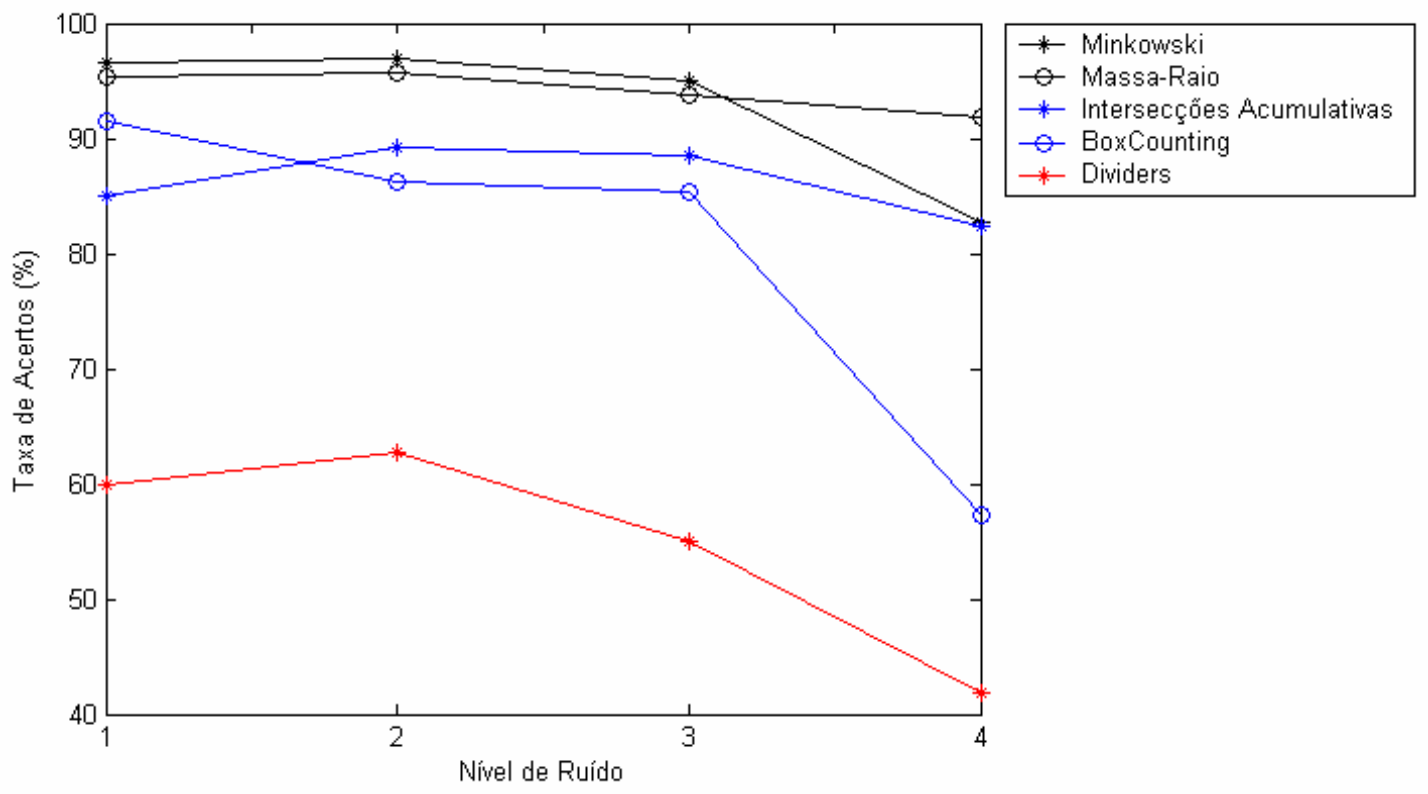

Figura 53 - Comparação da tolerância a ruídos de cada método.

Apesar da curva MultiEscala obtida a partir do método Dividers apresentar um resultado inferior ao obtido com os outros métodos, este algoritmo foi o que apresentou melhor desempenho em termos de velocidade de cálculo (Tabela 17) (Figura 54). Por outro lado, o 
método Minkowski foi o que apresentou o pior desempenho em termos de velocidade, excedendo os demais métodos em tempo de cálculo. Com relação à velocidade de cálculo, o método de Massa-Raio demonstrou-se também superior ao Minkowski, mas inferior aos demais métodos.

\begin{tabular}{|l|c|}
\hline \multicolumn{1}{|c|}{ Método Utilizado } & Tempo de Execucão (ms) \\
\hline Minkowski & 2.628 \\
\hline Massa-Raio & 671 \\
\hline Intersecç̃̃es Acumulativas & 96 \\
\hline BoxCounting & 116 \\
\hline Dividers & 61 \\
\hline
\end{tabular}

Tabela 17 - Tempo necessário para o cálculo da curva MultiEscala em cada método.

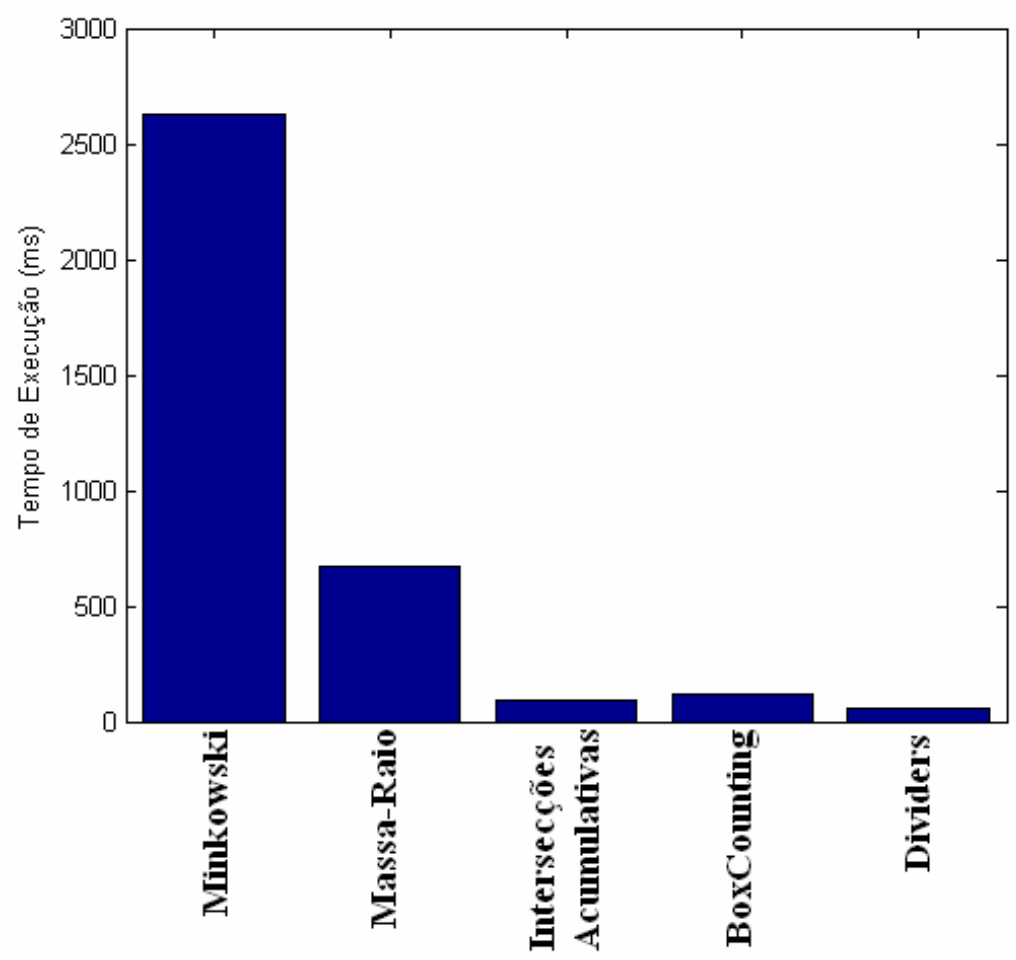

Figura 54 - Comparação do tempo necessário para o cálculo da curva MultiEscala em cada método.

Os métodos de Intersecções Acumulativas e BoxCounting também demonstraram um bom desempenho em termos de velocidade de cálculo. Apesar de o Dividers obter o melhor resultado em termos de velocidade de cálculo, seus resultados de classificação ficaram abaixo das expectativas quando comparados com os obtidos com os demais métodos. Isso se deve aos problemas relacionados à sua configuração e ao conjunto de imagens selecionado para análise. 
Embora esses resultados pudessem ter sido melhorados significativamente por meio de mecanismos mais eficientes de classificação como, por exemplo, redes neurais artificiais, os resultados demonstram o potencial da técnica MultiEscala na análise e classificação de imagens. 


\section{Análise de Texturas}

A textura constitui uma característica diretamente relacionada com as propriedades físicas que a superfície de um objeto apresenta, descrevendo o padrão de variação de tons de cinza ou cor numa determinada área. Trata-se de um termo intuitivo e de largo emprego, mas que apesar de sua grande importância, não possui uma definição precisa (EBERT, 1994).

Uma textura se caracteriza pela repetição de um modelo sobre uma região, sendo que este modelo pode ser repetido de forma exata ou com pequenas variações. Através de sua análise é possível distinguir regiões que apresentem as mesmas características de refletância (e portando mesmas cores em determinada combinação de bandas). Isso torna a textura um excelente descritor regional, contribuindo para uma melhor precisão do processo de reconhecimento, descrição e classificação de imagens. Apesar de seus benefícios, seu processo de reconhecimento exige um alto nível de sofisticação e complexidade computacional (EBERT, 1994). Diversas abordagens encontradas na literatura operaram sobre texturas, realizando análise ou segmentação.

Nessa etapa do trabalho foram utilizadas as técnicas de lacunaridade e Dimensão Fractal (BoxCounting) afim de obter uma assinatura para as texturas analisadas. Tais assinaturas foram utilizadas para segmentar as imagens, de modo a obter diferentes regiões de similaridade através do uso de análise de aglomerados.

\subsection{Assinatura}

A assinatura de uma imagem pode ser definida como uma função ou matriz simplificada que consiga representar ou caracterizar a mesma. Em geral as técnicas utilizadas realizam transformações $T: I^{2} \rightarrow R$ ou $T: I^{2} \rightarrow I$, onde a função ou vetor de característica obtido é capaz de representar e caracterizar a imagem. Exemplos e teorias sobre assinaturas podem ser encontrados em (CASTLEMAN, 1996) (GONZALEZ; WOODS, 1992).

Neste trabalho a lacunaridade e o BoxCounting foram utilizadas como técnicas plausíveis de caracterizar uma imagem pela sua textura e deste modo foram consideradas neste trabalho como técnicas de assinatura de textura de imagens. 
Tanto a lacunaridade quando a Dimensão Fractal por BoxCounting, ainda podem ser exploradas com uma abordagem MultiEscala, permitindo obter assinaturas que aferem o comportamento da imagem, região ou objeto em função da escala de observação. Isto é possível, através do seu cálculo para diferentes tamanhos de caixas, uma vez que ambas são características dependentes da escala. Deste modo, é possível representar o comportamento da textura de uma imagem por uma função 1-D que relaciona o tamanho da caixa utilizada no cálculo com o valor da lacunaridade ou da Dimensão Fractal obtido, apresentando informações MultiEscala (Figura $55)$.
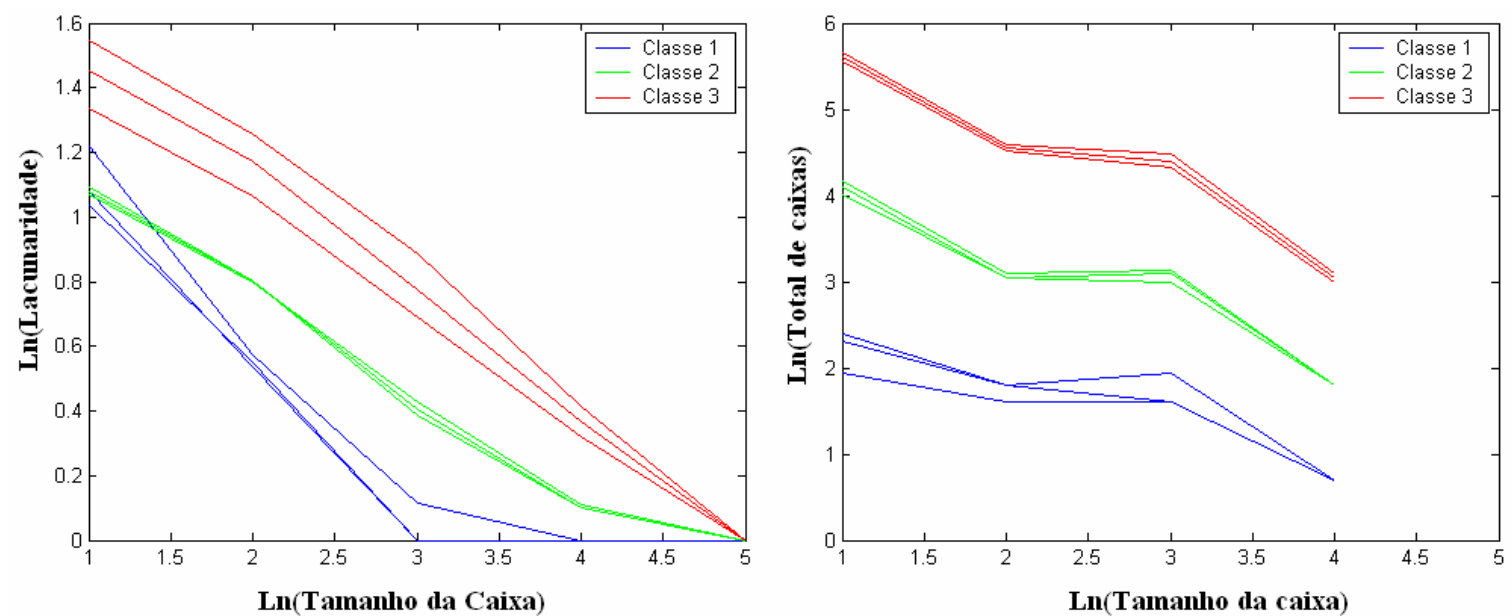

Figura 55 - Gráfico log-log da lacunaridade e da Dimensão Fractal pelo tamanho da caixa.

\subsection{Análise de Aglomerados}

A análise de aglomerados é adotada na Ciência da Computação em problemas que envolvem classificação de dados multivariados. Estes surgem freqüentemente em áreas tais como mineração de dados, processamento de imagens, visualização científica entre outras. Existem diversos algoritmos para realizar a análise de aglomerados, que fornecem uma metodologia para explorar e verificar as estruturas presentes nos dados, organizando-os em diferentes grupos ou aglomerados. Essa organização é realizada com base em medidas de similaridades e dissimilaridades (distâncias), de modo a agrupar objetos semelhantes segundos suas características (variáveis) (FRED, 001) (DUDA et. al, 2001).

Neste trabalho foi adotado o algoritmo de K-means como técnica de classificação, o qual particiona um conjunto de dados em $K$ aglomerados. Esses aglomerados são formados com base 
em alguma medida de similaridade, sendo que o algoritmo ainda faz uso de uma técnica de realocação iterativa de modo a encontrar um local ótimo (DUDA et. al, 2001).

Basicamente o algoritmo de K-means começa inicializando um conjunto de $K$ centróides para os aglomerados. Cada ponto do conjunto de dados é então associado ao aglomerado com centróide mais próximo. Em seguida os centróides são recalculados. Esse processo é repetido até que os centróides não sejam mais alterados (DUDA et. al, 2001). O critério de agrupamento do K-Means pode ser descrito como sendo

$$
E=\sum_{k=1}^{K} \sum_{x_{i} \in C_{k}} d\left(x_{i}, x_{0 k}\right)
$$

onde $x_{0 k}$ é o centróide do aglomerado $C_{k}$ e $d\left(x_{i}, x_{0 k}\right)$ é a distancia entre os pontos $x_{i}$ e $x_{0 k}$. O centróide pode ser a média ou a mediana de um grupo de pontos. Em outras palavras, o objetivo do K-means é minimizar a distância entre cada ponto e o seu respectivo centróide (HALKIDI et. al, 2001). Em (DUDA et. al, 2001) é encontrada uma explanação mais detalhada sobre o método K-means e sobre a análise de aglomerados.

\subsection{Experimentos e Resultados}

Visando comprovar e comparar a eficiência da lacunaridade e da Dimensão Fractal por BoxCounting como métodos de segmentação de textura, foram selecionadas imagens médicas e de imagens formadas por texturas de Brodatz. Nelas os métodos foram aplicados, sendo também aqui apresentada uma discussão a respeito dos resultados obtidos.

A base do algoritmo de segmentação consistiu na análise individual de pequenas regiões da imagem. Está análise foi feita mediante a convolução de uma janela de dimensões $W x W$ na imagem. Para cada posição desta janela foi realizada a estimativa da lacunaridade ou da Dimensão Fractal, e o valor foi atribuído ao pixel da imagem correspondente ao centro da janela. Uma vez computados todos os elementos desta matriz, foi realizada a classificação dos aglomerados através do algoritmo K-means, resultando em uma matriz de rótulos, que apresenta o mapa de regiões aglomeradas com a mesma textura. $\mathrm{O}$ número de classes $K$, adotado no algoritmo de classificação, foi estimado visando obter o menor número de regiões diferentes, evitando assim o particionamento excessivo da imagem e o surgimento de regiões similares. 
A Tabela 18 apresenta as imagens que foram consideradas no experimento, das quais como podemos observar as duas primeiras são imagens médicas ( $\mathrm{a}$ e b) e as outras duas são mosaicos sintéticos formados por texturas de Brodatz, freqüentemente utilizadas na literatura como benchmarks para texturas. A escolha em utilizar imagens reais e imagens sintéticas de Brodatz foi feita com o intuito de testar o potencial real dos métodos.

O conjunto de caixas utilizado nos métodos de lacunaridade e Dimensão Fractal foi escolhido com base no valor da janela $W$ utilizada no experimento. Sendo assim, iniciava-se o cálculo com uma caixa de largura igual a dois, sendo esse valor incrementado a cada nova iteração do método, até que a largura da caixa atingisse o valor de $W$. Dessa maneira evita-se o uso de caixas com largura maior que $W$, as quais provocariam inconsistências nos resultados.

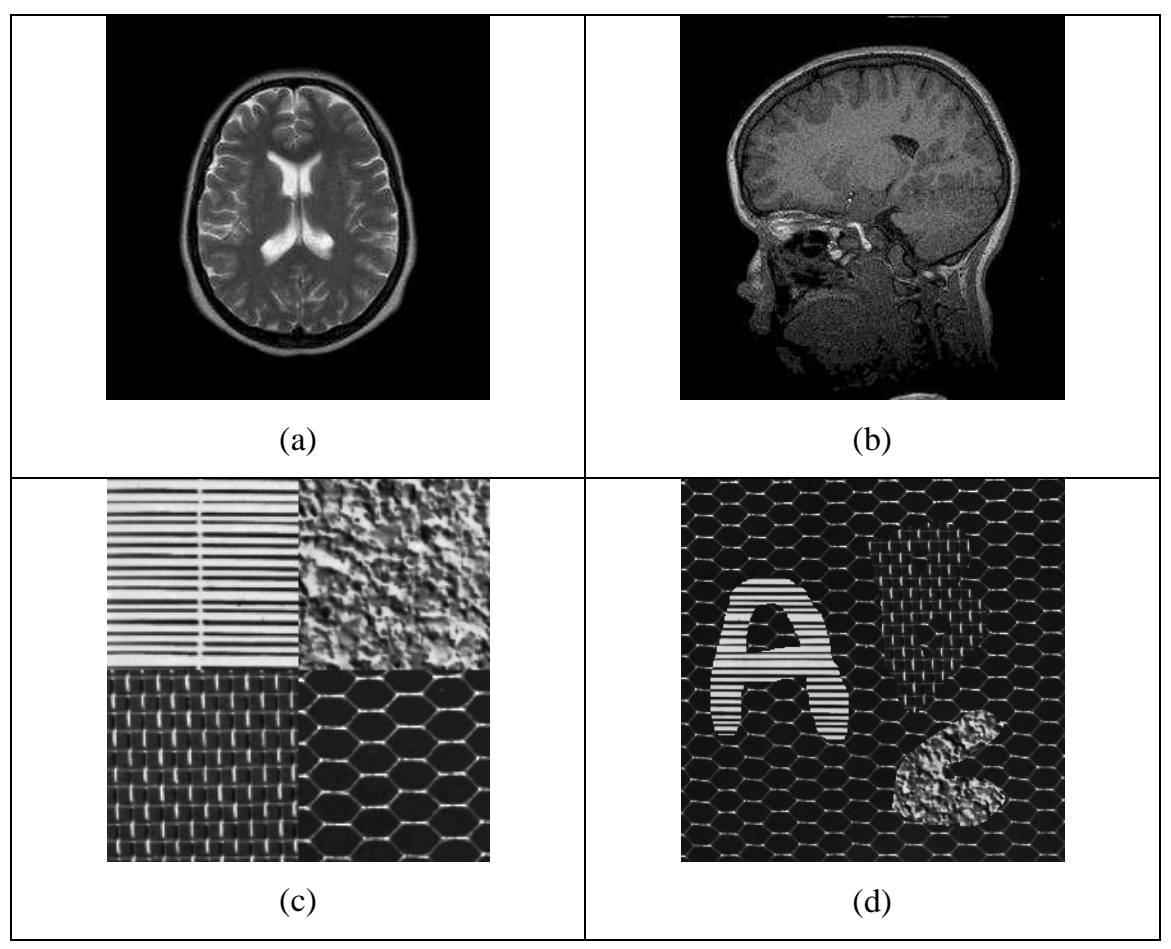

Tabela 18 - (a)-(d) Imagens selecionadas para o experimento.

Outro atributo testado se refere ao número de classes $K$ adotado no algoritmo de classificação. Durante a realização do experimento percebeu-se que um número muito pequeno de classes produzia a união de classes pouco similares. Por outro lado, o uso de um número alto de classes produziria classes altamente similares entre si.

Os resultados obtidos foram divididos em 4 tabelas: cada uma das tabelas agrupou os resultados obtidos para uma das quatro imagens contidas na Tabela 18. 
A Tabela 19 e a Tabela 20 agrupam os resultados obtidos, respectivamente, para as imagens (a) e (b) da Tabela 18. Nelas é possível perceber a importância dos parâmetros de configuração $W$, relativa à janela de amostragem da imagem, e $K$, relacionado ao número de regiões distintas que a imagem será segmentada. Por se tratarem de imagens médicas, formadas por microtexturas, faz-se necessário utilizar um valor pequeno para o parâmetro $W$. Isso por que as imagens médicas, como as obtidas por meio de Ressonância Magnética, carecem de contornos distintos que separem as diferentes regiões do órgão analisado, neste caso o cérebro. Percebe-se que a utilização de uma janela $W=3$ evita que as diferentes texturas existentes na imagem sejam unidas numa mesma janela de amostragem. Conseqüentemente, a utilização de um valor maior para a janela $W$, como $W=10$, provoca uma maior confusão nas áreas de transição entre texturas, já que esse valor de janelamento proporciona uma maior união dos diferentes tipos de texturas numa mesma janela, comprometendo a separação das mesmas em diferentes regiões, produzindo classificações errôneas. Além disso, o parâmetro $K$, o qual se refere ao número de regiões em que a imagem será dividida, se mostra igualmente importante na etapa de classificação. Nos resultados obtidos percebe-se que valores menores para o parâmetro $K$, como $K=3$, produzem uma melhor classificação das regiões. Isso ocorre, pois esse tipo de imagem possui poucas regiões com características distintas. Por outro lado, percebe-se que a utilização de um valor maior para o parâmetro $K$, como $K=6$, produz uma subdivisão excessiva das regiões, enfatizando pequenas variações existentes dentro de uma mesma região.

Os resultados obtidos para as imagens (c) e (d) da Tabela 18 foram agrupados, respectivamente, nas Tabelas 21 e 22. Esses resultados são referentes às imagens formadas por mosaicos de texturas de Brodatz. Diferente das imagens médicas, formadas por micro-texturas, esse tipo de imagem é formado por macro-texturas. Percebe-se que a utilização de um valor menor para o parâmetro $W$, como o utilizado para as micro-texturas, provoca uma subdivisão do modelo formador da textura, provocando a separação de um padrão de textura em vários e, conseqüentemente, produzindo classificações errôneas. Por meio da utilização de valores maiores para o janelamento, como $W=25$, é possível evitar essa quebra do modelo formador da textura. No entanto, valores muito grandes para $W$ devem ser utilizados com cautela, já que podem introduzir erros de classificação na faixa onde diferentes se encontram. Nos testes com esse tipo de imagem o parâmetro $K$ não foi avaliado, uma vez que o número de texturas que compunham o 
mosaico era conhecido, não fazendo sentido segmentar a imagem com um número de regiões diferentes das existentes.

Com relação aos métodos utilizados, percebe-se que a Dimensão Fractal proporcionou uma melhor segmentação quando comparada com a lacunaridade. Isso se deve pelo fato da Dimensão Fractal apresentar uma maior tolerância a pequenas variações na disposição dos pixels que formam a textura, tendo como resultado uma medida do nível de ocupação do espaço. A lacunaridade, por sua vez, mede a maneira como o espaço está preenchido, de modo que pequenas variações na disposição dos pixels provocam alterações no modo como aquela textura é percebida pelo método.

\begin{tabular}{|c|c|c|c|c|}
\hline$W$ & 10 & 5 & 3 & 3 \\
\hline $\boldsymbol{K}$ & 4 & 4 & 4 & 6 \\
\hline 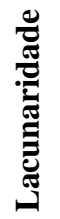 & & & & \\
\hline 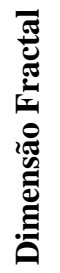 & & & & \\
\hline
\end{tabular}

Tabela 19 - Resultados dos experimentos para a imagem (a) da Tabela 18. 


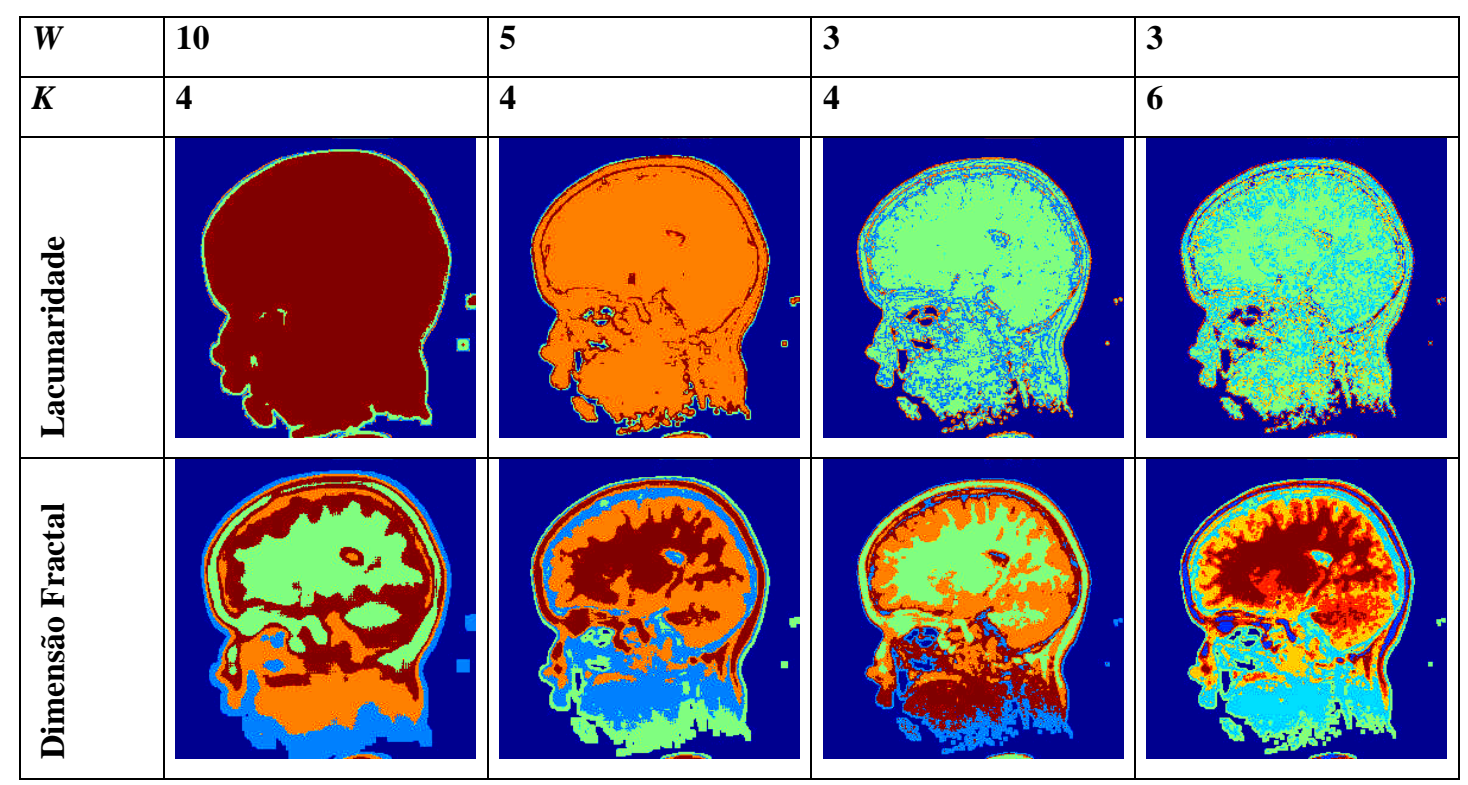

Tabela 20 - Resultados dos experimentos para a imagem (b) da Tabela 18.

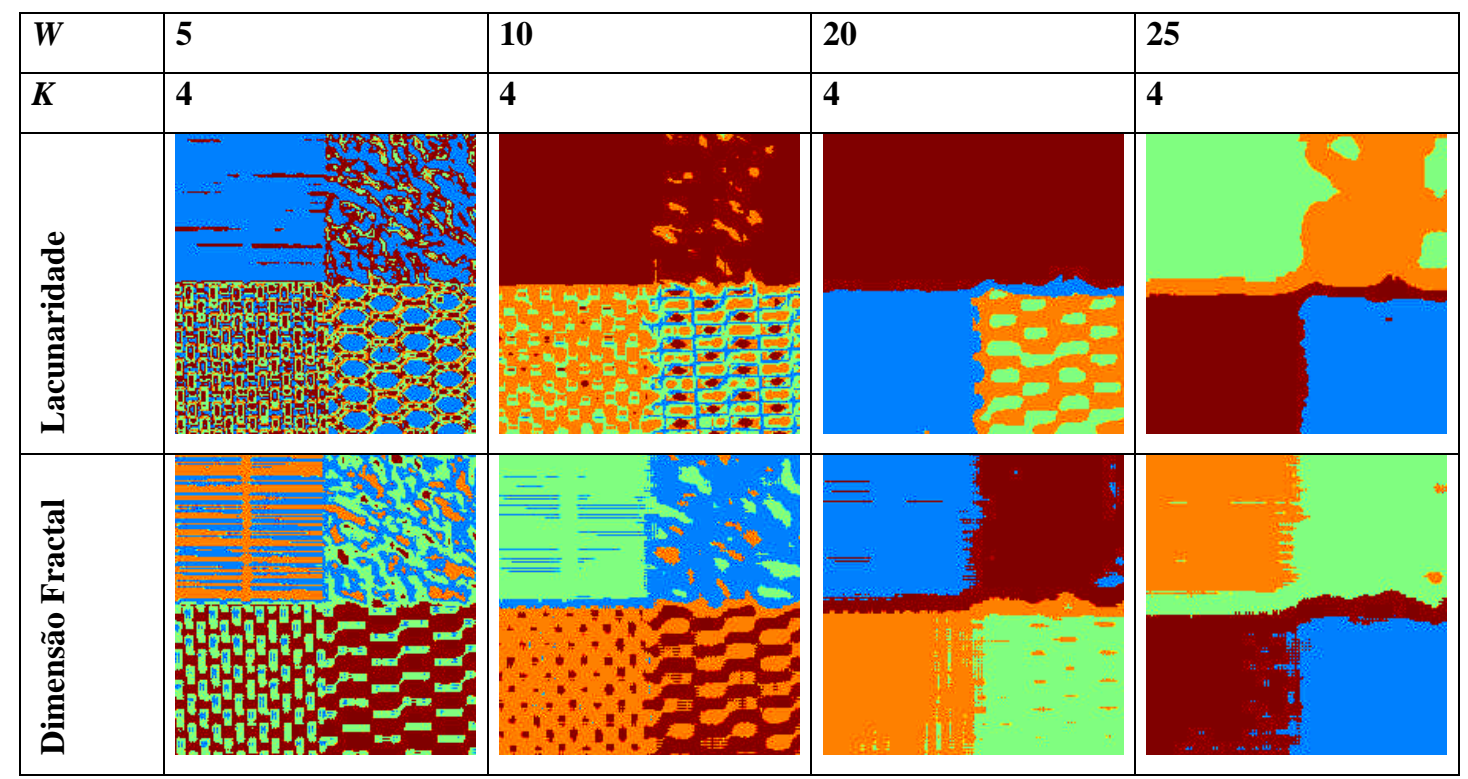

Tabela 21 - Resultados dos experimentos para a imagem (c) da Tabela 18. 


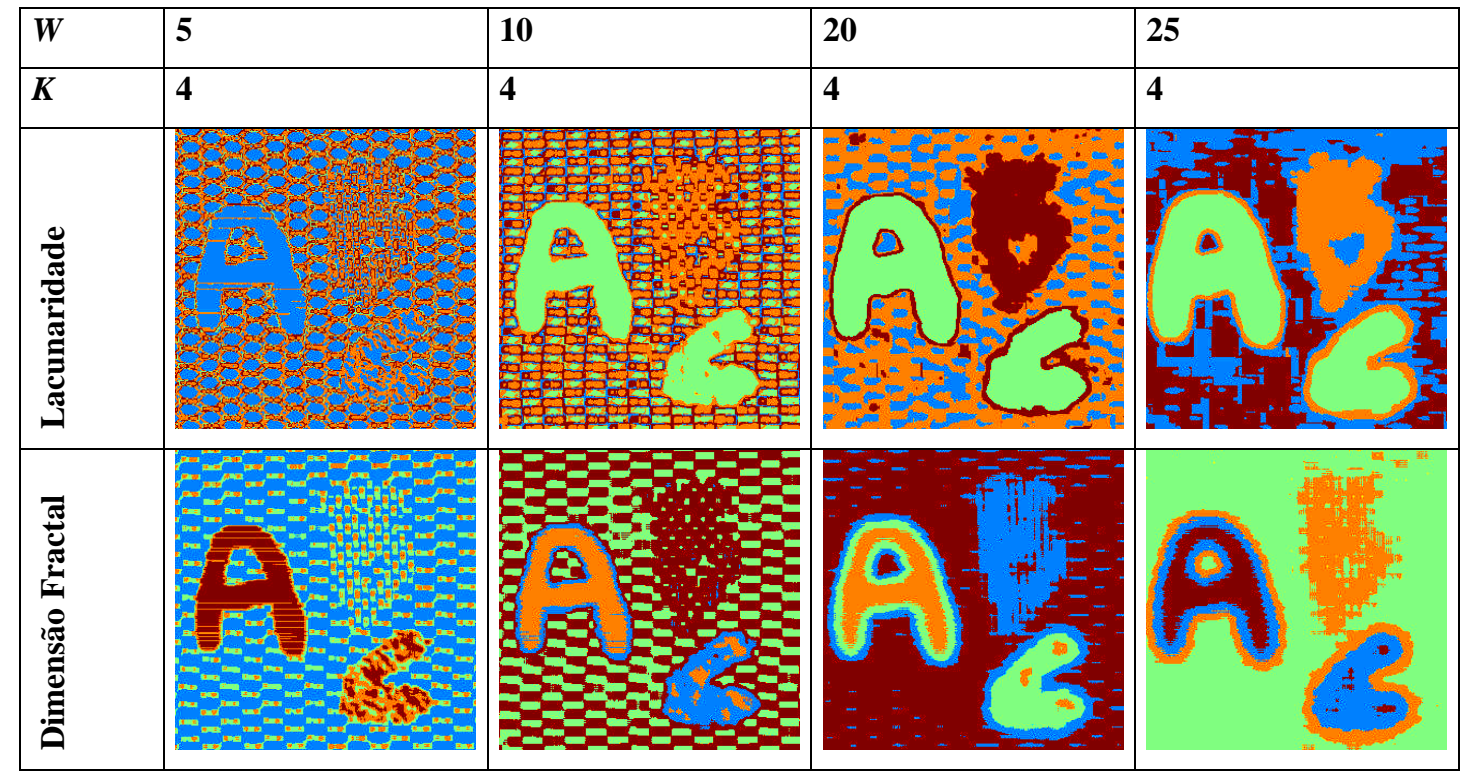

Tabela 22 - Resultados dos experimentos para a imagem (d) da Tabela 18.

A partir dos experimentos de segmentação de texturas realizados com os métodos propostos pôde-se constatar que o método baseado na Dimensão Fractal possui um grande potencial para a análise de textura. Os resultados obtidos mostraram-se satisfatórios e, apesar do uso de uma técnica menos elaborada na classificação das assinaturas em aglomerados, demonstram o potencial da técnica na segmentação de texturas reais ou sintéticas (Mosaicos formados com texturas de Brodatz).

Embora esses resultados pudessem ter sido melhorados significativamente por meio do uso de técnicas mais elaboradas de análise, tais como descritores de fourier ou wavelet, e mecanismos mais eficientes de classificação como, por exemplo, redes neurais artificiais, os resultados atenderam ao propósito do trabalho proposto nesse artigo, verificando o potencial da análise de texturas baseada na complexidade da distribuição dos pixels. 


\section{Considerações Finais}

\subsection{Conclusões}

Esta Dissertação de Mestrado teve como objetivo mostrar alguns dos principais métodos existentes na literatura atual para estimativa da Dimensão Fractal, ressaltando as características mais relevantes de cada método, além de suas vantagens e desvantagens. Durante os trabalhos de pesquisa e validação desses métodos foram estudadas diversas abordagens de aplicações para a Dimensão Fractal e para a Dimensão Fractal MultiEscala na área de Visão Computacional, privilegiando a análise e o reconhecimento de imagens e padrões.

Por meio de validação experimental puderam-se observar as restrições que cada método apresenta para a sua utilização bem como a sua configuração mais apropriada para determinado uso. Foi observado também que a má configuração de parâmetros iniciais dos métodos são responsáveis por variações e inconsistências na estimativa da Dimensão Fractal e que, dentre os métodos apresentados, o algoritmo mais eficiente e menos sujeito a estas variações e inconsistências é o Bouligand-Minkowski. Foi também demonstrado a possibilidade de se obter a curva de Dimensão Fractal MultiEscala a partir de outros métodos, além do Minkowski. Com base em experimentos de análise e classificação de imagens pôde-se comprovar seu grande potencial para análise de formas, além de serem observadas as restrições de utilização de cada curva MultiEscala bem como a sua configuração mais apropriada, a fim de evitar variações e inconsistências nos resultados de classificação.

Os trabalhos e aplicações desenvolvidos durante as etapas de pesquisa e validação dos métodos evidenciaram o fato da Dimensão Fractal ser uma excelente ferramenta para analisar e reconhecer padrões de forma e complexidade existentes em uma imagem. As aplicações e experimentos desenvolvidos no campo da Visão Computacional evidenciaram a alta tolerância a ruídos e variações que as técnicas de Dimensão Fractal e Dimensão Fractal MultiEscala apresentam, permitindo analisar e classificar formas distorcidas ou ruidosas presentes na imagem.

A partir dos resultados obtidos com os experimentos de análise e classificação de imagens realizados com as diferentes curvas MultiEscala, é possível notar que os métodos baseados em dilatações de círculos (Minkowski, Massa-Raio e Intersecções Acumulativas) apresentam 
resultados mais consistentes e menos suscetíveis a ruídos e variações. A MultiEscala obtida a partir do método Massa-Raio demonstra grande potencial de utilização, superando inclusive a MultiEscala convencional (Minkowski) em taxa de acertos e tolerância a ruídos de diversas intensidades. No entanto, a MultiEscala obtida por Massa-Raio demanda um tempo maior de processamento para ser calculada, superando os demais métodos, enquanto que a MultiEscala obtida por BoxCounting é a que demanda menos tempo de cálculo para ser obtida.

Além das aplicações já citadas envolvendo o reconhecimento de padrões, foram estudadas também aplicações envolvendo a análise e o reconhecimento de texturas. Tais aplicações fizeram uso da Dimensão Fractal, neste caso da técnica de BoxCounting, e da Lacunaridade como ferramentas para análise e segmentação de imagens, sejam elas imagens naturais ou artificiais.

Por meio dos resultados obtidos nessas aplicações, ficou evidente a possibilidade de se utilizar às técnicas de Dimensão Fractal e Lacunaridade como ferramentas para a análise e segmentação de texturas. No entanto, apesar do nível de sucesso obtido nessas aplicações, se fazem necessários maiores estudos relacionando a Dimensão Fractal e a Lacunaridade com a análise de texturas, de modo a suprir as deficiências que as técnicas ainda possuem nesse tipo de análise e propor melhorias.

\subsection{Contribuições}

As principais contribuições deste trabalho são:

- Levantamento bibliográfico atualizado sobre os principais algoritmos de Dimensão Fractal; classificação desses algoritmos; e descrição detalhada de suas configurações e limitações.

- Análise comparativa e validação dos principais algoritmos de estimativa da Dimensão Fractal; análise experimental avaliando características como, precisão, detalhes de implementação e variação de resultados segundo ajustes de parâmetros e orientação.

- Validação da curva de Dimensão Fractal MultiEscala de Minkowski. 
- Desenvolvimento e validação das técnicas de estimativa da Dimensão Fractal MultiEscala, sendo demonstrado a possibilidade de se obter a curva de Dimensão Fractal MultiEscala a partir de outros métodos, além do Minkowski.

- Análise comparativa das curvas de Dimensão Fractal MultiEscala obtidas para cada método; análise experimental avaliando características como, precisão, detalhes de implementação e variação de resultados segundo ajustes de parâmetros e tolerância a ruídos.

- Análise comparativa dos métodos de Dimensão Fractal e Lacunaridade voltados à análise e segmentação de texturas, avaliando detalhes de implementação, precisão e variação de resultados segundo ajuste de parâmetros.

\subsection{Publicações}

A elaboração de artigos científicos, que reflitam o grau de desenvolvimento do projeto e as contribuições para literatura, foi realizada de forma contínua durante todo o mestrado. A seguir são apresentadas as publicações realizadas até o momento:

BACKES, A. R.; BRUNO, O. M.; Técnicas de estimativa de dimensão fractal aplicadas em imagens digitais. Relatórios Técnicos do ICMC-USP, Nº 247, ISSN 01032569, 2005.

BACKES, A. R.; BRUNO, O. M.; Técnicas de estimativa da Dimensão Fractal: Um estudo comparativo. INFOCOMP Journal of Computer Science, Lavras, MG, v. 4, n. 3, p. 50-58, 2005.

BACKES, A. R.; BRUNO, O. M.; Lacunaridade Aplicada em Análise de Textura. In: $1^{\circ}$ Workshop de Visão Computacional, Piracicaba, 2005.

BACKES, A. R.; BRUNO, O. M.; Segmentação de Texturas por Análise de Complexidade. INFOCOMP Journal of Computer Science, Lavras, MG, 2006. (já aceito para publicação). 
Além dos artigos já publicados, outros se encontram em fase de redação. A seguir são apresentados alguns artigos em fase de redação e que serão finalizados e submetidos a revistas internacionais após a defesa dessa dissertação.

BACKES, A. R.; BRUNO, O. M. Using MultiScale Fractal Dimension with Fourier and Wavelet Descriptors as a feature for image recognition.

Neste artigo é apresentado um estudo do uso da curva de Dimensão Fractal MultiEscala juntamente com descritores de Fourier e Wavelet como assinatura de complexidade de imagem. Os descritores são utilizados para se extrair as informações mais relevantes da curva MultiEscala, de modo a facilitar as etapas de comparação e classificação de imagens.

BACKES, A. R.; BRUNO, O. M. Extraction and Confrontation of MultiScale Curves got by methods based on Hausdorff-Besicovitch Dimension.

Neste artigo é apresentado um estudo sobre a possibilidade de se extrair a curva de Dimensão Fractal MultiEscala a partir de outros métodos e não somente a partir do método de Minkowski, sendo também avaliado o seu potencial de uso na comparação e classificação de imagens. 


\section{Bibliografia}

(ALLAIN; CLOITRE, 1991) ALLAIN, C.; CLOIRE, M. Characterizing the lacunarity of random and deterministic fractals sets, Phys. Rev. A 44 (6) 3552. 1991.

(BRACEWELL, 2000) BRACEWELL, R. The Fourier transform and its applications, McGrawHill, New York, 2000.

(BRIGHAM, 1988) BRIGHAM, E. O. The Fast Fourier Transform, $2^{\circ}$ Ed. New Jersey, Prentice Hall, 1988.

(BRUNO; COSTA, 2004) BRUNO, O. M.; COSTA, L. F. A parallel implementation of exact euclidean distance transform based on exact dilations. Microprocessors and Microsystems, v.28, n.3, p.107 - 113, 2004.

(CARLIN, 2000) CARLIN, M. Measuring the complexity of non-fractal shapes by a fractal method. Pattern Recognition Letters 21, p.1013-1017, 2000.

(CASTLEMAN, 1996) CASTLEMAN, K. R. Digital Image Processing. Englewood Cliffs, NJ, 1996.

(CESAR; COSTA, 2000) CESAR, R. M. Jr; COSTA, L. F. Shape Analysis and Classification: Theory and Practice. Hardcover, 2000.

(COELHO; COSTA, 1995) COELHO, R. C.; COSTA, L. F. "The Box-Counting Fractal. Dimension: Does it provide an Accurate Subsidy for Experimental Shape Characterization? If So, How to Use It?”. Anais do Sibgrapi 95: p. 183-191, 1995.

(CORNFORTH et. al, 2002) CORNFORTH, D.; JELINEK, H.; PEICHL, L. Fractop: a tool for automated biological image classification. 6th Australasia-Japan Joint Workshop, 2002. 
(CRIMMINS, 1982) CRIMMINS, T. A complete set of Fourier descriptors for 2-D shapes, IEEE Trans. Syst. Man Cybern. 12 170-179. 1982.

(DUDA et al, 2001) DUDA, R.; HART, P.; STORK, D. Pattern Classification. John Wiley \& Sons. 2001.

(DUMAS, 1993) DUMAS, P.; BOUFFAKHREDDINE, B.; AMRA, C.; VALTEL, O.; ANDRÉ, E.; GALINDO, R.; SALVAN, F. Quantitative Microroughness Analysis down to the Nanoeter scale. Europhysics Letters, 22(9), p. 717-722. 1993.

(EBERT, 1994) EBERT, D. S. Texturing and Modeling: A Procedural Approach, Academic Press, Cambridge, MA, 1994.

(EMERSON, 1999) EMERSON, C. W.; LAM, N. S.; QUATTROCHI, D. A. Multi-Scale fractal analysis of image texture and pattern. Photogrammetric Enginnering \& Remote Sensing, 1999.

(FALCONER, 1990) FALCONER, K. J. Fractal Geometry: mathematical and applications. New York, John wiley, 1990.

(FRED, 2001) FRED, A. L. N. Finding consistent clusters in data partitions. In J. Kittler \& F. Roli (Eds). MCS '01: Proceedings of the Second International Workshop on multiple Classifier Systems, Volume 2096 of Lecture Notes in Computer Science, Cambridge, UK, pp. 209-318. 2001.

(GAUTESTTAD; MYSTERUD, 1994) GAUTESTAD, A.O.; MYSTERUD, I. Fractal analysis of population ranges: methodological problems and challenges. Oikos 69: 154-157. 1994.

(GONZALEZ; WOODS, 1992) GONZALEZ, R. C.; WOODS, R. E. Digital Imaging Processing, Addison-Wesley, Reading, Massachusetts, USA, 1992. 
(GULICK, 1992) GULICK, D. Encounters with Chaos, McGraw-Hill International Editions Mathematics and Statistics Series, 1992.

(HALKIDI et. al, 2001) HALKIDI, M.; BATISTAKIS, Y.; VAZIRGIANNIS, M. On clustering validation techniques. Inteligent Information Systems Journal 17(2-3), 107-145. 2001.

(HAMILTON et al, 1992) HAMILTON, S.K.; MELACK, J.M.; GOODCHILD, M.F.; LEWIS, W.M. Estimation of the fractal dimension of terrain from lake size distributions. In: P.A. Carling and G.E. Petts (Eds.). Lowland Floodplain Rivers: geomorphological perspectives. pp. 145-163. J. Wileyand Sons, New York. 1992.

(HONDA et. al, 1991) HONDA E.; DOMON, M.; SASAKI, T. A Method for Determination of Fractal Dimension of Sialographic Images, Investigative Radiology, Vol.26. 1991.

(KENKEL; WALKER, 1993) KENKEL, N. C.; WALKER, D. J. Fractals and ecology. Abst. Bot. 17: 53-70. 1993.

(KUHL; GIARDINA, 1982) KUHL, I.; GIARDINA, C. Elliptic Fourier features of a closed contours, Computer Graphics Image Process. 18 236-258. 1982.

(LANDINI; RIPPIN, 1993) LANDINI, G.; RIPPIN, J.W. Fractal dimensions of the epithelialconnective tissue interfaces in premalignant and malignant epithelial lesions of the floor of the mouth. Analytical and Quantitative Cytology and Histology, 15(2), 144-149, 1993.

(MALLAT, 1998) MALLAT, S. Wavelet Tour of Signal Processing, Academic Press, New York, 1998.

(MANDELBROT, 2000) MANDELBROT, B. B. "The Fractal Geometry of Nature". 19th Edition, W.H. Freeman \& Company, 2000. 
(MARSHALL, 1989) MARSHALL, S. Review of shape coding techniques. Image and Vision Computing, 7(4):281-294, 1989.

(MOKHTARIAN; MACKWORT, 1986) MOKHTARIAN, F.; MACKWORT, A. Scale based description and recognition of planar curves and two-dimensional shapes. IEEE Transactions on Pattern Analysis and Machine Intelligence, PAMI-8(1):34-43, 1986.

(MORENCY; CHAPLEAU, 2003) MORENCY, C.; CHAPLEAU, R. HarFA - Harmonic and Fractal Image Analysis, pp. 30 - 34. 2003.

(NORMANT; TRICOT, 1991) NORMANT, F.; TRICOT, C. Methods for evaluating the fractal dimension of curves using convex hulls, Phys. Rev. A 43: 6518-6525. 1991.

(PEITGEN, 1988) PEITGEN, H. O.; SAUPE, D. The Science of Fractal Images. New York, Springer Verlag. 1988.

(PINTO, 2001) PINTO, S. C. D. Estimação da Dimensão Fractal de Imagens de SPM, Usp, São Carlos - SP, 2001.

(PlOTNICK et al, 1996) PLOTNICK, R.E.; GRADNER, R. H.; HARGROVE, W. W., PRESTEGAARD, K.; PERLMUTTER, M. Lacunarity analysis: a general technique for the analysis of spatial patterns, Phys. Rev. E 53 (5) 5461. 1996.

(PlOTZE et. al, 2004) PLOTZE, R. O.; FALVO, M.; BRUNO, O. M. FRACTAL DIMENSIONS APPLIED TO PLANT IDENTIFICATION (submetido para publicação na Pattern Recogniton Lettes), 2004.

(SCHIERWAGEN, 1990) SCHIERWAGEN, A. "Scale-invariant diffusive growth: a dissipative principle relating neuronal form to function". In: J. Maynard-Smith and G. Vida, editors, Organisational constraints on the dynamics of evolution, pp. 167-189, Manchester University Press. 1990. 
(SERRA, 1982) SERRA, J. Image Analysis and Mathematical Morphology. London: Academic Press, v.1. p.600. 1982.

(SHOLL, 1953) SHOLL, D. Dendritic organization in the neurons of the visual cortices of the cat. Journal of Anatomy, 87:387-406, 1953.

(SHROEDER, 1996) SHROEDER, M. Fractals, Chaos, Power Laws - Minutes from an infinite Paradise. New York, W. H. Freeman and Company, 1996.

(SMITH, 1992) SMITH, G. D. Numerical Solution of Partial Differential Equations: Finite Difference Methods. Oxford, Clarendon Press, 1992.

(STOYAN; STOYAN, 1994) STOYAN, D.; STOYAN, H. Methods for the empirical determination of fractal dimension. In: Stoyan, D., Stoyan, H. (Eds.), Fractals, Random Shapes

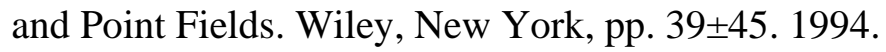

(SUGIHARA; MAY 1990) SUGIHARA, G.; MAY, R. M. Applications of fractals in ecology. Trends Ecol. Evol. 5: 79-86. 1990.

(TAKAYASU, 1990) TAKAYASU, H. Fractals in the Physical Sciences. Manchester University Press. Manchester. 1990.

(TRICOT, 1995) TRICOT, C. Curves and Fractal Dimension. New York: Springer-Verlag. 1995.

(VAlTEL, 1993) VAlTEl, O.; DUMAS, P.; CHOLlet, F.; SAlVAN, F.; ANDRÉ, E. Roughness Assessment of Polysilicon Usig Power Spectral Density. Jpn. J. Appl. Phys. 32 (12A). P.5671-5674. 1993.

(WICKERHAUSER, 1991) WICKERHAUSER, M.V. Lectures on wavelet packet algorithms, Department of Mathematics, Washington University, St. Louis, 1991. 
(WUNSCH; LAINE, 1995) WUNSCH, P.; LAINE, A. Wavelet descriptors for multiresolution recognition of handprinted characters, Pattern Recognition 28 1237-1249. 1995. 